\title{
Facility to Alleviate Salt Technology Risks (FASTR): Preliminary Design Report with Failure Modes and Effects Analysis
}

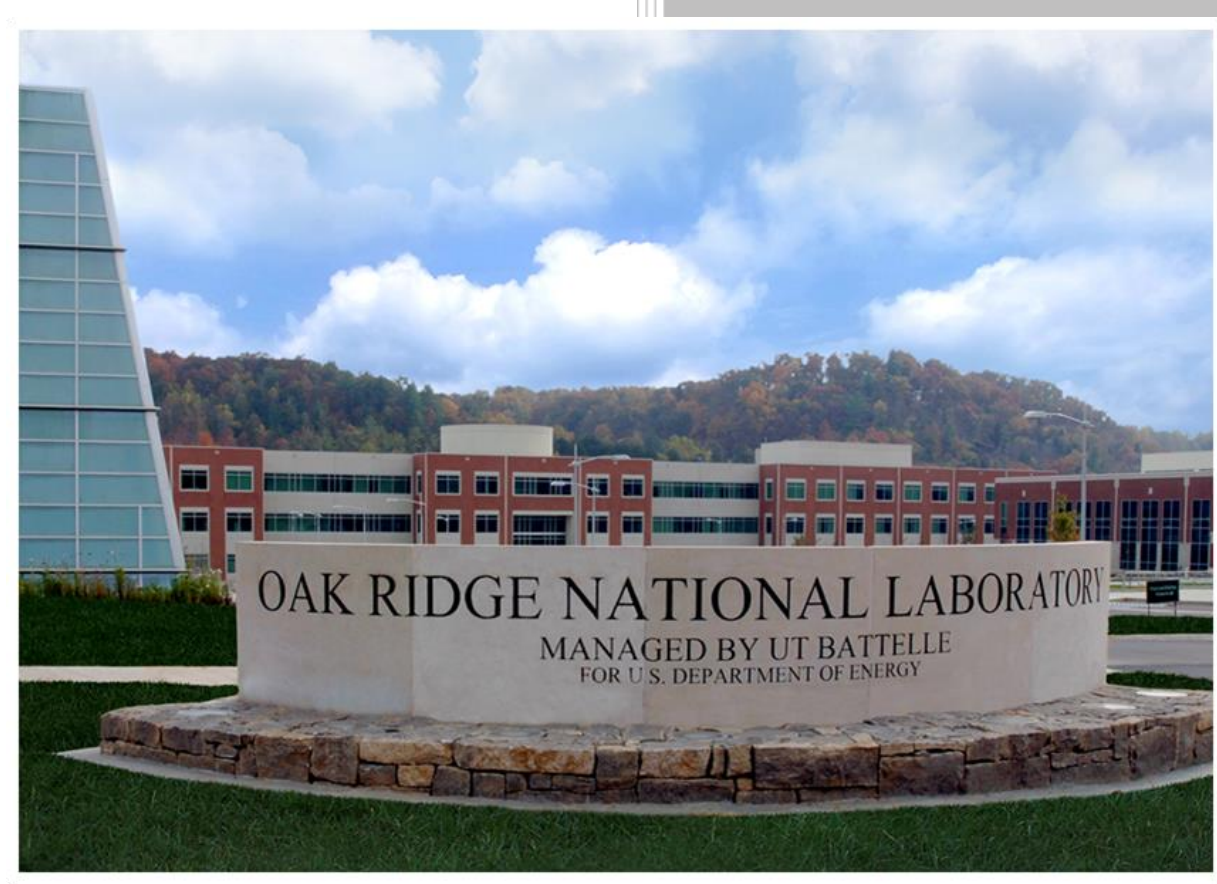

Kevin Robb

Padhraic Mulligan Graydon Yoder, Jr. Kurt Smith Jordan Massengale

December 2019 


\title{
DOCUMENT AVAILABILITY
}

Reports produced after January 1, 1996, are generally available free via US Department of Energy (DOE) SciTech Connect.

Website www.osti.gov

Reports produced before January 1, 1996, may be purchased by members of the public from the following source:

\author{
National Technical Information Service \\ 5285 Port Royal Road \\ Springfield, VA 22161 \\ Telephone 703-605-6000 (1-800-553-6847) \\ TDD 703-487-4639 \\ Fax 703-605-6900 \\ E-mail info@ntis.gov \\ Website http://classic.ntis.gov/
}

Reports are available to DOE employees, DOE contractors, Energy Technology Data Exchange representatives, and International Nuclear Information System representatives from the following source:

Office of Scientific and Technical Information

PO Box 62

Oak Ridge, TN 37831

Telephone 865-576-8401

Fax 865-576-5728

E-mail reports@osti.gov

Website http://www.osti.gov/contact.html

This report was prepared as an account of work sponsored by an agency of the United States Government. Neither the United States Government nor any agency thereof, nor any of their employees, makes any warranty, express or implied, or assumes any legal liability or responsibility for the accuracy, completeness, or usefulness of any information, apparatus, product, or process disclosed, or represents that its use would not infringe privately owned rights. Reference herein to any specific commercial product, process, or service by trade name, trademark, manufacturer, or otherwise, does not necessarily constitute or imply its endorsement, recommendation, or favoring by the United States Government or any agency thereof. The views and opinions of authors expressed herein do not necessarily state or reflect those of the United States Government or any agency thereof. 
Reactor and Nuclear Systems Division

\title{
Facility to Alleviate Salt Technology Risks (FASTR): Preliminary
} Design Report with Failure Modes and Effects Analysis

\author{
Kevin Robb \\ Padhraic Mulligan \\ Graydon Yoder, Jr. \\ Kurt Smith \\ Jordan Massengale
}

December 2019

Prepared by

OAK RIDGE NATIONAL LABORATORY

Oak Ridge, TN 37831-6283

managed by

UT-BATTELLE, LLC

for the

US DEPARTMENT OF ENERGY

under contract DE-AC05-00OR22725 



\section{TABLE OF CONTENTS}

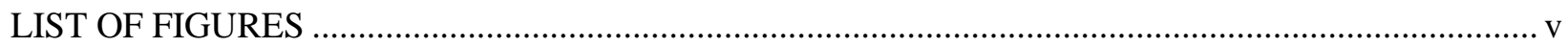

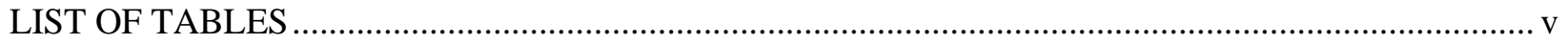

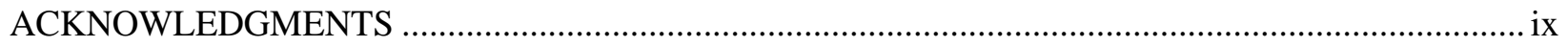

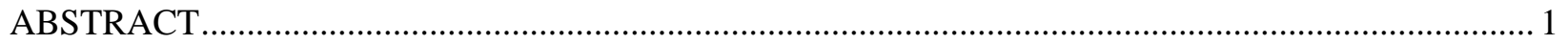

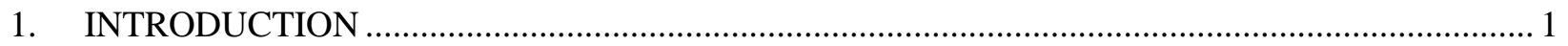

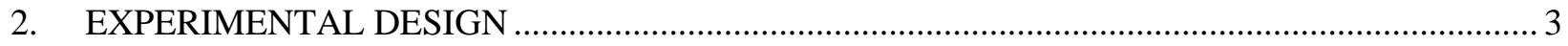

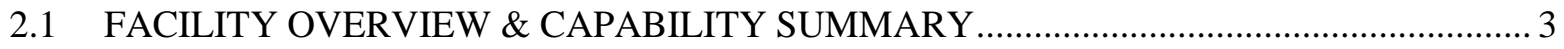

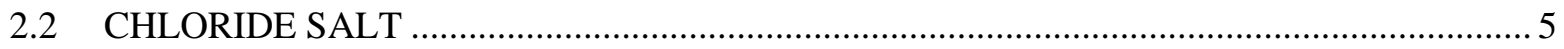

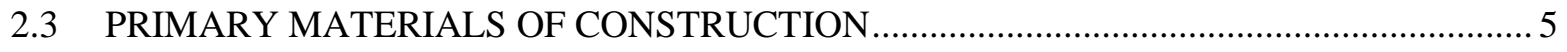

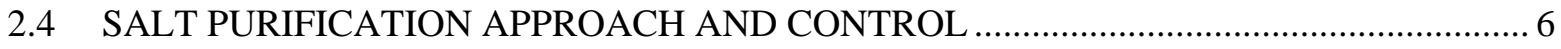

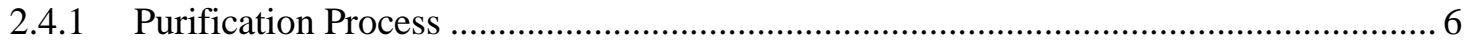

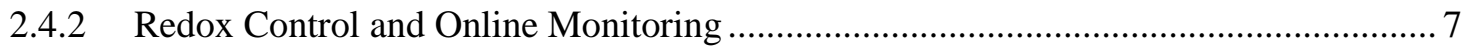

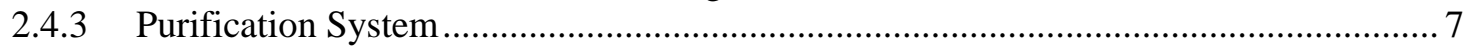

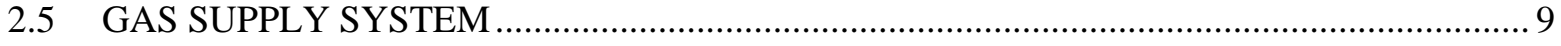

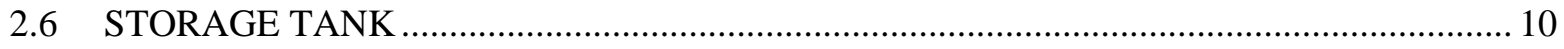

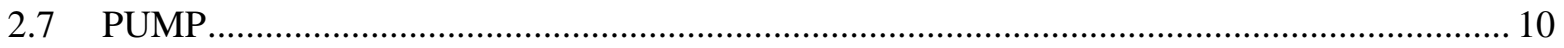

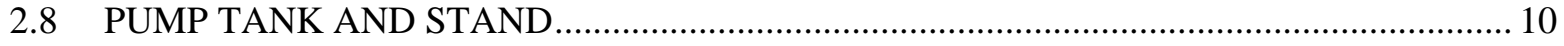

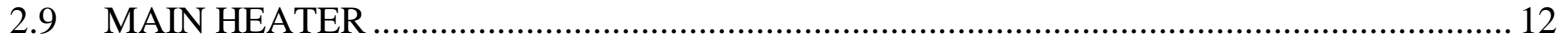

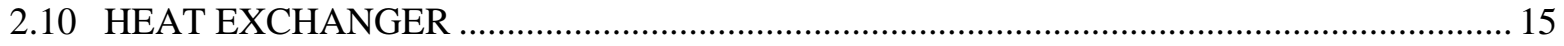

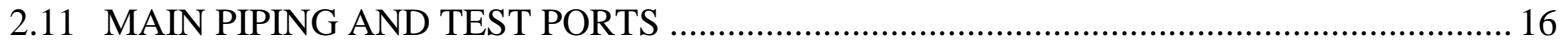

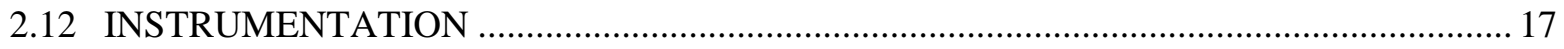

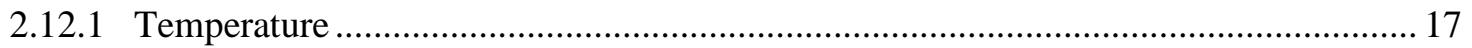

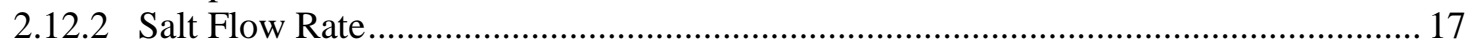

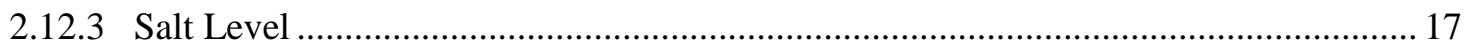

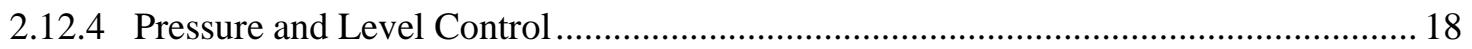

2.13 CONTROL SYSTEM AND TRACE HEATING SUMMARY ............................................ 18

2.14 SALT-TO-SCO ${ }_{2}$ HEAT EXCHANGER TESTING INFRASTRUCTURE........................... 20

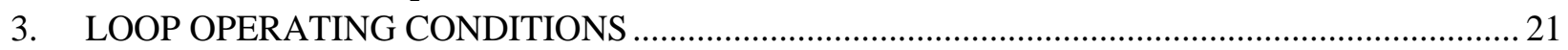

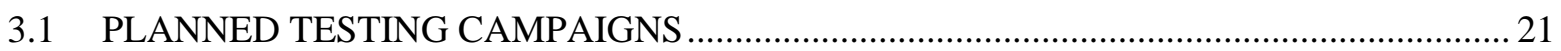

3.2 PREDICTED OPERATING ENVELOPE AND CONDITIONS ….................................... 23

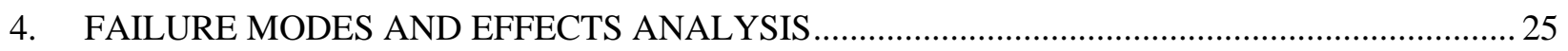

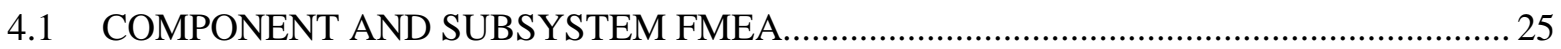

4.2 PURIFICATION AND LOOP OPERATION PROCESS FMEA ....................................... 28

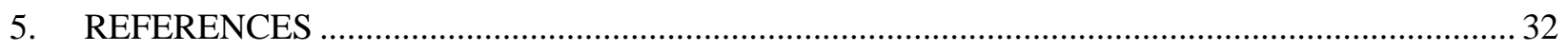

APPENDIX A. MAIN HEATER FINITE ELEMENT ANALYSIS ................................................ A-1

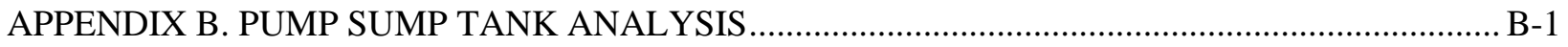

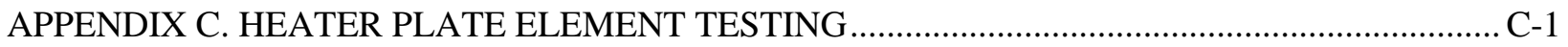

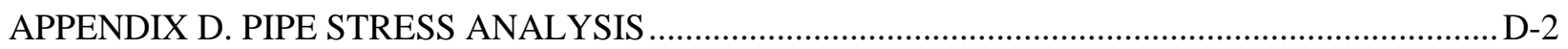





\section{LIST OF FIGURES}

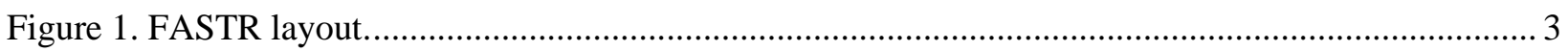

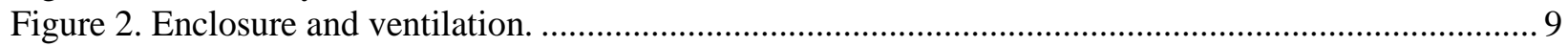

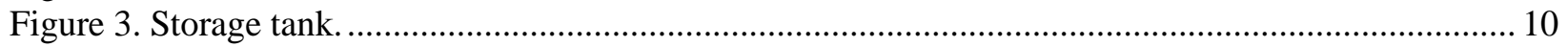

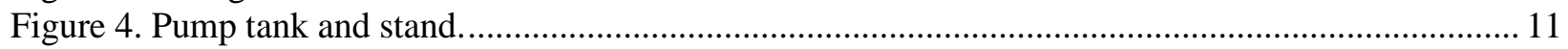

Figure 5. Pump tank gas entrainment prediction ( 8 inches of salt and 60 gpm flowrate)....................... 11

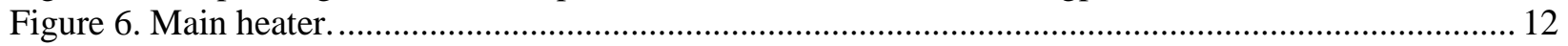

Figure 7. Thermal conductivity and coefficient of thermal expansion for C-276 and Inconel 600.......... 13

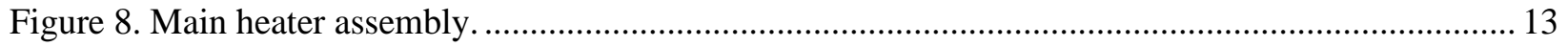

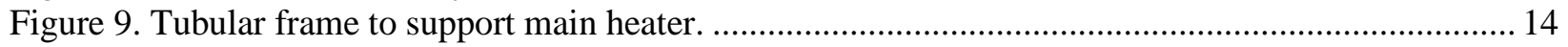

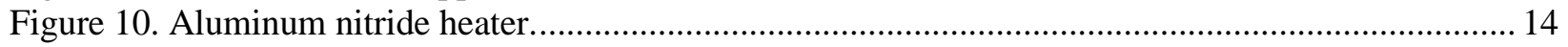

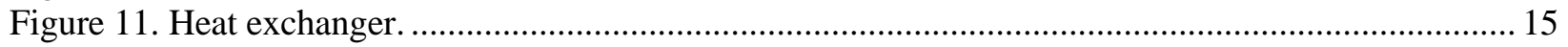

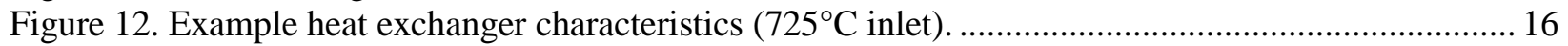

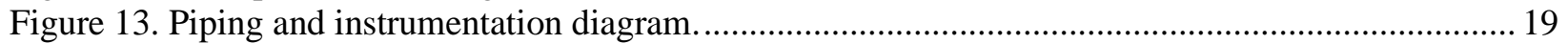

Figure 14. Predicted pressure drop vs. mass flowrate.......................................................................... 23

Figure 15. Maximum heater power at various max salt temperatures based on heat exchanger

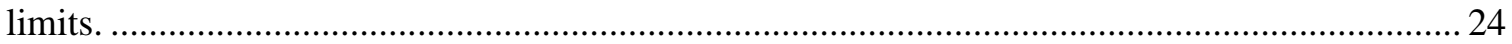

Figure 16. Salt $\Delta \mathrm{T}$ based on flowrate and main heater power. ............................................................. 24

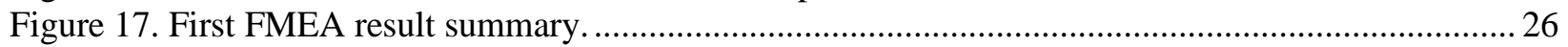

Figure 18. Salt purification process FMEA - results summary......................................................... 29

Figure 19. Loop Operation process FMEA - results summary.............................................................. 30

\section{LIST OF TABLES}

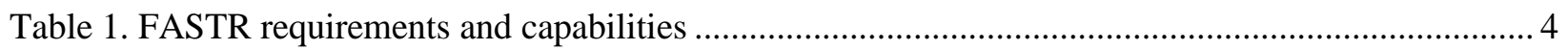

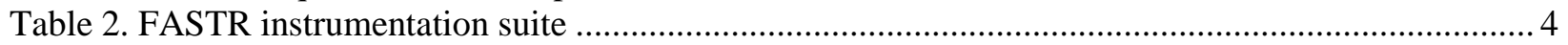

Table 3. Composition (wt \%) of Hastelloy ${ }^{\circledR}$ C-276 …........................................................................... 5

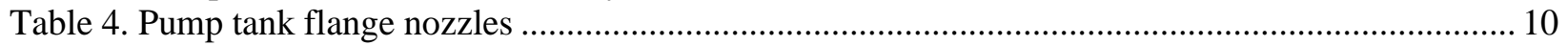

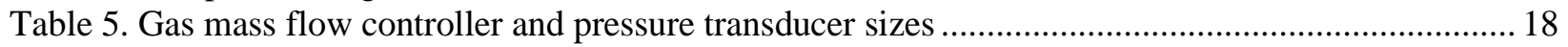

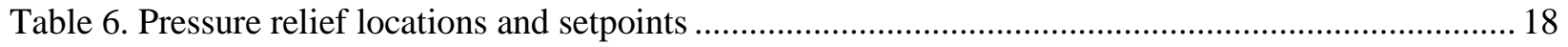

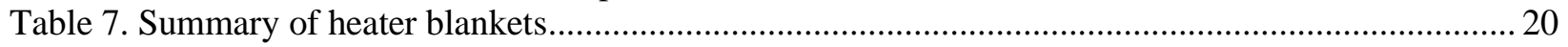

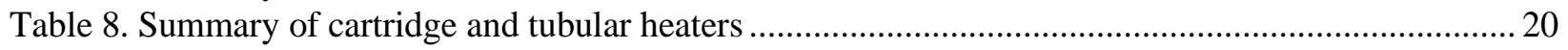

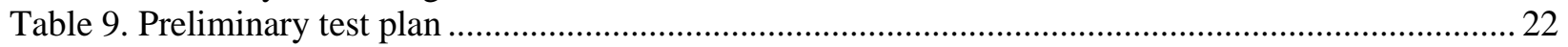

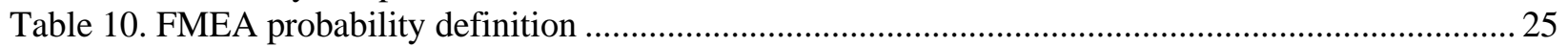

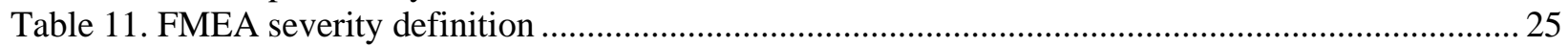

Table 12. Component and subsystem FMEA: medium-risk items .................................................... 26

Table 13. Component and subsystem FMEA: mitigation efforts for medium-risk failure modes.............. 27

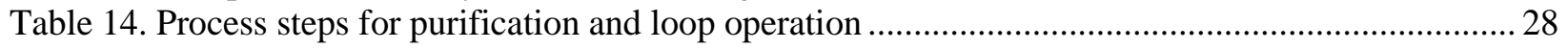

Table 15. Salt purification process FMEA: medium- and high-risk results............................................ 29

Table 16. Loop operation process FMEA - medium- and high-risk results ............................................. 30 



\section{LIST OF ACRONYMS}

$\begin{array}{ll}\text { AlN } & \text { Aluminum Nitride } \\ \text { ASME } & \text { American Society of Mechanical Engineers } \\ \text { CFD } & \text { computational fluid dynamics } \\ \text { CFM } & \text { cubic feet per minute } \\ \text { CSP } & \text { concentrated solar power } \\ \text { EERE } & \text { Energy Efficiency \& Renewable Energy } \\ \text { ES\&H } & \text { environment, safety and health } \\ \text { FASTR } & \text { Facility to Alleviate Salt Technology Risks } \\ \text { FEA } & \text { finite element analysis } \\ \text { FMEA } & \text { failure modes and effects analysis } \\ \text { Gen3 } & \text { Generation 3 } \\ \text { HX } & \text { heat exchanger } \\ \text { I\&C } & \text { instrumentation and controls } \\ \text { kPa } & \text { kiloPascals } \\ \text { kW } & \text { kiloWatt } \\ \text { LED } & \text { light emitting diode } \\ \text { lpm } & \text { liters per minute } \\ \text { LSTL } & \text { liquid salt test loop } \\ \text { MFC } & \text { mass flow controller } \\ \text { MW/m }{ }^{2} & \text { megaWatt per meter squared } \\ \text { PLC } & \text { programmable logic controller } \\ \text { ppb } & \text { parts per billion } \\ \text { ppm } & \text { parts per million } \\ \text { psid } & \text { pounds per square inch differential } \\ \text { psig } & \text { pounds per square inch gauge } \\ \text { PTFE } & \text { polytetrafluoroethylene } \\ \text { sch } & \text { schedule (pipe) } \\ \text { sCO } 2 & \text { supercritical carbon dioxide } \\ \text { SETO } & \text { Solar Energy Technologies Office } \\ \text { SLPM } & \text { standard liters per minute } \\ \text { UHP } & \text { ultra-high purity } \\ & \end{array}$





\section{ACKNOWLEDGMENTS}

This material is based upon work supported by the U.S. Department of Energy's Office of Energy Efficiency and Renewable Energy (EERE) under Solar Energy Technologies Office (SETO) Agreement Number 33875 



\begin{abstract}
The Facility to Alleviate Salt Technology Risks (FASTR) is a versatile, high-temperature $\left(>600^{\circ} \mathrm{C}\right)$ molten chloride salt test facility designed to enable a variety of testing to advance the Generation 3 (Gen 3) Concentrated Solar Power (CSP) molten salt technology. FASTR includes a salt preparation system and a forced flow test loop with a suite of instrumentation. The FASTR loop is capable of $725^{\circ} \mathrm{C}$ operation and flow rates of 3-7 kg/s, and it includes heated and cooled sections and swappable components to enable testing of future vendor-supplied hardware. The salt preparation system supplies large batches (e.g., $200 \mathrm{~kg}$ ) of clean salt for use in the FASTR forced convection loop. In addition, FASTR includes the capability to test salt to supercritical carbon dioxide $\left(\mathrm{sCO}_{2}\right)$ heat exchangers. This report summarizes the planned design and capabilities of FASTR. In addition, a failure modes and effects analysis of the system is reported.
\end{abstract}

\title{
1. INTRODUCTION
}

The Facility to Alleviate Salt Technology Risks (FASTR) is a versatile, high-temperature $\left(>600^{\circ} \mathrm{C}\right)$ molten chloride salt test facility designed to enable a variety of testing to advance the Generation 3 (Gen 3) Concentrated Solar Power (CSP) molten salt technology.

Current state-of-the-art CSP plants use nitrate/nitrite salts to transport and store heat. However, nitrate salt systems are limited to approximately $585^{\circ} \mathrm{C}$ in practice. The use of chloride salts enables operating temperatures higher than those currently used in the field, allowing more efficient power cycles to be employed. Furthermore, bulk chloride salts are industrially available at reasonably low costs. For these reasons, chloride salts with higher efficiency power cycles are being investigated and developed by the Solar Energy Technologies Office (SETO) of the US Department of Energy's Office of Energy Efficiency \& Renewable Energy (EERE) to enhance the economic competitiveness of CSP [1].

Before a chloride salt-based Gen 3 CSP plant is deployed, several technological challenges and demonstrations MUST be addressed, including salt sourcing, preparation, and monitoring; component design; supply chain; reliability; and corrosion control. The number of test facilities available to mature and de-risk the required technology for molten chloride salts is limited. To address this need, SETO sponsored the development, construction, and the planned initial operation of FASTR.

FASTR includes a salt preparation system and a forced flow test loop with a suite of instrumentation. The FASTR loop is capable of operating at $725^{\circ} \mathrm{C}$ with flow rates of $3-7 \mathrm{~kg} / \mathrm{s}$. FASTR includes heated and cooled sections and swappable components to enable testing of future vendor-supplied hardware. The salt preparation system supplies large batches (e.g., $200 \mathrm{~kg}$ ) of clean salt for use in the FASTR forced convection loop. The project includes additional efforts focused on developing and demonstrating innovative sensors for monitoring the salt and structural materials.

FASTR and its accompanying research data will serve as a foundational capability for the Gen3 CSP development effort. Once built, FASTR will be the largest high-temperature (i.e., $>600^{\circ} \mathrm{C}$ ) molten salt test facility operating in the United States. Key facility demonstrations will include corrosion monitoring and control, as well as performance demonstrations of major components such as flanges, heat trace, heat exchangers, pumps, etc. FASTR will de-risk high-temperature molten salt technology and will demonstrate the viability of the Gen3 molten salt pathway.

This report summarizes the design and capabilities of FASTR. Currently, the major components described in Section 2 are under fabrication. Section 3 includes a discussion of the anticipated testing capability envelope and the initial planned tests. To reduce the risk of design changes or issues during operation, a 
failure modes and effects analysis (FMEA) of the system was conducted and is discussed in Section 4. The as-built facility may deviate from that described herein due to unforeseen issues during the fabrication and startup phase or changes resulting from new knowledge. 


\section{EXPERIMENTAL DESIGN}

\subsection{FACILITY OVERVIEW \& CAPABILITY SUMMARY}

A schematic of FASTR is provided in Figure 1. The salt preparation is conducted inside a ventilated enclosure. A separate storage tank for the salt is also located in the enclosure. Transfer lines, which are not illustrated, interconnect the processing, storage, and pump vessels. The pump is located outside the enclosure, and it forces salt in a counterclockwise direction around the loop. The main heater heats the salt, and an air-cooled heat exchanger removes heat from the loop. Trace heating, insulation, and instrumentation are located throughout the facility. The key technical specifications and capabilities for FASTR are summarized in Table 1. A separate summary of the instrumentation and controls (I\&C) capabilities is highlighted in Table 2 . The following subsections provide further description of the various major components.

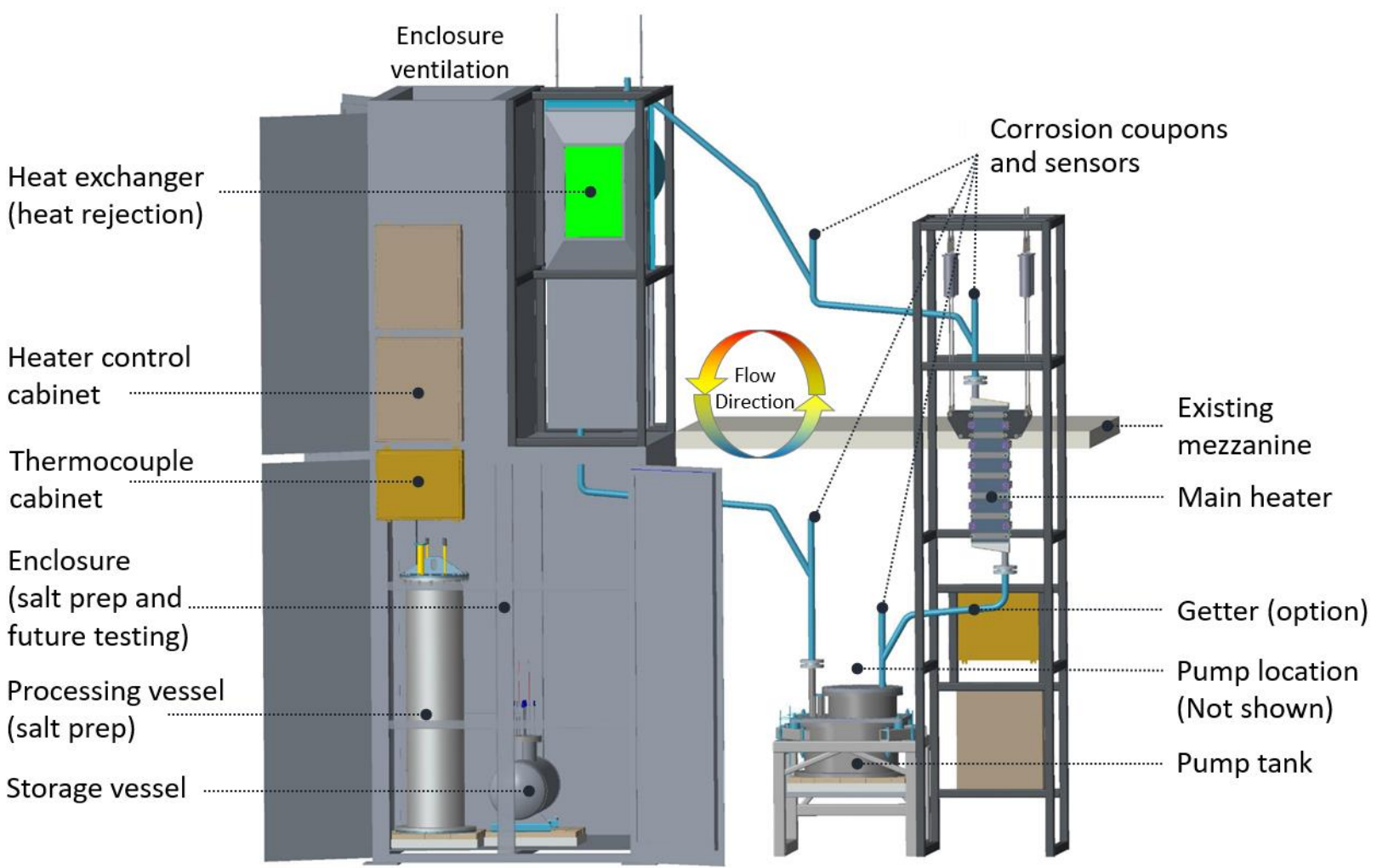

Figure 1. FASTR layout. 
Table 1. FASTR requirements and capabilities

\begin{tabular}{|c|c|c|c|c|}
\hline Capability & Detail & Value & Units & Comments \\
\hline System design temperature & Hot side & 725 & ${ }^{\circ} \mathrm{C}$ & \\
\hline Primary alloys of construction & & $\begin{array}{l}C-276 \\
600\end{array}$ & - & \\
\hline Primary piping size & & 2 & in. & Schedule 40 , seamless \\
\hline \multirow{2}{*}{ System design pressure } & Salt processing & 206 & $\mathrm{kPa}$ & 30 psig \\
\hline & Flow loop & $145-310$ & $\mathrm{kPa}$ & $21-45$ psig \\
\hline \multirow{2}{*}{ Flow rate } & Mass flow rate & $3-7$ & $\mathrm{~kg} / \mathrm{s}$ & $3-6 \mathrm{~kg} / \mathrm{s}$ is primary goal \\
\hline & Volume flow rate & $114-228$ & $1 \mathrm{pm}$ & 30-70 gpm \\
\hline \multirow{2}{*}{ Salt volume/mass } & Purification system & $\geq 200$ & $\mathrm{~kg}$ & if loaded as powder/granules \\
\hline & Salt loop & 120 & $\mathrm{~L}$ & $200 \mathrm{~kg}(\sim 120 \mathrm{~L}, 32$ gallon $)$ \\
\hline \multirow{4}{*}{ Main heater } & Total power & 350 & $\mathrm{~kW}$ & $\begin{array}{l}\text { Potential for } 400 \mathrm{~kW} \\
\text { transient operation }\end{array}$ \\
\hline & Maximum heat flux & 1 & $\mathrm{MW} / \mathrm{m}^{2}$ & to the salt \\
\hline & Axial zones & 6 & qty & \\
\hline & $\begin{array}{l}\text { Reynolds } \\
\text { number (salt) }\end{array}$ & $\begin{array}{c}15,000- \\
50,000\end{array}$ & - & $\begin{array}{l}\text { Reynolds number indicating } \\
\text { salt in channels, based on } \\
\text { estimated salt properties }\end{array}$ \\
\hline \multirow{2}{*}{ Trace heating } & Controlled zones & 48 & qty & \\
\hline & Total power & 65 & $\mathrm{~kW}$ & \\
\hline Test ports & & 5 & qty & $\begin{array}{l}2 \times \text { hot zone, } 3 \times \text { cold zone } \\
\text { (e.g., corrosion samples, } \\
\text { sensors) }\end{array}$ \\
\hline
\end{tabular}

Table 2. FASTR instrumentation suite

\begin{tabular}{|c|c|c|c|c|}
\hline Instrumentation suite & Detail & Qty & Units & Comments \\
\hline Pressure & Gas space & 6 & places & \\
\hline \multirow{2}{*}{ Salt level } & Thermocouple probe & 4 & places & \\
\hline & Radar & 1 & places & optional \\
\hline Flow rate & Ultrasonic & 1 & places & \\
\hline \multirow{7}{*}{ Temperature: thermocouples } & Main heater & 48 & qty & \\
\hline & Trace heating & 98 & qty & \\
\hline & Flowmeter & 4 & qty & \\
\hline & Heat exchanger & 11 & qty & \\
\hline & Level probes & 40 & qty & \\
\hline & Spare & 7 & qty & \\
\hline & Total & 208 & qty & \\
\hline Salt redox potential & \multirow{4}{*}{$\begin{array}{l}\text { Multielectrode array } \\
\text { voltammetry sensor with } \\
\text { dynamic reference }\end{array}$} & \multirow{4}{*}{2} & \multirow{4}{*}{ places } & $<5 \%$ relative error \\
\hline Corrosion product concentrations & & & & $\begin{array}{l}\text { Metal ion impurities } \\
(\mathrm{Cr}, \mathrm{Fe}, \mathrm{Ni}) \\
(1-5,000 \mathrm{ppm})\end{array}$ \\
\hline Salt impurity concentrations & & & & $\mathrm{MgOH}^{+}$and $\mathrm{O}^{2-}$ impurities \\
\hline Soluble metal concentration & & & & Mg metal \\
\hline
\end{tabular}




\subsection{CHLORIDE SALT}

Chloride salts are being considered for Gen3 CSP due to their attractive economics, their ability to operate at high temperatures while at low pressure, and their heat storage capability. A mixture of $\mathrm{NaCl}$, $\mathrm{KCl}$ and $\mathrm{MgCl}_{2}$ salts was chosen due to their attractive economics and their ability to form a low melting point mixture.

The salt is planned to be a mixture of two industrially available chloride salt mixtures. An anhydrous carnallite (nominal wt\%: 9-18 NaCl, 36-43 KCl, 43-52 $\mathrm{MgCl}_{2}$, with traces of $\mathrm{MgO}, \mathrm{C}, \mathrm{H}_{2} \mathrm{O}$ and $\mathrm{SO}_{4}$ ), will be used as the base salt. To increase the $\mathrm{NaCl}$ concentration of the salt to yield a lower melting point mixture, a halite salt will be added (nominal wt $\%: 92.5 \mathrm{NaCl}, 6 \mathrm{KCl}, 1.4 \mathrm{CaSO}_{4} \cdot 2 \mathrm{H}_{2} \mathrm{O}$, with traces of $\mathrm{LiCl}$ and $\mathrm{MgCl}_{2}$ ). The final salt mixture (approximate mol\%: $21-23 \mathrm{NaCl}, 42-43 \mathrm{KCl}, 34-36 \mathrm{MgCl}_{2}$; wt\% $16-17 \mathrm{NaCl}, 39-41 \mathrm{KCl}, 41-43 \mathrm{MgCl}_{2}$ ) has a melting point of approximately $400^{\circ} \mathrm{C}$. Compositional analysis of the salt will be conducted and reported in the future.

\subsection{PRIMARY MATERIALS OF CONSTRUCTION}

Alloy C-276 (Table 3) was selected as the primary material for FASTR. All salt wetted surfaces are C276 except for the main heater (Section 2.9) and level probes (Section 2.12.3) which are constructed of Alloy 600. This nickel-based alloy has a chromium content similar to Alloy 600 but lower than Haynes 230 (22 wt\%); it also includes molybdenum as a major alloying constituent. Alloy C-276 is used industrially for its exceptional resistance to stress corrosion cracking and to halides (i.e., $\mathrm{Cl}^{-}$and $\mathrm{F}^{-}$). Both Alloy 600 and C-276 are used by the chemical industry, so they are reasonably available and have 50+ year track records.

Table 3. Composition (wt \%) of Hastelloy ${ }^{\circledR}$ C-276

\begin{tabular}{ccccccccccc}
\hline $\mathbf{N i}$ & $\mathbf{C r}$ & $\mathbf{W}$ & $\mathbf{M o}$ & $\mathbf{F e}$ & $\mathbf{C o}$ & $\mathbf{M n}$ & $\mathbf{S i}$ & $\mathbf{V}$ & $\mathbf{C u}$ & $\mathbf{C}$ \\
\hline 57 & \multirow{2}{*}{16} & \multirow{2}{*}{4} & \multirow{2}{*}{16} & 5 & $\begin{array}{c}2.5 \\
\text { Bal }\end{array}$ & $\begin{array}{c}1 \\
\text { Max }\end{array}$ & $\begin{array}{c}\text { Max } \\
0.08\end{array}$ & $\begin{array}{c}0.35 \\
\text { Max }\end{array}$ & $\begin{array}{c}\text { Max } \\
\text { Max }\end{array}$ \\
\hline
\end{tabular}

Limited studies have been conducted to determine C-276's corrosion resistance to molten chloride salts. Sun [2] evaluated stainless steel (SS) 316 and seven Ni-based alloys in ternary $\mathrm{NaCl}-\mathrm{KCl}-\mathrm{MgCl}_{2}$ at $700^{\circ} \mathrm{C}$ for $100 \mathrm{~h}$. With respect to Cr depletion depth, C-276 was the top performer in corrosion resistance. This was attributed to its high molybdenum content. Vignarooban compared the corrosion rates of C-276, $\mathrm{C}-22$, and Hastelloy ${ }^{\circledR} \mathrm{N}$ in NaCl-KCl-ZnCl 2 salt [3]. At $500^{\circ} \mathrm{C}, \mathrm{C}-276$ was the top performer. While limited, the work by $\mathrm{Xu}$ [4] showed that C-276 and Haynes 230 have comparable reductions in strength at high temperatures. This reduction was independent of the high-temperature environment with two different chloride salts and argon. A recent paper by Ding [5] compared the corrosion rates of C-276, Inconel $800 \mathrm{H}$, and $310 \mathrm{SS}$ in a ternary $\mathrm{NaCl}-\mathrm{KCl}-\mathrm{MgCl}_{2}$ salt at $700^{\circ} \mathrm{C}$ for 500 hours with and without the addition of $\mathrm{Mg}$. The C-276 material performed substantially better than $800 \mathrm{H}$ and 310SS with and without Mg addition. Several ongoing corrosion studies have included alloy C-276. Forthcoming results support continued use of C-276.

Alloy C-276 is approved for use by the American Society of Mechanical Engineers (ASME) Boiler and Pressure Vessel Code (BPVC) Section VIII on pressure vessels, and it approved for use in ASME B31.3 for process piping up to $1250^{\circ} \mathrm{F}\left(676^{\circ} \mathrm{C}\right)$. The codes note that the allowed stresses are time dependent, and they provide values up to $700^{\circ} \mathrm{C}$ to aid design. The allowed stresses for temperatures $>600^{\circ} \mathrm{C}$ are approximately $5 \times$ greater than those for Alloy 600. 
FASTR has a high-temperature goal of $725^{\circ} \mathrm{C}$. To support this, a literature review of C-276 high temperature $\left(>675^{\circ} \mathrm{C}\right)$ properties was initiated, focusing on high-temperature creep properties. A preliminary review indicated that $\mathrm{C}-276$ creep properties at $750^{\circ} \mathrm{C}$ appear to align with the values for Hastelloy® S and Alloy 600. Because the data from open literature data were limited, a major metal manufacturer provided creep data for temperatures up to $982^{\circ} \mathrm{C}$. This literature review and analysis will be published at a later date. Ultimately, an allowed stress values of $39.3 \mathrm{MPa}(5.7 \mathrm{ksi})$ at $725^{\circ} \mathrm{C}\left(1337^{\circ} \mathrm{F}\right)$ and $45.2 \mathrm{MPa}(6.5 \mathrm{ksi})$ at $704^{\circ} \mathrm{C}\left(1300^{\circ} \mathrm{F}\right)$ were chosen for design. To monitor the material's long-term performance, corrosion and tensile specimens will be included in the loop for periodic inspection.

\subsection{SALT PURIFICATION APPROACH AND CONTROL}

\subsubsection{Purification Process}

Anhydrous chloride salts readily absorb moisture, particularly $\mathrm{MgCl}_{2}$. Moisture and hydroxides are known to negatively impact high-temperature chloride salt corrosion. The complex hydroxides of $\mathrm{MgCl}_{2}$ (e.g., $\mathrm{MgCl}_{2} \bullet 6 \mathrm{H}_{2} \mathrm{O}, \mathrm{MgCl}_{2} \bullet 4 \mathrm{H}_{2} \mathrm{O}, \mathrm{MgCl}_{2} \bullet 2 \mathrm{H}_{2} \mathrm{O}$ ) are reduced at elevated temperatures, liberating $\mathrm{H}_{2} \mathrm{O}$ and $\mathrm{HCl}$. However, $\mathrm{MgCl}_{2} \cdot \mathrm{H}_{2} \mathrm{O}$ can undergo partial hydrolysis, forming $\mathrm{MgOHCl}$, which is difficult to remove, requiring some other process beyond vacuum heating the salt.

At the outset of the FASTR project, the method for chloride salt preparation had not been determined. Oak Ridge National Laboratory (ORNL) was creating highly purified chloride salts through carbochlorination using carbon tetrachloride as the reagent $[6,7]$. Carbochlorination has been used at the industrial scale to purify $\mathrm{MgCl}_{2}$ through sparging $\mathrm{Cl}_{2}$ gas in the presence of a separate source of solid carbon. Similarly, another carbochlorination alternative sparges $\mathrm{Cl}_{2}$ and $\mathrm{CO}$ gases [7]. While this process is effective, it produces hazardous effluent, and the reagents require thoughtful monitoring and controls.

An alternative process uses metallic $\mathrm{Mg}$ to reduce $\mathrm{MgCl}_{2} \mathrm{OH}_{\mathrm{x}}$ and to set a low redox potential. Brookhaven National Laboratory (BNL) explored the use of $\mathrm{NaCl}-\mathrm{KCl}-\mathrm{MgCl}_{2}$ (30-20-50 mol\%) for low temperature $-500^{\circ} \mathrm{C}$, nuclear applications in the 1950 s [8]. Their purification process involved heating the salt under vacuum conditions, followed by contact with a liquid metal mixture of bismuth combined with 5,000 ppm Mg, $250 \mathrm{ppm} \mathrm{Zr}$, and 1,000 ppm U. The BNL description explains that $\mathrm{Zr}$ was added to reduce container corrosion during the process, and the $\mathrm{Mg}$ and $\mathrm{U}$ were used to reduce oxidizing impurities. The purified salt was transferred out of the vessel through a $35 \mu \mathrm{m}$ filter.

Following the general procedure used by BNL, Argonne National Laboratory (ANL) purified over $1,000 \mathrm{~kg}$ of chloride salt, including $\mathrm{NaCl}-\mathrm{KCl}-\mathrm{MgCl}_{2}(30-20-50 \mathrm{~mol} \%)$, for nuclear applications in the 1960s [9]. The ANL process included a few steps, beginning with mixing and melting the salt mixture in a vessel open to the air. Magnesium rods were then inserted into the melt until gas production stopped. This treated salt was then solidified and stored for later use. The next step in the purification process involved vacuum heating the salt at $300-350^{\circ} \mathrm{C}$ in a vessel containing a $\mathrm{Mg}-30$ at $\% \mathrm{Cd}$ alloy. After vacuum heating, the salt and magnesium alloy were heated past their melting points to $575^{\circ} \mathrm{C}$ while under 5 psig of argon. The liquid was agitated, and eventually the salt was transferred through a filter to a receiving vessel. Analysis of the oxygen content of the purified salt indicated levels of 500-2,000 ppm in the form of $<5 \mu \mathrm{m} \mathrm{MgO}$ particles. However, the technique had a lower measurement limit of 1,000-2,000 $\mathrm{ppm}$. Dissolving the purified salt in distilled water and analyzing the insoluble formed indicated an oxygen level of 50-500 ppm. The authors note that varying the pore size of the filter by $65-20 \mu \mathrm{m}$ had no significant impact on the treated salt's oxygen content.

Four different processes for purifying $\mathrm{KCl}-\mathrm{MgCl}_{2}$ salt were investigated by Ambrosek [10]. As described in his 2011 dissertation, the first step slowly heated the salt in an alumina crucible while simultaneously bubbling ultra-high purity (UHP) argon through the salt. The salt was held at $550^{\circ} \mathrm{C}$ for 16 hours before 
being cooled and stored for future use. Ambrosek then explored three different processes, all conducted at $550^{\circ} \mathrm{C}$, to further purify the salt: bubbling $\mathrm{HCl}$ for 12 hours, bubbling $\mathrm{CCl}_{4}$ for 30 minutes, or $\mathrm{Mg}$ contact for 10 hours. Based on the corrosion rate of alloy $800 \mathrm{H}\left(850^{\circ} \mathrm{C}\right.$ for 24 hours), the $\mathrm{CCl}_{4}$ bubbling and $\mathrm{Mg}$ contact purification processes yielded the best results. Since the use of $\mathrm{CCl}_{4}$ requires additional controls, Ambrosek adopted the $\mathrm{Mg}$ contact purification method for the remainder of this research.

To support this project and other SETO R\&D efforts, a collective of national laboratories, including ORNL, ANL, Savannah River National Laboratory, and the National Renewable Energy Laboratory, defined a standardized purification procedure in 2018 covering hardware, heating protocol, and $\mathrm{Mg}$ contact. While the purification process is still under development, the baseline process involves drying the salt granules through heating to various temperature hold points over an extended duration and then contacting the salt with magnesium. At this point, the salt remains quiescent for a time to allow impurities to settle. For the larger scale batch size of FASTR, a transfer tube with trace heating and an in-line filter will then be inserted into the processing vessel and used to transfer the molten salt to the storage tank (Section 2.6).

\subsubsection{Redox Control and Online Monitoring}

During loop operations, air, moisture and other impurities could inadvertently be introduced into the system. The air and moisture would interact with the salt, changing its redox potential and increasing its corrosivity.

As noted in the previous section, metallic magnesium has been shown to be effective at purifying relevant chloride salts. This experience is explained by basic salt chemistry that is illustrated by an Ellingham diagram. $\mathrm{MgCl}_{2}$ has the highest redox potential of the salt constituents (i.e., $\mathrm{MgCl}_{2}, \mathrm{NaCl}, \mathrm{KCl}$ ), and it has a redox potential below that of potential corrosion products of the metallic system (e.g., chlorides of $\mathrm{Cr}$, $\mathrm{Fe}$, and $\mathrm{Ni}$ ). Having $\mathrm{Mg}$ available in the system fixes the redox potential below that of corrosion products, inhibiting their formation while also maintaining a high enough redox potential to prevent reduction of the other salt constituents. For a more thorough discussion, the reader is referred to references on molten salt chemistry such as Ambrosek's dissertation [10]). Based on the previous purification experiences using $\mathrm{Mg}$ and the basic salt chemistry of the system of interest, it follows that adding Mg to the FASTR system will assist in maintaining the salt purity and ensuring a sufficiently low redox potential to inhibit corrosion of the system hardware. Indeed, adding $\mathrm{Mg}$ to chloride salt has been shown to reduce corrosion during static corrosion tests $[5,11,12]$. In addition, SETO recently sponsored development of a thermal convection corrosion loop constructed of Alloy 600 and operated with a peak temperature of $700^{\circ} \mathrm{C}$ for 1,000 hours. This loop demonstrated that adding $\mathrm{Mg}$ is also a promising technique for corrosion control in a flowing system with a temperature gradient [13]. For these reasons, $\mathrm{Mg}$ contact will be incorporated into the FASTR system to inhibit corrosion.

To monitor the state of the salt, a multifunctional voltammetry sensor is being developed at ANL for inclusion in the loop. As noted in Table 2, the sensor(s) will be able to detect the salt redox potential and the concentration of $\mathrm{Mg}$, some oxide impurities, as well as key metallic species. Online detection of changes in specie concentrations and/or redox potential will serve to indicate corrosion or air/moisture ingression and will be used to help determine the need for corrective action.

\subsubsection{Purification System}

The purification system for the chloride salt includes the processing vessel, the ventilated enclosure, the gas supply system, and an effluent scrubber. Because the final process to purify the chloride salt was undetermined at the project's onset, a ventilated enclosure capable of confining potential toxic gases was included. The enclosure has an $8 \times 8 \mathrm{ft}(2.44 \times 2.44 \mathrm{~m})$ floor area. Half of the enclosure is $22 \mathrm{ft}(6.7 \mathrm{~m})$ 
tall, and the other half is $12 \mathrm{ft}(3.66 \mathrm{~m})$ tall, as shown in Figure 2. The taller section includes a chain hoist that is used to lift the processing vessel, vessel liners, lid, and transfer lines. The heat exchanger described in Section 2.10 sits atop the shorter 12-foot section. The enclosure is ventilated with outside air, with the supply entering towards the bottom, and the return ductwork located at the top. The return houses a blower with a capacity of 3,000 cubic feet per minute (CFM). The blower is controlled via a variable frequency drive (VFD).

The processing vessel is made of C-276 and includes an inner C-276 liner. It was designed to accommodate a pressure of $206.8 \mathrm{kPa}(30 \mathrm{psig})$ at $700^{\circ} \mathrm{C}$, and it was sized to hold a batch of approximately $200 \mathrm{~kg}$ of powdered salt to yield approximately 120 liters of liquid salt. A heater blanket surrounds the tank with three vertical heater zones, and the vessel sits atop a heater plate. A firebrick tray is located beneath the heater plate.

The effluent from the processing vessel is vented through a scrubber system designed to capture $\mathrm{H}_{2} \mathrm{O}$ and $\mathrm{HCl}$. The system consists of a vacuum break and a series of three scrubber bottles. All tanks and lines are made of chemical-resistant plastics such as polytetrafluoroethylene (PTFE). The vacuum break prevents water in the scrubbers from backflowing into the processing vessel if there is a loss of pressure control in the processing vessel due to power failure accompanied by vessel cooldown, for example. The three scrubber bottles are partially filled with deionized water through which the effluent is bubbled. After the effluent has gone through the final scrubber, it is vented towards the top of the ventilated enclosure. Two toxic gas sensors survey the gas space inside the enclosure. Currently, these detectors have been set for hydrogen chloride; however different species can be selected for detection. 


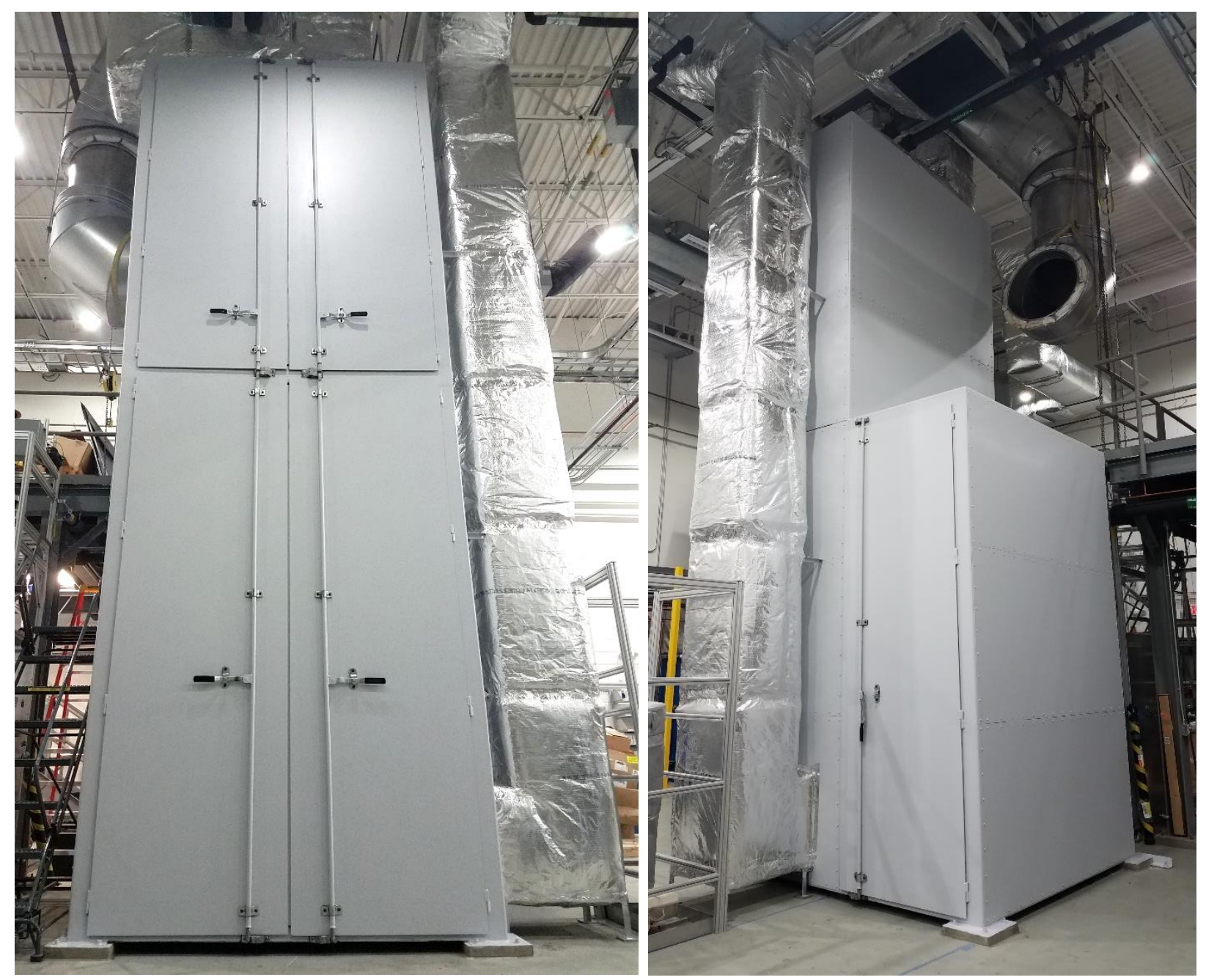

Figure 2. Enclosure and ventilation.

\subsection{GAS SUPPLY SYSTEM}

Argon is used as a cover gas, and it is also used to pneumatically move salts from one vessel to another. The gas supply system includes a source of argon, a gas supply panel, a gas purifier, and downstream mass flow controllers. UHP argon is supplied either via a 16-pack of large (i.e., $300 \mathrm{ft}^{3}$ ) high-pressure bottles or by a large cryogenic dewar (e.g., $270 \mathrm{~L}$ ). UHP has a specification of $99.999 \%$ purity with a maximum of $1 \mathrm{ppm} \mathrm{O}_{2}, 1 \mathrm{ppm} \mathrm{H}_{2} \mathrm{O}$, and traces of $\mathrm{CO}, \mathrm{CO}_{2}$ and $\mathrm{N}_{2}$. The supply panel includes a pressure regulator, pressure relief set to $90 \mathrm{psig}$, and isolation valves. A bank of six parallel combined oxygen and moisture molecular sieve traps is used to remove traces of $\mathrm{O}_{2}, \mathrm{H}_{2} \mathrm{O}, \mathrm{CO}_{2}$, and $\mathrm{CO}$ in the UHP gas or

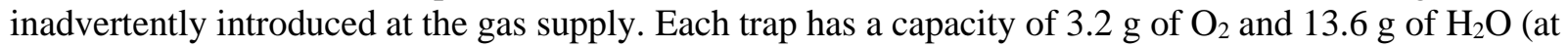
$100 \%$ capacity). The purifier was sized to accommodate at least 60 SLPM of flow and can purify at least $420 \times 300 \mathrm{ft}^{3}$ bottles of UHP argon to impurity concentrations of ppb. Once the argon leaves the gas purifier, it is piped to mass flow controllers (MFCs) to perform various functions (see Section 2.12.4). 


\subsection{STORAGE TANK}

The storage tank (Figure 3), stores the salt when not in use and is designed to accommodate salt freeze/thaw cycles. It is made of C-276 and has a total volume of approximately 2401. The vessel is a horizontal cylinder with semi-spherical heads. It was designed to accommodate a pressure of $206.8 \mathrm{kPa}(30$ psig) at $700^{\circ} \mathrm{C}$. A heater blanket surrounds the tank and has three horizontal heater zones and 4 inches of hightemperature insulation. The storage tank is placed on top of a firebrick tray. A scale under the firebrick tray is used to monitor and record changes in salt mass.

\subsection{PUMP}

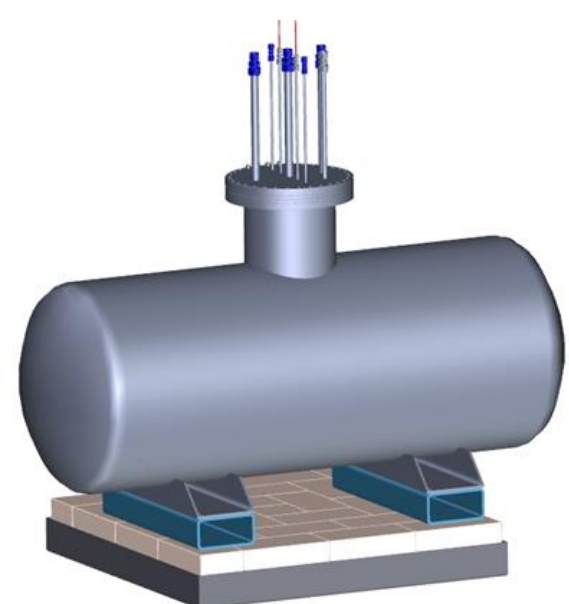

Figure 3. Storage tank.

A custom high-temperature molten salt pump is used to circulate the salt in the loop. A cantilevered centrifugal type pump was selected. This type of pump does not have bearings located in the salt. The salt pump was competitively sourced, and the wetted materials are constructed of C-276. The pump produces up to $70 \mathrm{gpm}$ at $29 \mathrm{ft}$ of head, with a maximum temperature rating of $1,337^{\circ} \mathrm{F}\left(725^{\circ} \mathrm{C}\right)$. The low range of the pump depends on seal performance and is anticipated to be $30 \mathrm{gpm}$. A VFD connected to the programmable logic controller (PLC), (see Section 2.13) controls the speed of the motor and therefore the salt flow rate.

\section{$2.8 \quad$ PUMP TANK AND STAND}

The pump is inserted into the pump tank, which was designed separately at ORNL. To limit the salt volume, the tank was designed with an obround shape, which is two semicircles joined together with a flat region in between (Figure 4). The tank is supported by the top flange. A separate mounting plate for the pump is located above the main flange of the tank. The pump can be removed while the tank remains in place. A stand supports the top flange of the tank and is designed to accommodate the tank's thermal expansion. The salt return line penetrates through the top flange. Several other nozzles also penetrate the top flange, as summarized in Table 4.

Table 4. Pump tank flange nozzles

\begin{tabular}{lcl}
\hline \multicolumn{1}{c}{ Flange } & Nozzle ID (in.) & \multicolumn{1}{c}{ Baseline purpose } \\
\hline \multirow{3}{*}{ Top flange } & 2.067 & Salt return \\
& 2.067 & Large test port \\
& 0.902 & Corrosion samples \\
& 0.902 & Spare \\
& 0.430 & Level probe \\
& 0.430 & Level probe \\
\hline \multirow{2}{*}{ Pump mounting flange } & 0.430 & Cover gas inlet \\
& 0.430 & Cover gas vent \\
\hline
\end{tabular}

Given the nontraditional design, a finite element stress analysis was conducted using ANSYS (see Appendix B). Based on the analysis, the tank is capable of 21.5 psig pressure at $704^{\circ} \mathrm{C}\left(1300^{\circ} \mathrm{F}\right)$. 
To reduce agitation of the salt-free surface and entrainment of gases into the salt, the return line discharges into a flow distributor. The flow distributor is made of two C-276 plates that form an annular region around the bottom of the tank. A small gap around between the flow distributor and tank wall facilitates distributed discharge of the salt into the tank. Computational fluids analysis was used to optimize the flow distributor design and to investigate whether gas would be entrained into the pump impeller. The computational fluid dynamics (CFD) results indicate that even with a high flow rate and a low amount of salt in the tank, no gas entrainment is predicted (see Figure 5).

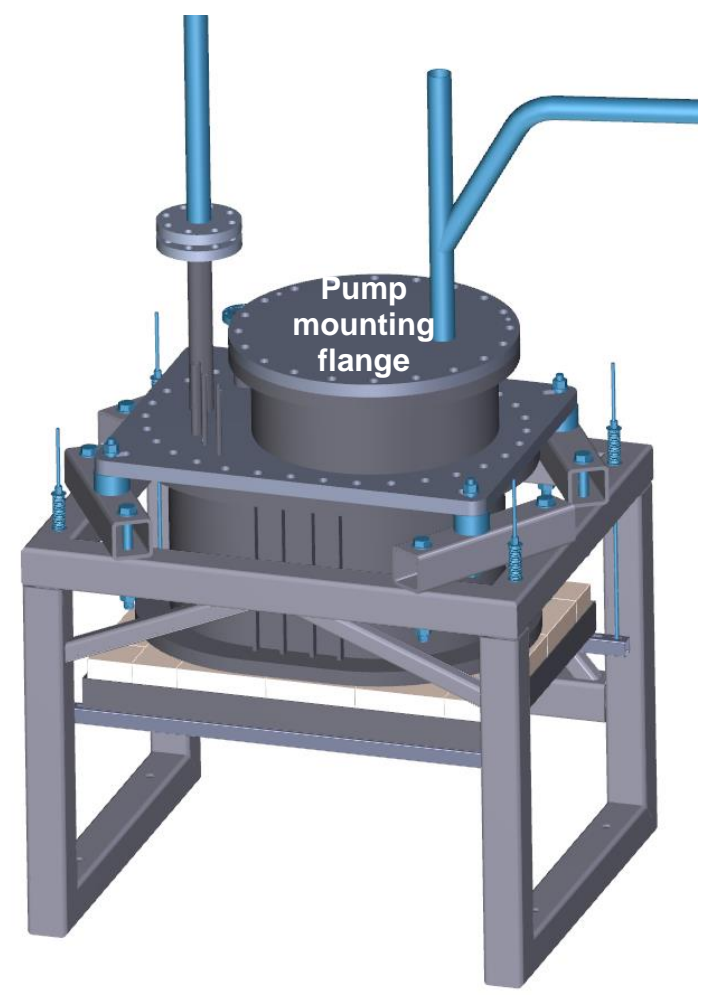

Figure 4. Pump tank and stand.

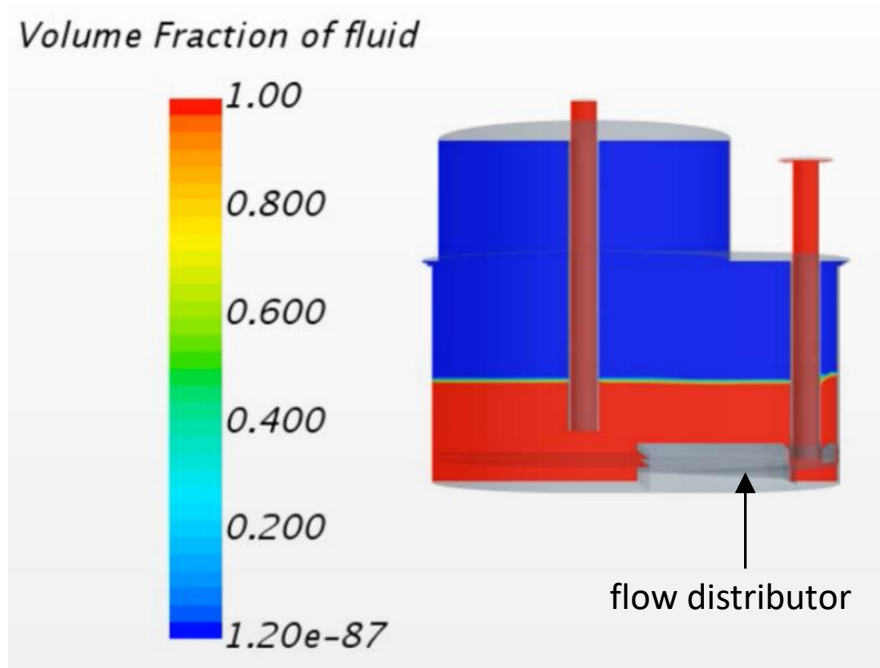

Figure 5. Pump tank gas entrainment prediction (8 inches of salt and $60 \mathrm{gpm}$ flowrate). 


\subsection{MAIN HEATER}

FASTR includes heated and cooled sections so that a temperature difference can be developed across the loop as required for prototypic corrosion studies.

The goal for the heater is to provide up to $725^{\circ} \mathrm{C}$ salt at the outlet and to have a peak attainable heat flux to the salt of $1 \mathrm{MW} / \mathrm{m}^{2}$. Various options for the main heater were explored, including induction, direct joule heating of the piping, natural gas, quartz near infrared lamps, xenon lamps, high-powered light emitting diodes (LEDs), and traditional resistance-based heaters. The need to achieve a high heat flux at high temperatures, combined with overall system cost limitations, drove the down-selection to aluminum nitride (AlN) heaters placed onto a flat rectangular main heater plate.

The main heater plate shown in Figure 6 is composed of a single 0.75inch thick Inconel 600 plate measuring 46.25 inches long and 13 inches wide. Fourteen holes 0.313 inches in diameter were gun drilled at a 0.785 -inch pitch through the length of the plate. These holes serve as vertical salt channels. The dimensions were determined through an optimization study using ANSYS to achieve uniform temperature distributions in the salt channel, maximum heat flux, and minimum peak temperature while conforming to real-world machinable dimensions. Inconel 600 was selected as the heater plate material because of its slightly higher thermal conductivity and its coefficient of thermal expansion that is similar to C-276 (Figure 7). The higher thermal conductivity reduces the temperature distribution in the heater plate and reduces the plate's maximum temperature. The front and rear faces of the plate contain twelve 0.063-inch channels for thermocouple placement. Twelve flat AlN heaters ( 2 units wide $\times 6$ units high) were placed against each side of the main heater plate. Holes on either edge of the plate are used for mounting the plate and securing heating elements and insulation to the plate's front and rear faces (Figure 8). Plate temperatures are regulated using six axial heater zones that are independently controlled. Salt enters the main heater through the bottom plenum and exits through the top plenum. The main heater assembly shown in Figure 8 will be suspended using spring hangars attached to a tubular frame, Figure 9.

An AlN heater is shown in Figure 10. A sample heater was cyclically heated and cooled in a furnace at temperatures up to $925^{\circ} \mathrm{C}$ for a total of 427 hours of hold time at temperature. The post-test heater resistance remained steady over this testing, which adds confidence in its ability to operate at high temperatures.

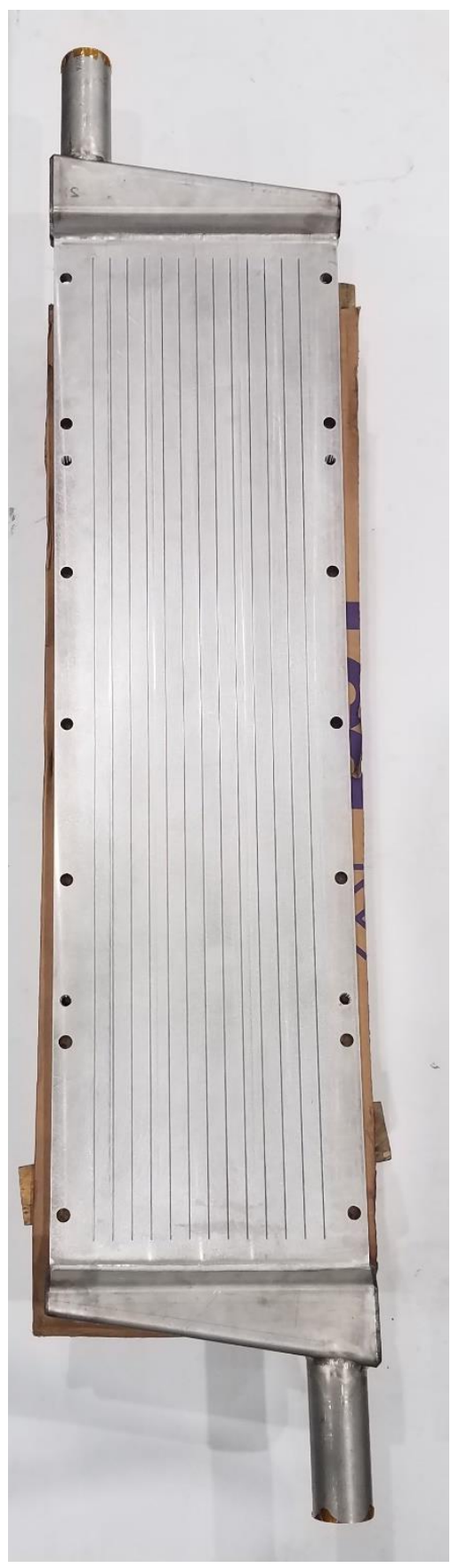

Figure 6. Main heater. 


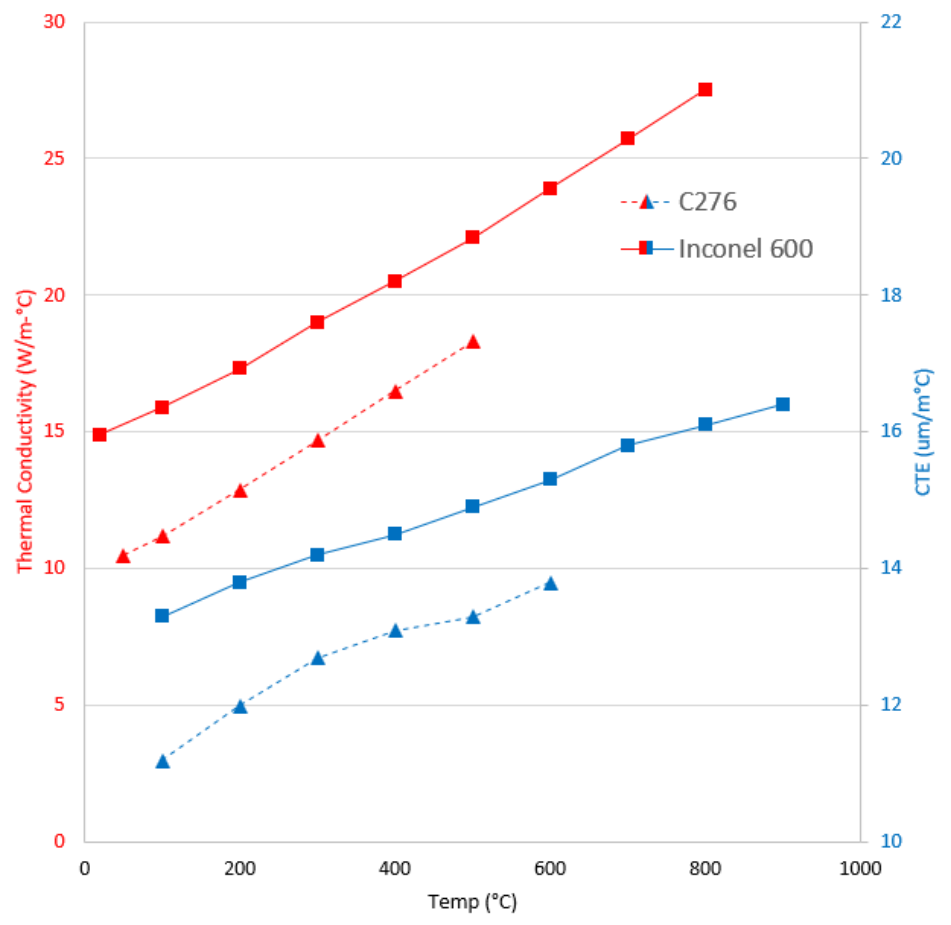

Figure 7. Thermal conductivity and coefficient of thermal expansion for C-276 and Inconel 600.

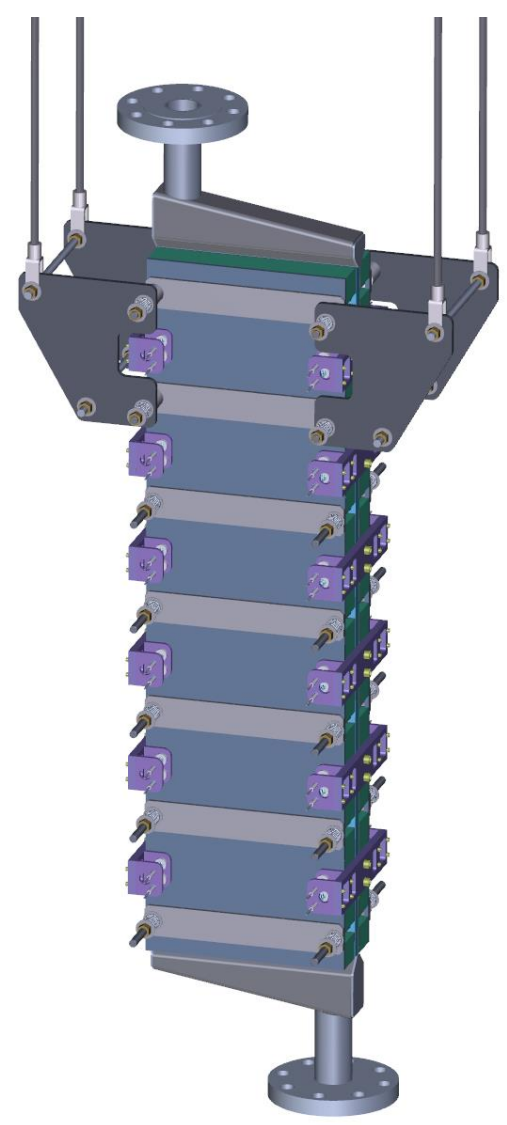

Figure 8. Main heater assembly. 


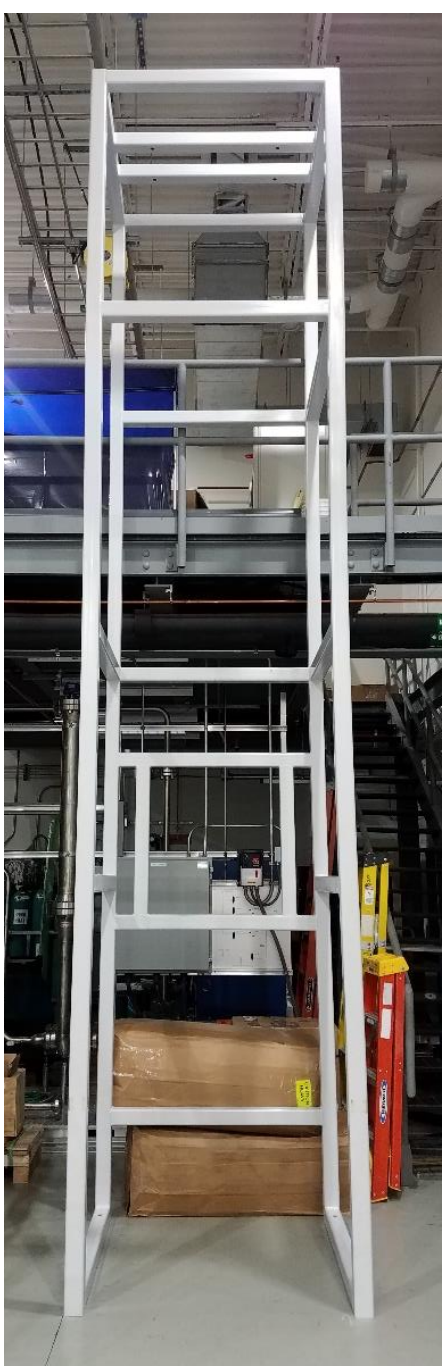

Figure 9. Tubular frame to support main heater.

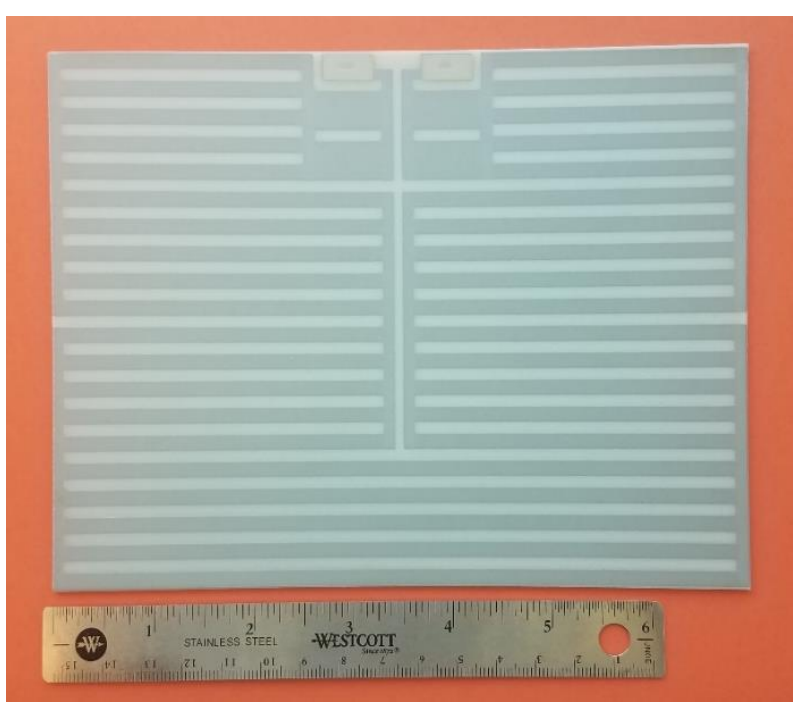

Figure 10. Aluminum nitride heater. 


\subsection{HEAT EXCHANGER}

An air-cooled heat exchanger was chosen to reject heat from the loop. The liquid salt test loop (LSTL) at ORNL uses a finned tube, air-cooled heat exchanger to reject heat $[14,15]$. This design and ORNL's relevant experience were leveraged to design the heat exchanger for FASTR.

The following design constraints were applied when sizing the heat exchanger. The predicted surface temperature had to remain above $475^{\circ} \mathrm{C}$ to provide $>50^{\circ} \mathrm{C}$ salt superheat to prevent the salt from freezing within the heat exchanger. The maximum air flow rate was restricted to 10,000 CFM based on considerations of duct and blower sizes, and the peak outlet air temperature was considered. In coordination with the remainder of the loop, the predicted pressure drop around the system was restricted to two atmospheres (29.4 psid). Finally, the design was restricted to standard tube/pipe and fin dimensions.

The final heat exchanger design includes two rows of eight pipes for a total of 16 pipes that are 46.5 inches long (Figure 11). Based on material sourcing and US finned tube manufacturing capabilities, the finned pipes are constructed from 1-inch schedule 40 seamless C-276 pipes with 0.5-inch long SS fins. The finned pipes are welded to tube sheets in a staggered pattern. The tube sheets are welded to plenums on either side where the salt enters/exits the heat exchanger. The heat exchanger is inside an enclosure with doors on the front and back faces. Between the doors and the heat exchanger, tubular heaters are used to increase the temperature before salt is introduced. The doors are then manually lowered or raised as needed.

The heat exchanger was modeled using correlations for finned tube array heat transfer [16]. Example performance curves of the design under specific conditions are provided in Figure 12. The required airflow indicated in the figures does not account for leaks or bypass flow around the heat exchanger.

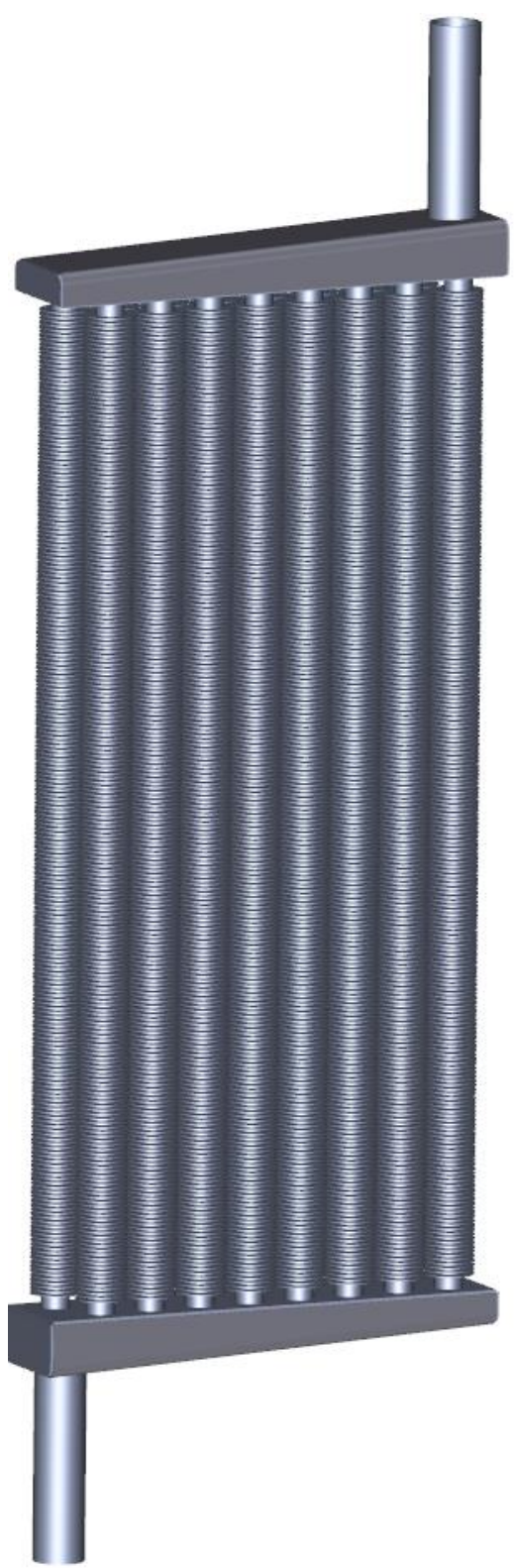

Figure 11. Heat exchanger. 

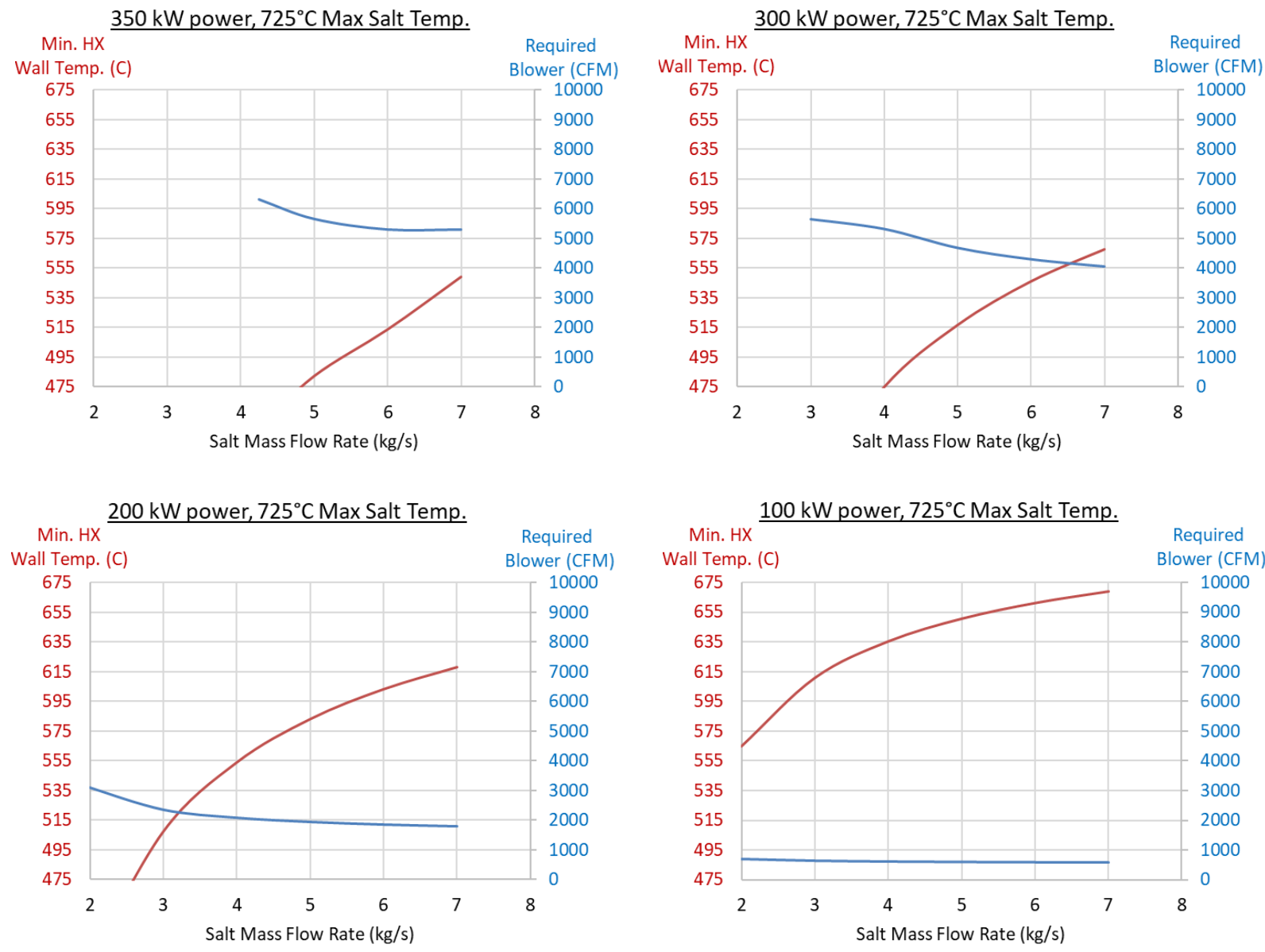

Figure 12. Example heat exchanger characteristics $\left(725^{\circ} \mathrm{C}\right.$ inlet $)$.

\subsection{MAIN PIPING AND TEST PORTS}

The main piping of the loop is 2-inch schedule 40 seamless C-276 pipe. Flanges custom developed at ORNL are included on either side of the major components - the pump tank, the main heater, and the heat exchanger - to facilitate swapping out components in the future. At four locations in the piping, ports with an inner nominal diameter of $2.067 \mathrm{in}$. are included to allow for the introduction of corrosion coupons, sensors, or other experimental apparatuses. This includes two ports on the cold side and two ports on the hot side of the loop. The pump tank includes one large test port and a few other smaller ports.

Another port located at the very top of the loop is included specifically for venting/refilling gas as the loop is filled/drained. To fill the loop with salt, after the loop is pre-heated, the gas space of the pump tank will be pressurized to force the salt into the loop. During this initial filling, an argon layer will be maintained in the top port through the addition and/or venting of gas by MFCs. After loop filling, a slight overpressure of gas will be maintained in the top port. When the pump is started this gas space will be partially compressed. The liquid level in the port will then be again adjusted through the addition/venting of the gas by the MFCs.

The main heater and heat exchanger are suspended by variable spring hangars. Four hangars are used to support the main heater and either two or four hangars will support the heat exchanger. A preliminary stress analysis of the piping network was conducted using finite element analysis (FEA) and documented in Appendix D. This preliminary stress analysis demonstrated the stresses are acceptable for a wide range 
of operating conditions and the analysis was used to size the spring hangars. The piping layout could be further optimized to lower stresses at the highest operating temperatures.

\subsection{INSTRUMENTATION}

The piping layout and general location of the instrumentation are identified on the piping and instrumentation diagram, Figure 13.

\subsubsection{Temperature}

Temperature is measured by standard type $\mathrm{N}$ and type $\mathrm{K}$ thermocouples placed externally throughout the system. The number and general locations of thermocouples are summarized in Table 2. Temperature measurements in the salt are included in the salt level probes (Section 2.12.3).

\subsubsection{Salt Flow Rate}

The salt flow rate is measured using an ultrasonic flow meter manufactured by Flexim, Inc. This is the same flowmeter used on the LSTL [15]. The Flexim WaveInjector meter was specifically designed to operate at a loop temperature of $700^{\circ} \mathrm{C}$. Wave guides were designed to ensure that the piezoelectric transducers remain at a safe operating temperature. Metal clamps attach the flow meter wave guides to flats machined on the surface of a pipe. These metal clamps and wave guides pose a thermal management challenge with respect to maintaining the pipe temperature above the salt freezing point while maintaining the piezoelectrics below their safe operating temperature. A heater and insulation solution for temperature control developed on the LSTL will be used for FASTR to regulate the component temperatures. The flow meter will be attached to the cold side of the loop between the heat exchanger and the pump tank. This length of pipe will allow for approximately 25 pipe diameters of development length before the flow meter and at least 5 pipe diameters after the flow meter.

\subsubsection{Salt Level}

The salt level is monitored through heated thermocouple arrays, a radar liquid level sensor, and a custom voltammetry sensor.

Heated thermocouple arrays are located inside the storage tank, in the pump tank, in the top vent port, and inside one test port. Each array consists of five thermocouples and a heater wire. A pair of arrays is inserted into a given component. The heater wire of one of the two arrays is heated. The temperatures of the thermocouples below the salt surface are lower than the temperatures of the thermocouples in the gas space due to differences in heat transfer. The second unheated array is used to measure and correct for axial temperature gradients in the salt and gas space. The salt level can be predicted by comparing the temperatures of the heated and un-heated thermocouple arrays. This technique can only detect whether the salt level is between two discrete thermocouple elevations.

Using a technique proven in the LSTL, an optional radar-based level detector can be included in one of the five test ports. In this set-up, the detector is located away from the salt, so it uses radar signals through a wave guide to detect the liquid level surface.

A multifunctional voltammetry sensor is being developed at Argonne National Laboratory. This sensor is also capable of measuring liquid level. This sensor will be inserted into two of the test ports on the loop to monitor the salt redox potential and the concentration of specific species (see Table 2). 


\subsubsection{Pressure and Level Control}

The gas pressure is measured and controlled at several locations (Table 5). The gas pressure is measured with standard pressure transducers (Honeywell model FP2000). A set of in- and out-flow of mass flow controllers (MFCs) (MKS model GE50A) can add or remove gas to the space. An additional solenoid valve on the pump tank facilitates more rapid depressurization and draining of the salt loop piping. The operators can set a manual flow rate, or they can specify a target pressure, and the MFC adjusts accordingly. Several relief valves are located throughout the system, as shown in Table 6. The setpoints for the tanks are based on their respective analyses.

Table 5. Gas mass flow controller and pressure transducer sizes

\begin{tabular}{lcc}
\hline \multicolumn{1}{c}{ Location } & $\begin{array}{c}\text { Maximum } \\
\text { flow rate (SLPM) }\end{array}$ & $\begin{array}{c}\text { Pressure transducer } \\
\text { maximum (psig) }\end{array}$ \\
\hline Flanges (in and out) & 0.200 & 50 \\
\hline Top gas vent (in and out) & 10 & 50 \\
\hline Test port (in and out) & 10 & 50 \\
\hline Storage tank (in and out) & 50 & 50 \\
\hline Pump tank (in and out) & 50 & 50 \\
\hline Process vessel (sweep line) & 5 & 30 \\
\hline Process vessel (bubbler line) & 5 & \\
\hline
\end{tabular}

Table 6. Pressure relief locations and setpoints

\begin{tabular}{lc}
\hline \multicolumn{1}{c}{ Location } & Relief setpoint (psig) \\
\hline Gas supply panel & 90 \\
Processing vessel & 30 \\
Storage tank & 30 \\
Pump tank & 21.5 \\
\hline
\end{tabular}

\subsection{CONTROL SYSTEM AND TRACE HEATING SUMMARY}

The data acquisition and control system is driven by an Allen Bradley 1756 PLC containing various input and output modules for data acquisition and control. Two cabinets house Allen Bradley 1794 FLEX I/O thermocouple input modules. This thermocouple data is passed to the PLC via ethernet modules.

Three custom heater control cabinets were designed and fabricated at ORNL. Each heater control cabinet is comprised of 16 controllable heater zones, for a total of 48 total zones. Each zone includes a breaker and a relay that is controlled via the PLC. The main heater, described above in Section 2.9, has 6 additional heater zones that are controlled by a separate control system.

The processing vessel, storage tank, and pump tank are wrapped in heater blankets, which include embedded heaters with surrounding insulation. Table 7 summarizes the heater blanket locations and maximum powers. Cartridge or tubular heaters are also used to provide trace heating to some components. Table 8 summarizes the tubular/cartridge heater locations and maximum powers. Finally, heat tapes of various sizes are used to supply trace heating to tubing and piping throughout the loop and transfer lines. 
SAMPLE Port

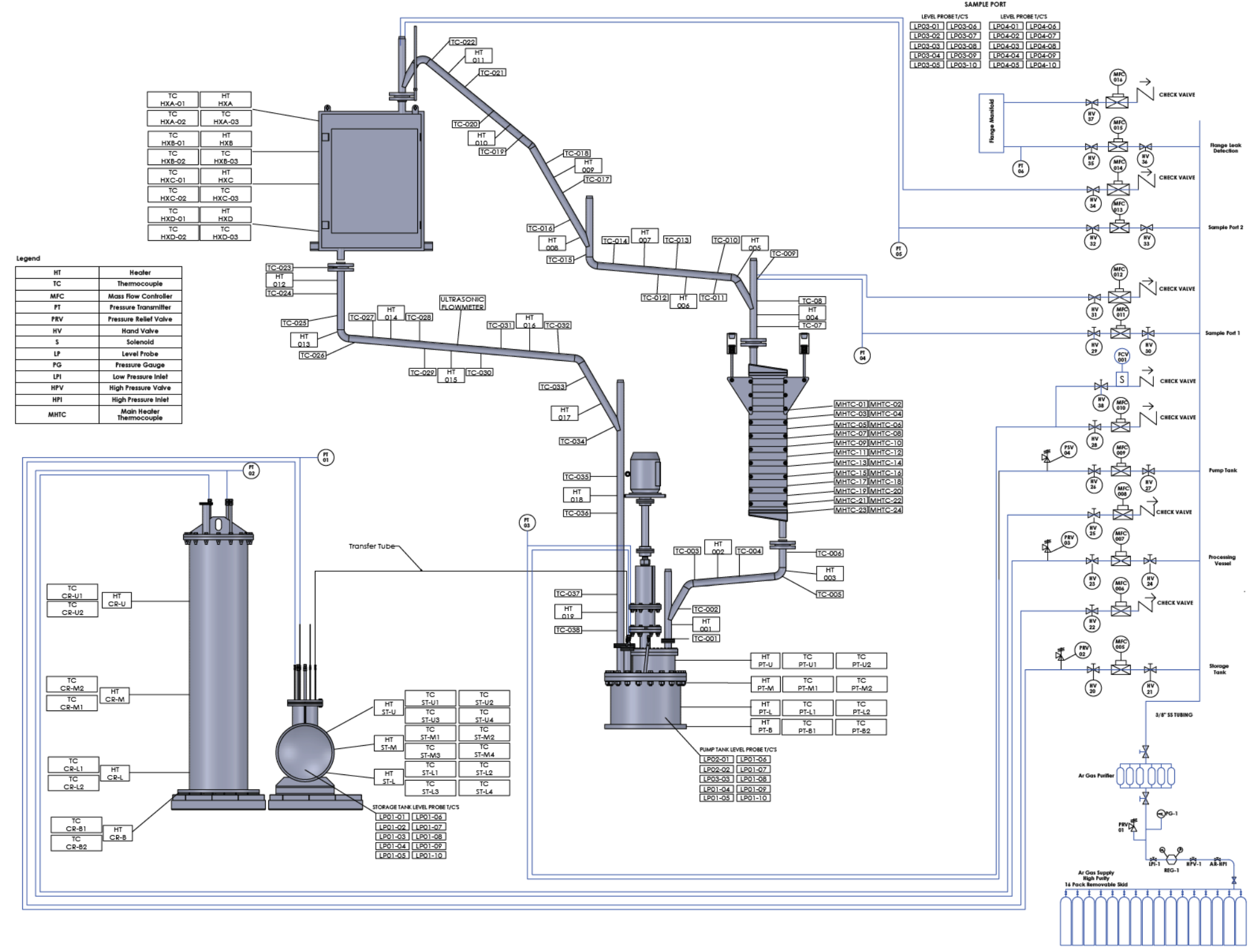

Figure 13. Piping and instrumentation diagram. 
Table 7. Summary of heater blankets

\begin{tabular}{|c|c|c|}
\hline Component & Location & $\operatorname{Max}$ power $(\mathrm{W})$ \\
\hline \multirow{3}{*}{ Processing vessel } & Upper & 3,600 \\
\hline & Middle & 3,600 \\
\hline & Lower & 2,400 \\
\hline \multirow{3}{*}{ Storage tank } & Upper & $1,783 \times 2$ \\
\hline & Middle & $734 \times 2$ \\
\hline & Lower & $1,081 \times 2$ \\
\hline \multirow{3}{*}{ Pump tank } & Upper & 1,000 (estimate) \\
\hline & Middle & 1,750 (estimate) \\
\hline & Lower & 1,750 (estimate) \\
\hline
\end{tabular}

Table 8. Summary of cartridge and tubular heaters

\begin{tabular}{lcc}
\hline \multicolumn{1}{c}{ Component } & Location & Max power $(\mathbf{W})$ \\
\hline Processing vessel & Bottom & 1,590 \\
\hline Pump tank & Bottom & $1,500 \times 2$ \\
\hline \multirow{2}{*}{ Main heater guard } & Top plenum & $500 \times 2$ \\
& Bottom plenum & $500 \times 2$ \\
& Top plenum & $600 \times 2$ \\
Heat exchanger guard & Bottom plenum & $600 \times 2$ \\
& Face top & $1,750 \times 2$ \\
& Face bottom & $1,750 \times 2$ \\
\hline
\end{tabular}

\subsection{SALT-TO-SCO ${ }_{2}$ HEAT EXCHANGER TESTING INFRASTRUCTURE}

The capabilities of FASTR were recently extended to include the capability to test salt-to-supercritical carbon dioxide $\left(\mathrm{sCO}_{2}\right)$ heat exchangers. This type of heat exchanger operates under challenging conditions and is critical to the coupling of a molten-salt heat transfer and energy storage fluid to a $\mathrm{sCO}_{2}$ power cycle.

To facilitate this testing, a $\mathrm{sCO}_{2}$ loop will be developed in collaboration with Sandia National Laboratories and constructed near the ventilated enclosure (see Section 2.4). The salt-to-sCO $\mathrm{CO}_{2}$ heat exchanger will be located within the ventilated enclosure directly below the air-cooled heat exchanger. The ventilated enclosure will confine and vent any carbon dioxide leakage from the $\mathrm{sCO}_{2}$ loop or heat exchanger. Nearby chilled water and the ventilated enclosure will provide routes for heat removal from the $\mathrm{sCO}_{2}$ loop. 


\section{LOOP OPERATING CONDITIONS}

\subsection{PLANNED TESTING CAMPAIGNS}

A preliminary test plan is provided in Table 9. The test plan covers the shakedown testing of the installed system, determination of the system characteristics and operation envelope, and testing to be completed for scientific data to guide the Gen3 CSP molten salt pathway.

As operational experience is accumulated, the logistics by which the system is operated will progress. Initially, FASTR will be staffed and monitored by two personnel during normal business hours. During off-normal hours, the system will be placed in hot standby with the pump disabled and the system drained. With experience, FASTR will progress towards the goal of operating the loop without local staff, first during normal business hours, and eventually during off-normal hours. This progression will depend on system performance and experience and input from environment, health, and safety (ES\&H) personnel and other stakeholders. 
Table 9. Preliminary test plan

Phase: Shakedown

Purpose: Ensure that subcomponents meet performance expectations before salt introduction

I\&C verification

Heater operation

Pump operation

Heat exchanger operation

System leak check

(gas, room temperature)

Heat system: isothermal

System leak check (gas, high temperature)

System trips
Verify temperature, gas pressure, gas flowrate sensor readings

Verify individual heater integrity

Run dry, take up to speed, and balance as needed

Verify fan operation

Leak check fittings, flanges, etc., at low temperatures

Ensure the ability to maintain system temperatures; estimate heat losses

Leak check fittings, flanges, etc., at high temperatures

Verify preset system trips to the extent possible

Phase: Startup

Purpose: (1) Characterize integral system behavior, and (2) determine the system operational envelope

Salt characterization

$\mathrm{I} \& \mathrm{C}$ verification

Isothermal operation

Heater performance

Pump performance

Heat exchanger performance

System trips

Phase: Test Campaigns

Purpose: Obtain quality scientific data

Corrosion control demonstration

Conduct coupon tests: $2 \times$ lines $(1 \times$ hot leg, $1 \times$ cold leg) of 12 samples $(6 \times$

C-276, 6x Inconel 600); conducted over $100 \mathrm{~h}$ and $200 \mathrm{~h}$

In-situ corrosion measurement (as applicable)

Heat transfer

REDOX control system and oxygen/impurity sensors demonstration

Test heat transfer vs. fan speed, salt flow rate $(3-6 \mathrm{~kg} / \mathrm{s})$ Reynolds number $(15,000-50,000)$, salt inlet temp $\left(500-700^{\circ} \mathrm{C}\right)$

Demonstrate reduction and control of oxygen/impurities using the REDOX control system as applicable (e.g., getter can, electrochemical oxygen removal). This testing will occur over the course of other planned tests and does not include intentional introduction of impurities.

Extended operation demonstration Demonstrate robustness of system through $1 \times 100 \mathrm{~h}$ run and $>200 \mathrm{~h}$ of cumulative runtime by $1 / 31 / 2021$, with salt circulating in the system $>500^{\circ} \mathrm{C}$ and a $>25^{\circ} \mathrm{C}$ temperature gradient.

$\mathrm{sCO}_{2} \mathrm{HX}$ testing
Evaluate the heat transfer performance and demonstrate the durability of a salt-to-s $\mathrm{CO}_{2}$ heat exchanger 


\subsection{PREDICTED OPERATING ENVELOPE AND CONDITIONS}

The flow loop was modeled to predict the system pressure drop, the heat exchanger, and the main heater characteristics using analytical and semi-empirical techniques. The spreadsheet model and supplemental higher fidelity analyses of the heat exchanger and main heater were used to size components and predict the potential operating envelope for the system. There are uncertainties in salt thermophysical properties as well as the correlations used for pressure drop and heat transfer. As noted in Section 3.1, the actual operating envelope will be determined during the system startup phase.

Pressure losses were modeled around the flow loop for isothermal conditions, as seen in Figure 14. Form loss (i.e., K coefficient) was modeled as 0.45 for pipe bends and 1.4 for combined contraction-expansion losses (e.g., inlet and outlet of heat exchanger tubes). The salt thermophysical properties were taken as those for $\mathrm{KCl}-\mathrm{MgCl}_{2}$ [17]. The results shown in Figure 14 indicate that the pressure drop is not sensitive to the salt temperature.

To keep the heat exchanger tube surface temperature above $475^{\circ} \mathrm{C}$, a self-imposed limit to ensure salt does not freeze in the channels, the maximum main heater power is given in Figure 15. For a given curve, areas under the curve are feasible operating conditions, while areas above the curve are predicted to have tube surface temperatures below $475^{\circ} \mathrm{C}$. Manipulating the heat exchanger doors and/or the use of trace heating may expand the operational envelope.

Based on a constant specific heat of $1,150 \mathrm{~kJ} / \mathrm{kg}-\mathrm{K}$, the salt temperature difference between the hot and cold side of the loop is presented in Figure 16. A steady-state temperature difference up to $100^{\circ} \mathrm{C}$ is attainable based on a $3 \mathrm{~kg} / \mathrm{s}$ flow rate. However, as shown in Figure 15, the maximum power at $3 \mathrm{~kg} / \mathrm{s}$ may be $230 \mathrm{~kW}$ based on heat exchanger limits.

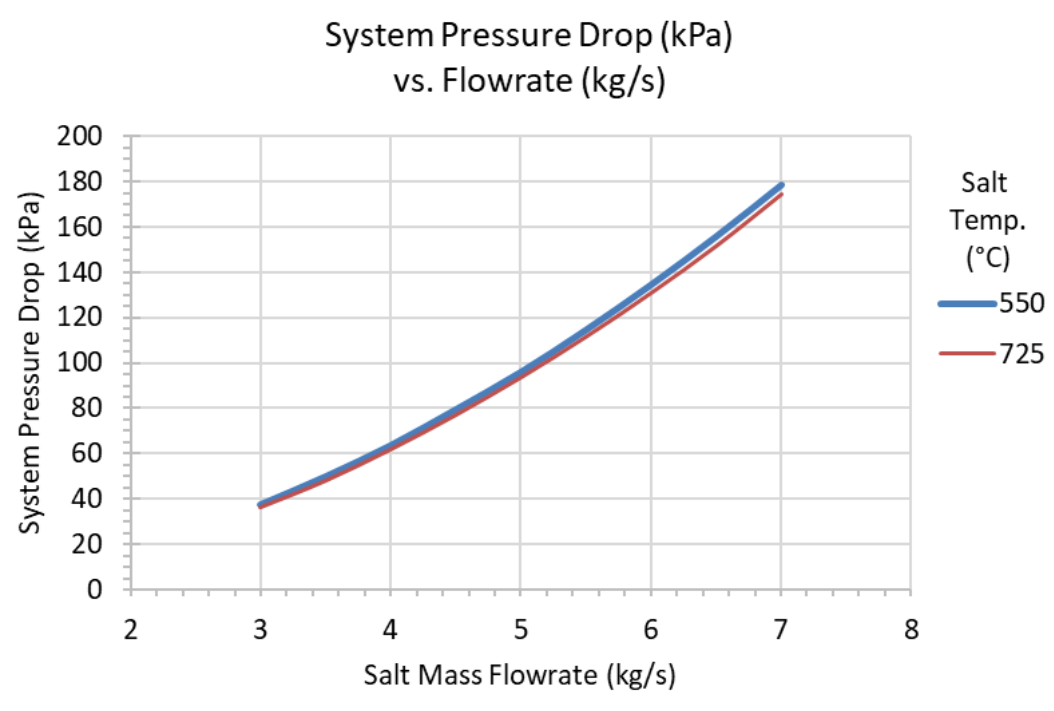

Figure 14. Predicted pressure drop vs. mass flowrate. 


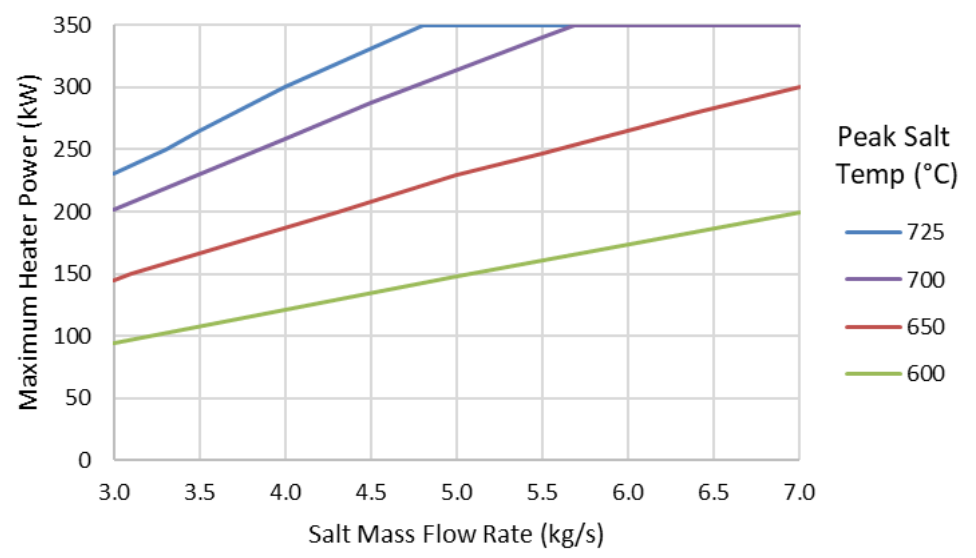

Figure 15. Maximum heater power at various max salt temperatures based on heat exchanger limits.

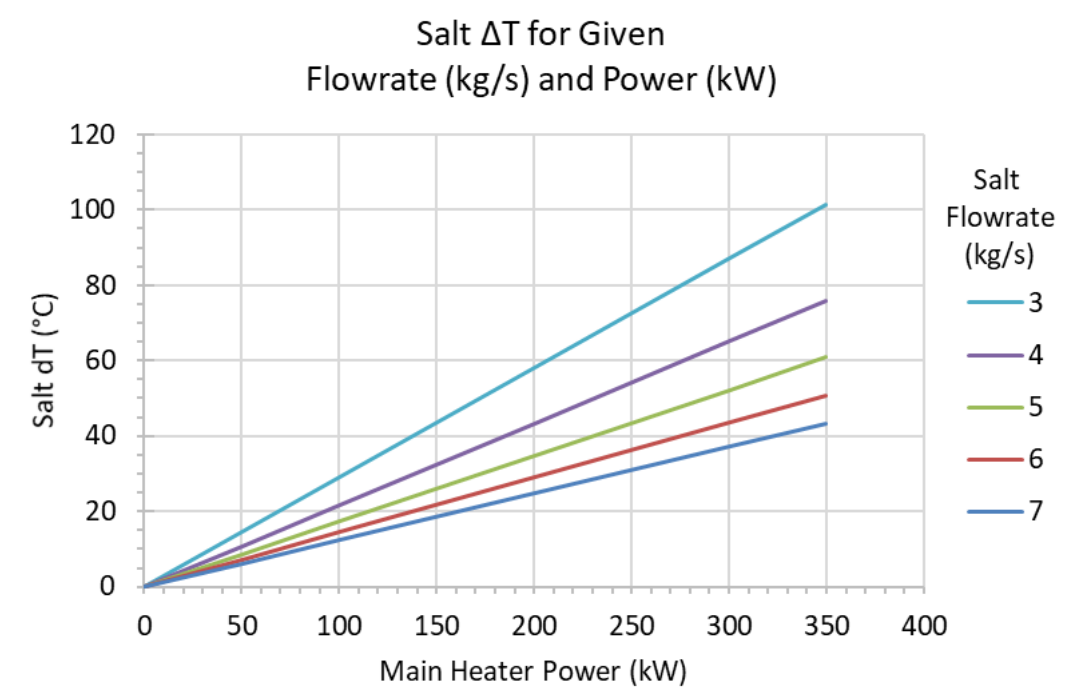

Figure 16. Salt $\Delta T$ based on flowrate and main heater power. 


\section{FAILURE MODES AND EFFECTS ANALYSIS}

Failure modes and effects analysis (FMEA) is a proactive method for analyzing various components, systems, and processes to identify potential failures and their impact. Different types and formats of FMEA cover a range of rigor. In this effort, two different FMEAs were developed. For the first FMEA, potential failure modes of specific components and subsystems were identified (see Section 4.1). For the second FMEA, the failure modes of various processes for salt purification and loop operation were identified (Section 4.2).

\subsection{COMPONENT AND SUBSYSTEM FMEA}

The first FMEA was constructed and ranked by the project principal investigator. In this FMEA, each major component was scrutinized for potential failure modes. In the analysis, 52 failure modes were identified for 6 categories (Generic/Global, Pump and Tank, Main Heater, Piping/Sample Ports, Heat Exchanger, Purification System). Each mode was then ranked for probability of occurrence and severity of impact. The definitions of the probability and severity are provided in Table 10 and Table 11, respectively. The probability is subjective, based on previous experience and perceived likelihood. The severity was focused on the failure mode's impact on the ability to operate the loop to complete the required testing.

Table 10. FMEA probability definition

\begin{tabular}{cl}
\hline Probability & \multicolumn{1}{c}{ Definition } \\
\hline 1 & Very unlikely \\
2 & Potential to occur infrequently $<1 / \mathrm{y}$ \\
3 & Chance to occur $\sim 1 / \mathrm{y}$ \\
4 & Higher chance to occur $>1 / \mathrm{y}$ \\
5 & Very likely \\
\hline
\end{tabular}

Table 11. FMEA severity definition

\begin{tabular}{cll}
\hline Severity & \multicolumn{1}{c}{ Definition } & \multicolumn{1}{c}{ Recovery } \\
1 & No/negligible impact & None \\
2 & Quickly resolved/minor impact & Redundancies, quick solution, test mod. \\
3 & Prevents loop operation - short term & $<1$ month \\
4 & Prevents loop operation - moderate term & $<4$ months \\
5 & System major disruption, destruction & $>4$ months, replace major component(s) \\
\hline
\end{tabular}

The number of failure modes for each position in the risk matrix were tallied and summarized in Figure 17: 6 failure modes were identified as having a probability rank of 1 and a severity rank of 3. Items in the top left of the image are of low risk (probability $\times$ severity), while items in the bottom right of the image are of high risk. Most items (75\%) are in the low- and minor-risk categories, 13 failure modes were in the medium-risk category, and no items were in the high risk categories. The medium-risk modes are summarized in Table 12. Some of the mitigating efforts for each of the medium-risk failure modes are noted in Table 13. 


\section{Severity}

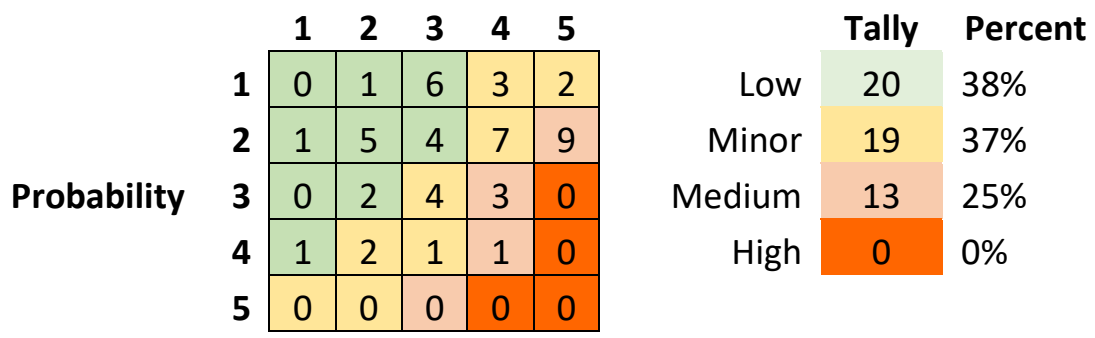

Figure 17. First FMEA result summary.

Table 12. Component and subsystem FMEA: medium-risk items

\begin{tabular}{llcc}
\hline \multicolumn{1}{c}{ Component } & \multicolumn{1}{c}{ Failure mode } & Probability & Severity \\
\hline \multirow{2}{*}{ Generic/global } & Wrong material in component & 2 & 5 \\
& (fabricator/vendor swapped material) & 2 & 5 \\
& Shaft seizure & 2 & 5 \\
\multirow{3}{*}{ Pump and tank } & Shaft failure & 2 & 5 \\
& Impeller disassembly during operation & 2 & 4 \\
\hline \multirow{2}{*}{ Main heater } & Impeller erosion (unacceptable level) & 3 & 4 \\
& Heater failure & 4 & 5 \\
\multirow{2}{*}{ Piping/sample Ports } & (electrical connection, burnout, oxidation, mechanical) & 2 & 5 \\
& Joint stress/creep failure (therm. exp) & 3 & 4 \\
\hline \multirow{2}{*}{ Heat exchanger } & Coupon detachment, leading to flow blockage & 2 & 5 \\
& Stress/creep failure (thermal exp) & 2 & 5 \\
\hline Purification system & Salt freezing (undetected/major) & 2 & 5 \\
\hline
\end{tabular}


Table 13. Component and subsystem FMEA: mitigation efforts for medium-risk failure modes

\begin{tabular}{|c|c|}
\hline Failure mode & Mitigation efforts \\
\hline $\begin{array}{l}\text { Generic/global - wrong material in component } \\
\text { (fabricator/vendor swaps material) }\end{array}$ & $\begin{array}{l}\text { Material certifications are requested for almost all salt- } \\
\text { wetted parts }\end{array}$ \\
\hline Pump and tank - shaft seizure & No salt-wetted bearings or other sliding contacts are used. \\
\hline Pump and tank - shaft failure & $\begin{array}{l}\text { A robust sized made of high-temperature, corrosion- } \\
\text { resistant material is used. }\end{array}$ \\
\hline $\begin{array}{l}\text { Pump and tank - impeller disassembly during } \\
\text { operation }\end{array}$ & $\begin{array}{l}\text { May include wire tie or another secondary device to secure } \\
\text { the impeller nut to the shaft. }\end{array}$ \\
\hline Pump and tank - impeller erosion (unacceptable level) & $\begin{array}{l}\text { Investigations into salt solids content have been requested. } \\
\text { Post-purified salt will be purified, and pump tank is } \\
\text { designed to facilitate impeller inspection. }\end{array}$ \\
\hline $\begin{array}{l}\text { Main heater - heater failure } \\
\text { (electrical connection, burnout, oxidation, mechanical) }\end{array}$ & Testing on heater durability is in process. \\
\hline Main heater - joint stress/creep failure (therm. exp) & FEA will be conducted on the entire system. \\
\hline $\begin{array}{l}\text { Piping/sample ports - coupon detachment leading to } \\
\text { flow blockage }\end{array}$ & $\begin{array}{l}\text { Coupon and attachment will be made of corrosion- } \\
\text { resistant materials with oversized attachments. }\end{array}$ \\
\hline $\begin{array}{l}\text { Heat exchanger - stress/creep failure (thermal } \\
\text { expansion) }\end{array}$ & $\begin{array}{l}\text { The final heat exchanger design is more robust than the } \\
\text { original design. FEA can be conducted in the future. }\end{array}$ \\
\hline Heat exchanger - salt freezing (undetected/major) & $\begin{array}{l}\text { A thermocouple will be attached near the outlet of each of } \\
\text { the eight tubes in the front row of the heat exchanger. The } \\
\text { heat exchanger cavity includes face heaters. }\end{array}$ \\
\hline Purification system - tank failure (corrosion) & $\begin{array}{l}\text { The purification process is being investigated by multiple } \\
\text { labs and at least one university and will be conducted on a } \\
\text { small scale prior to large system operation. }\end{array}$ \\
\hline
\end{tabular}




\subsection{PURIFICATION AND LOOP OPERATION PROCESS FMEA}

A second FMEA was conducted based on process steps for both salt purification and loop operation. Each of the two operations (salt loop and purification system) were divided into process steps as shown in Table 14. Failure modes and potential causes were identified for each process step, and each cause was rated for probability and severity using the metrics provided in Table 10 and Table 11 . The project PI and the LSTL PI developed this FMEA and independently rated the items. The combined severity and probability ratings for each item were then determined by taking the average and rounding up to the nearest whole number.

Table 14. Process steps for purification and loop operation

\begin{tabular}{rll}
\hline Step & \multicolumn{1}{c}{ Purification process step } & \multicolumn{1}{c}{ Loop operation step } \\
\hline 1 & Purification system instrument calibration & Loop instrument calibration \\
2 & Purification system leak check & Loop leak check \\
3 & Remove crucible flange & Loop heat-up \\
4 & Put salt in processing crucible & Install Storage tank to sump transfer tube \\
5 & Set up scrubber system & Transfer salt from storage to sump tank \\
6 & Install crucible flange & Raise salt into loop \\
7 & Purge crucible with argon & Operation of pump \\
8 & Heat up processing crucible & Shake down main heaters \\
9 & Initiate salt processing & Steady state operation \\
10 & Complete processing step - shut down hazardous gas flows & Gather data \\
11 & Purge crucible and off-gas system with argon & Change steady state conditions \\
12 & Install transfer tube between processing crucible and storage tank & Gather data \\
13 & Transfer salt to storage tank & Let salt down into sump tank \\
14 & Remove transfer tube & Transfer salt to storage tank \\
15 & Cool down processing system & Remove transfer tube \\
16 & Disassemble scrubber system & Cool down loop \\
17 & --- & Remove corrosion samples \\
\hline
\end{tabular}

For the salt purification operation, 16 process steps, 47 failure modes, and 96 potential unique causes for those failure modes were identified. The number of failure modes for each position in the risk matrix was tallied and is summarized in Figure 18: 89\% are in the low- and minor-risk categories. Ten items were in the medium-risk category, and one item was in the high-risk category. These eleven items are summarized in Table 15. 


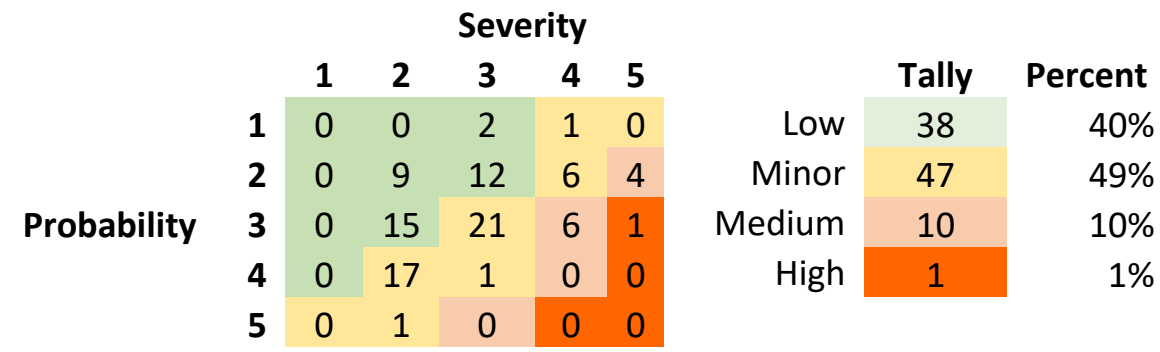

Figure 18. Salt purification process FMEA - results summary.

Table 15. Salt purification process FMEA: medium- and high-risk results

\begin{tabular}{|c|c|c|c|c|}
\hline Step & Failure mode & Cause & Probability & Severity \\
\hline \multicolumn{5}{|c|}{ High risk } \\
\hline 10 & Salt purity not as desired & Processing technique inadequate & 3 & 5 \\
\hline \multicolumn{5}{|c|}{ Medium risk } \\
\hline 2 & Leak in vessel & Cracked vessel or weld & 2 & 5 \\
\hline 9 & Hazardous gas alarms activate & $\begin{array}{l}\text { Ventilation system was not sufficient to dilute } \\
\text { hazardous off-gas }\end{array}$ & 2 & 5 \\
\hline 11 & $\begin{array}{l}\text { All hazardous gases are not } \\
\text { removed from system }\end{array}$ & Insufficient purge time & 2 & 5 \\
\hline 15 & Vessel or tubing cracks & $\begin{array}{l}\text { Vessel/tubing temperature gradients during } \\
\text { cooldown caused cracking due to thermal stress }\end{array}$ & 2 & 5 \\
\hline 2 & Leak found at crucible flange seal & Flange surface scarred & 3 & 4 \\
\hline 8 & $\begin{array}{l}\text { Trace/blanket/tubular heater does } \\
\text { not heat }\end{array}$ & Heating tape/blanket/tubular heater failed & 3 & 4 \\
\hline 9 & $\begin{array}{l}\text { Processing gas use is inconsistent } \\
\text { with instrument output }\end{array}$ & Mass flow meter failed or was out of calibration & 3 & 4 \\
\hline 10 & Salt purity not as desired & Processing time was not sufficient & 3 & 4 \\
\hline 12 & Filter gets clogged & Clean-up process produced unexpected solids & 3 & 4 \\
\hline 16 & Liquid $\mathrm{pH}$ exceeds expected values & $\begin{array}{l}\text { Process gas concentration was higher than } \\
\text { expected in exhaust stream }\end{array}$ & 3 & 4 \\
\hline
\end{tabular}


For the salt loop operation, 17 process steps, 62 failure modes, and 130 potential unique causes for those failure modes were identified. The number of failure modes for each position in the risk matrix was tallied and is summarized in Figure 17: 87\% are in the low- and minor-risk categories. Fifteen items were in the medium-risk category, and two items were in the high-risk category, Table 16.

\begin{tabular}{|c|c|c|c|c|c|c|c|c|c|}
\hline & & & & Sel & rity & & & & \\
\hline & & 1 & 2 & 3 & 4 & 5 & & Tally & Percent \\
\hline & 1 & 0 & 0 & 10 & 2 & 0 & Low & 60 & $46 \%$ \\
\hline & 2 & 0 & 12 & 15 & 11 & 5 & Minor & 53 & $41 \%$ \\
\hline robability & 3 & 0 & 23 & 19 & 10 & 2 & Medium & 15 & $12 \%$ \\
\hline & 4 & 0 & 15 & 5 & 0 & 0 & High & 2 & $2 \%$ \\
\hline & 5 & 0 & 1 & 0 & 0 & 0 & & & \\
\hline
\end{tabular}

Figure 19. Loop Operation process FMEA - results summary.

Table 16. Loop operation process FMEA - medium- and high-risk results

\begin{tabular}{|c|c|c|c|c|}
\hline Step & Failure mode & Cause & Probability & Severity \\
\hline \multicolumn{5}{|c|}{ High risk } \\
\hline 9 & Corrosion control insufficient & $\begin{array}{l}\text { Response is insufficient to reduce corrosion } \\
\text { (e.g., adding } \mathrm{Mg} \text { ) }\end{array}$ & 3 & 5 \\
\hline 9 & Corrosion control insufficient & $\begin{array}{l}\text { Deposition of products in cold-side } \\
\text { piping/tanks is excessive }\end{array}$ & 3 & 5 \\
\hline \multicolumn{5}{|c|}{ Medium risk } \\
\hline 2 & Leak in pipe or vessel & Cracked pipe, vessel, or weld & 2 & 5 \\
\hline 7 & Pump does not start & Pump shaft/impeller failed & 2 & 5 \\
\hline 9 & $\begin{array}{l}\text { Cannot maintain steady-state } \\
\text { thermal conditions }\end{array}$ & $\begin{array}{l}\text { Heat exchanger was not sized correctly } \\
\text { (salt side) }\end{array}$ & 2 & 5 \\
\hline 9 & $\begin{array}{l}\text { Cannot maintain steady-state } \\
\text { thermal conditions }\end{array}$ & $\begin{array}{l}\text { Heat exchanger air cooling was not sized } \\
\text { correctly (air side) }\end{array}$ & 2 & 5 \\
\hline 16 & Component or piping cracks & $\begin{array}{l}\text { Component/piping temperature gradients } \\
\text { during cooldown caused cracking due to } \\
\text { thermal stress }\end{array}$ & 2 & 5 \\
\hline 1 & No level indication & Failed heated thermocouple & 3 & 4 \\
\hline 2 & Leak found at a flanged joint & Flange surface scarred & 3 & 4 \\
\hline 2 & $\begin{array}{l}\text { Trace/blanket/tubular heater does } \\
\text { not heat }\end{array}$ & Heating tape/blanket/tubular heater failed & 3 & 4 \\
\hline 6 & $\begin{array}{l}\text { Salt freezes in a portion of the } \\
\text { piping system }\end{array}$ & $\begin{array}{l}\text { Loop not sufficiently heated before } \\
\text { initiating filling process }\end{array}$ & 3 & 4 \\
\hline 8 & $\begin{array}{l}\text { Test section heaters cannot } \\
\text { maintain desired temperature }\end{array}$ & Heaters failed during operation & 3 & 4 \\
\hline 9 & Salt leak occurs & Failed salt wetted seal or fitting & 3 & 4 \\
\hline 9 & $\begin{array}{l}\text { Corrosion coupon detaches } \\
\text { from holder }\end{array}$ & Coupons not secured sufficiently to holder & 3 & 4 \\
\hline 14 & Salt frozen in piping/vessel system & $\begin{array}{l}\text { Temperatures were allowed to get below salt } \\
\text { freeze point }\end{array}$ & 3 & 4 \\
\hline 17 & Some samples lost & Samples detached from the holder & 3 & 4 \\
\hline 17 & $\begin{array}{l}\text { Unable to keep samples from being } \\
\text { exposed to air }\end{array}$ & The sample removal port allowed air ingress & 3 & 4 \\
\hline
\end{tabular}


In total, 24 unique medium- or high-risk failure mode causes were identified for the purification and loop operation processes, 4 of which were common to the two process. These 24 failure mode causes can be broadly characterized as follows:

- 8 items, including the 3 high-risk items, were related to salt purification and corrosion control

- 7 items were related to design

- 5 items were related to thermal management

- 2 items were related to $I \& C$

- 2 items were related to operation procedure

Salt purification and corrosion control represent a key area of uncertainty and impact for molten salts. It was anticipated that medium- and high-risk items in the FMEA related to salt purification and corrosion control would be identified. Several SETO-sponsored projects at national laboratories and universities are researching, developing, and demonstrating solutions to mitigate these risks.

Research at the edge of material performance involving high-temperatures and long-lead time components carries some risk as to the adequacy of designs and the impact of failures (e.g., long leadtime replacements). The project has dedicated significant effort to component and system design to reduce risk Diverse design methods such as correlations and higher fidelity computational tools, limited pre-testing, and fabrication controls and requirements are some of the efforts being implemented to reduce risk.

Sustained operation at high temperatures with a fluid that can freeze at a medium-high temperature presents risks identified in the FMEA. Numerous controlled heater zones with I\&C to prevent and identify failures help reduce the probability of issues. Standardized operating procedures and previous experience also reduce the risk for inadvertent salt freezing.

Potential I\&C failures can cause issues with salt purification and loop operation. Quality parts with appropriate redundancies are being used to lower the associated risks of $\mathrm{I} \& \mathrm{C}$ failures.

Finally, standardized procedures and operator pre-training will be implemented to lower risk related to human factors. 


\section{REFERENCES}

1. M. Mehos, et al., "Concentrating Solar Power Gen3 Demonstration Roadmap.” National Renewable Energy Laboratory (NREL), Golden, Colorado, 2017.

2. H. Sun, J. Wang, Z. Li, P. Zhang, and X. Su. "Corrosion behavior of 316SS and Ni-based alloys in a ternary NaCl-KClMgCl2 molten salt,” Solar Energy, 171, pp. 320-329, 2018.

3. K. Vignarooban, et al., "Corrosion Resistance of Hastelloys in Molten Metal-Chloride Heat-Transfer Fluids for Concentrating Solar Power Applications,” Solar Energy 103, 2014.

4. Xiankun Xu et al., "Experimental Test of Properties of $\mathrm{KCl}-\mathrm{MgCl}_{2}$ Eutectic Molten Salt for Heat Transfer and Thermal Storage Fluid in Concentrated Solar power Systems," J. Solar Energy Engineering 140, 2018.

5. Wenjin Ding et al., "Molten Chloride Salts for next Generation Concentrated Solar Power plants: Mitigation Strategies against Corrosion of Structural Materials.” Solar Energy Materials and Solar Cells 193 pp. 298-313.

6. R. Mayes, J. M. Kurley, III, A. McAlister, D. Sulejmanovic, S. S. Raiman, B. A. Pint, P. W. Halstenberg, and S. Dai, "Purification of Chloride Salts for Concentrated Solar Applications," ORNL/LTR-2018/1052. Oak Ridge National Laboratory, Oak Ridge, TN, 2019.

7. J. M. Kurley, III, et al., "Enabling Chloride Salts for Thermal Energy Storage: Implications of Salt Purity,” RSC Adv. 9, pp. 25602-25608, 2019.

8. C. J. Raseman, H. Susskind, G. Farber, W. E. McNulty, and F. J. Salzano, "Engineering Experience at Brookhaven National Laboratory in Handling Fused Chloride Salts," BNL-627, Brookhaven National Laboratory, 1960.

9. T. R. Johnson, F. G. Teats, and R. D. Pierce, "A Method for the Purification of Molten Chloride Salts,” ANL-7603, Argonne National Laboratory, 1969.

10. J. W. Ambrosek, "Molten Chloride Salts for Heat Transfer in Nuclear Systems," Ph.D. Dissertation, The University of Wisconsin - Madison, 2011.

11. B. L. Garcia-Diaz, L. Olson, M. Martinez-Rodriguez, R. Fuentes, H. Colon-Mercado, J. Gray, "High temperature electrochemical engineering and clean energy systems," Journal of the South Carolina Academy of Science, 14(1), 4, 2016.

12. B. L. Garcia-Diaz, "Fundamental Corrosion Studies in High-Temperature Molten Salt Systems for Next Generation Concentrated Solar Power Systems," SRNL-STI-2019-00017. Savannah River Site, Aiken, SC, 2016. doi:10.2172/1491796.

13. B. A. Pint, J. W. McMurray, A. W. Willoughby, et al., "Re-Establishing the Paradigm for Evaluating Halide Salt Compatibility to Study Commercial Chloride Salts at $600-800^{\circ} \mathrm{C}$," Materials and Corrosion 70, pp. 1439-1449, 2019.

14. G. L. Yoder, Jr., et al., "An Experimental Test Facility to Support Development of the Fluoride-SaltCooled High-Temperature Reactor." Annals of Nuclear Energy 64: 511-517, 2014.

15. G. L. Yoder, Jr., A. M. Aaron, R. B. Cunningham, D. L. Fugate, D. E. Holcomb, R. A. Kisner, F. J. Peretz, K. R. Robb, and D. F. Wilson, "High Temperature Fluoride Salt Test Loop," ORNL/TM2012/430, Oak Ridge National Laboratory, 2015.

16. S. Kalac, R. K. Shah, and W. Aung, Handbook of Single-Phase Convection Heat Transfer, Chapter 6, John Wiley and Sons, 1987. 
17. M. Sohal, "Engineering Database of Liquid Salt Thermophysical and Thermochemical Properties," INL/EXT-10-18297, 2010.

18. Special Metals Corporation, "INCONEL® alloy C-276," Pub. ID SMC-019, https://www.specialmetals.com/assets/smc/documents/alloys/inconel/inconel-alloy-c-276.pdf 


\section{APPENDIX A. MAIN HEATER FINITE ELEMENT ANALYSIS}

After optimizing part dimensions by modeling a representative subsection of the heater plate, work was performed to understand the temperature evolution and maximum deformation in the entire component under typical operating conditions. A full-scale computer aided-design rendering of the heater plate was modeled using ANSYS finite element analysis (FEA) software, assuming axial symmetry through the plate thickness and width. User-defined heat fluxes were applied to six heaters composed of aluminum nitride along the length of the plate to simulate the planned six-zone independent heating configuration. Two inches of high-temperature block insulation were placed over the AlN heaters to minimize heat loss to the ambient atmosphere. Thermal convection coefficients and bulk temperatures for each salt channel were modeled as user-defined variables to allow for exploration of any loop operating condition. The range of values for heat flux, bulk temperature, and coolant heat transfer coefficient used in the FEA model are listed in Table A.1.

Table A.1. Limiting boundary conditions modeled in full scale heater plate FEA model.

\begin{tabular}{|c|c|c|c|}
\hline & $\begin{array}{c}\text { Applied heat flux } \\
\left(\mathbf{W} / \mathbf{m}^{2}\right)\end{array}$ & $\begin{array}{c}\text { Salt bulk temperature } \\
\left({ }^{\circ} \mathbf{C}\right)\end{array}$ & $\begin{array}{c}\text { Salt channel heat transfer } \\
\text { coefficient }\left(\mathbf{W} / \mathbf{m}^{2}-\mathbf{K}\right)\end{array}$ \\
\hline Minimum & $2.08 \times 10^{5}$ & 550 & $1.49 \times 10^{4}$ \\
\hline Maximum & $6.25 \times 10^{5}$ & 725 & $3.39 \times 10^{4}$ \\
\hline
\end{tabular}

\section{A.1 FEA THERMAL RESULTS}

FEA models with various boundary conditions were analyzed to understand temperature distributions and peak temperatures in the heater plate assembly. Figure A.1 depicts the temperature distribution with a linearly decreasing heat flux applied to each heater zone with Zone 1 using the highest value from Table A. 1 and Zone 6 using the lowest. Assuming a $725^{\circ} \mathrm{C}$ salt bulk temperature and a $14,900 \mathrm{~W} / \mathrm{m}^{2}-\mathrm{K}$ heat transfer coefficient, temperatures reached a maximum of $967^{\circ} \mathrm{C}$ in the plate and $1,000^{\circ} \mathrm{C}$ in the heating element. Future work may include coupling this FEA model to a fluid dynamics model with chloride salt properties for better understanding of loop heat transfer characteristics.

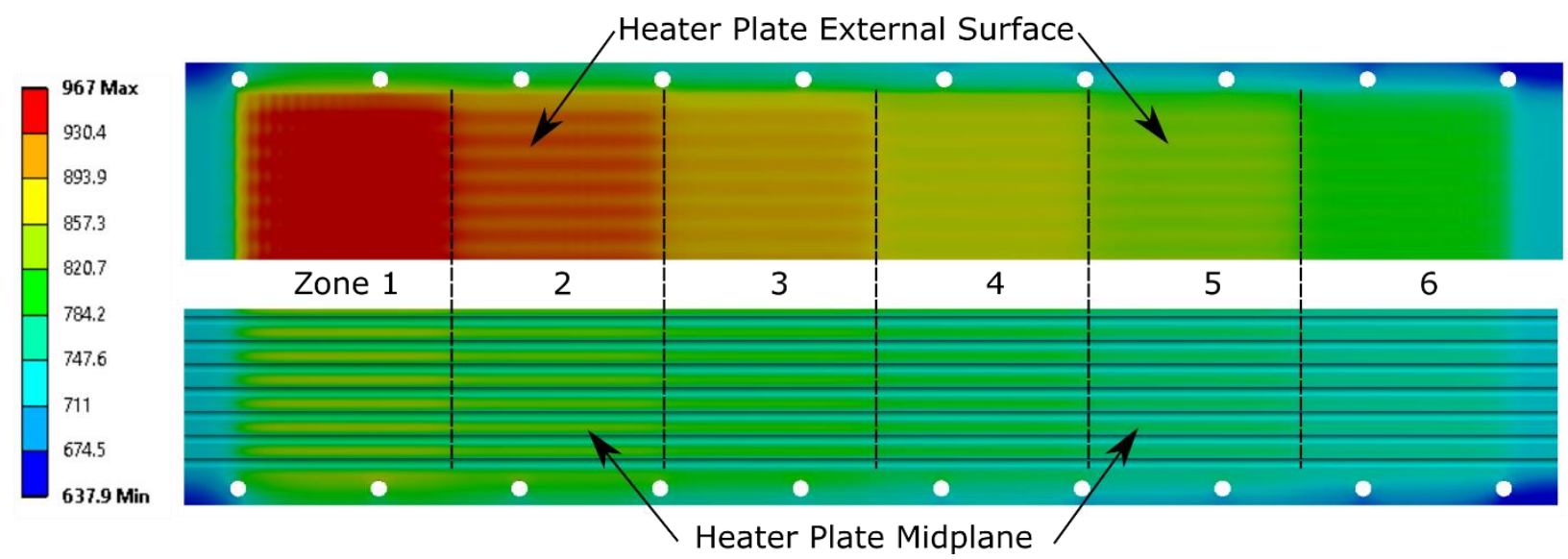

Figure A.1. Heater plate temperature distributions for linearly decreasing heat flux (from left to right).

\section{A.2 STRUCTURAL RESULTS}

Structural deformation in the plate under a range of operating conditions was analyzed by applying results of the ANSYS thermal solution to a structural simulation of the heater plate. Results of this analysis 
showed a maximum deformation of $1.96 \mathrm{~cm}$ along the length of the plate, $0.4 \mathrm{~cm}$ laterally, as well as a $0.74 \mathrm{~mm}$ increase in plate thickness. This analysis has informed the design of other support components in the heater plate assembly. 


\section{APPENDIX B. PUMP SUMP TANK ANALYSIS}

A finite element analysis (FEA) was conducted on the FASTR pump tank assembly using ANSYS version 19.0 engineering simulation design software. Stresses were analyzed using the expected structural and thermal loads and compared to the tank material's allowable stress at a temperature of $700^{\circ} \mathrm{C}$. The computer aided-design geometry was originally created in Creo/Parametric 3D modeling software. A STEP file of this solid model was exported from Creo/Parametric and imported into ANSYS. ANSYS was used to simplify the geometry, create a mesh, and apply the appropriate thermal/structural loads and boundary conditions.

\section{B.1 FEA MESH}

Meshing was developed using ANSYS's automatic meshing tool. The resulting mesh consists of 845,618 tetrahedral elements with a 0.4 inch maximum side length. The meshed model is shown below in Figure B.1, Figure B.2, and Figure B.3. A mesh refinement (Figure B.3) was created in the reinforced section of the vessel where the higher stress was observed.

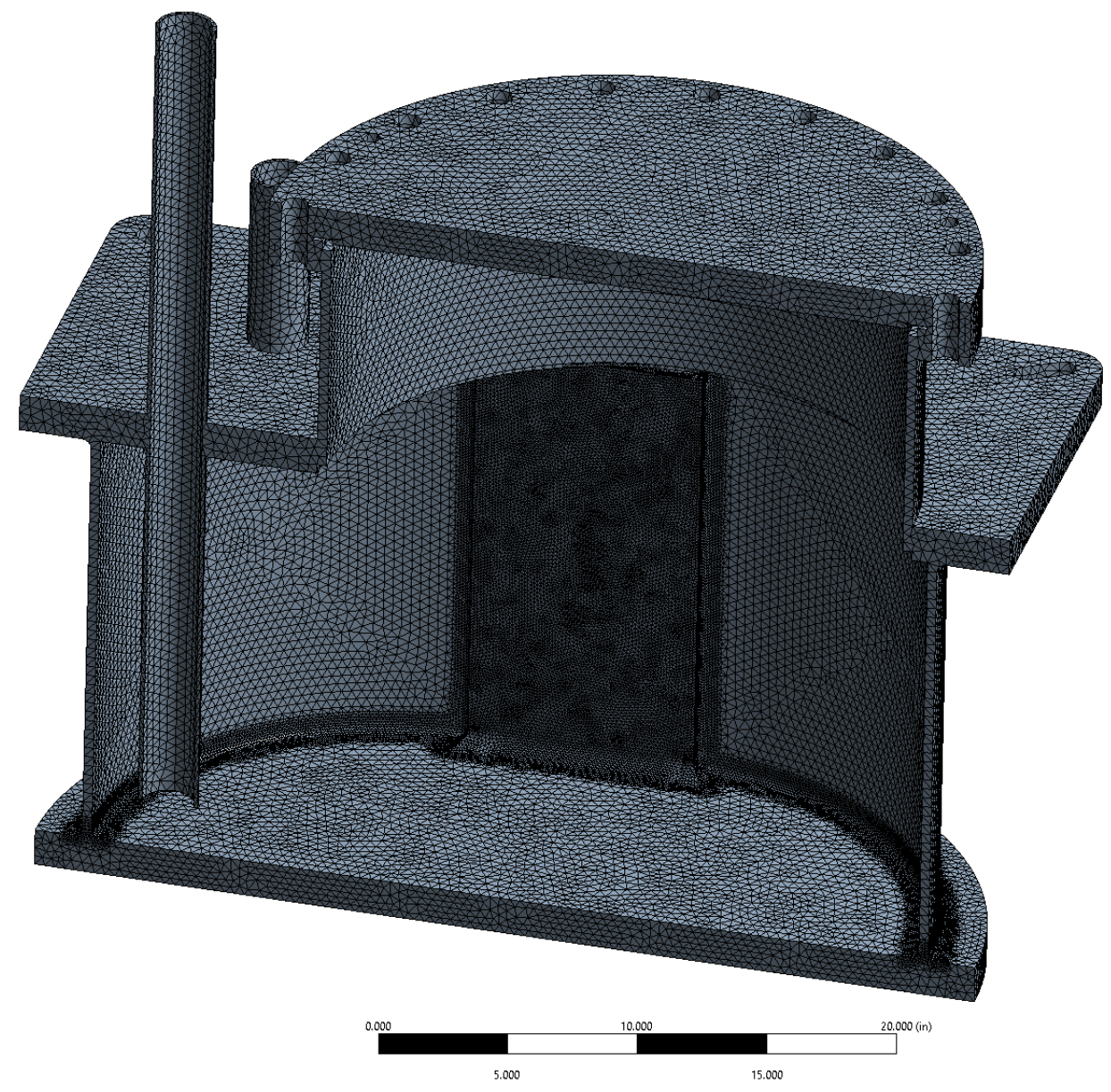

Figure B.1. Finite element model mesh. 


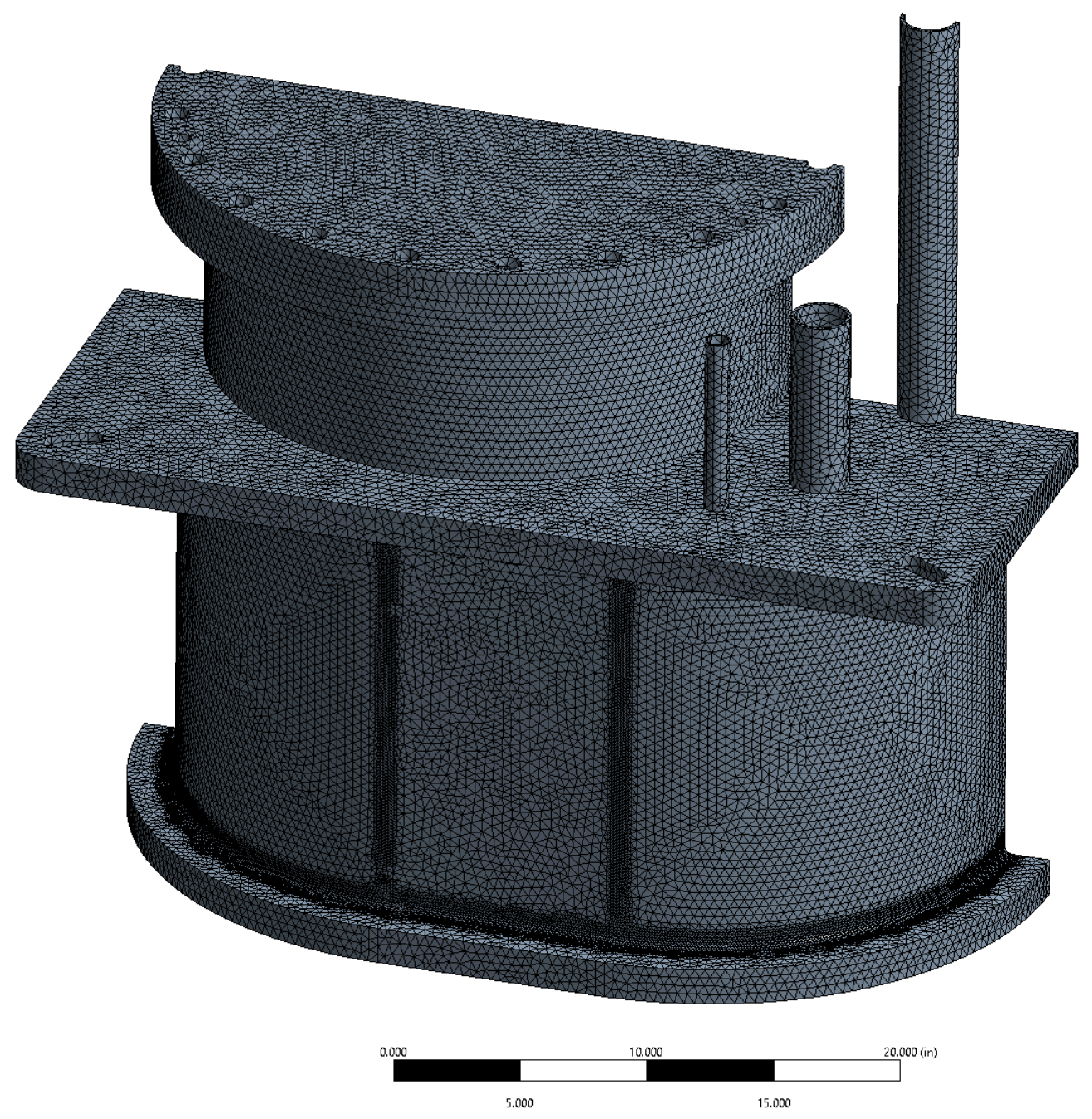

Figure B.2. Finite element model mesh.

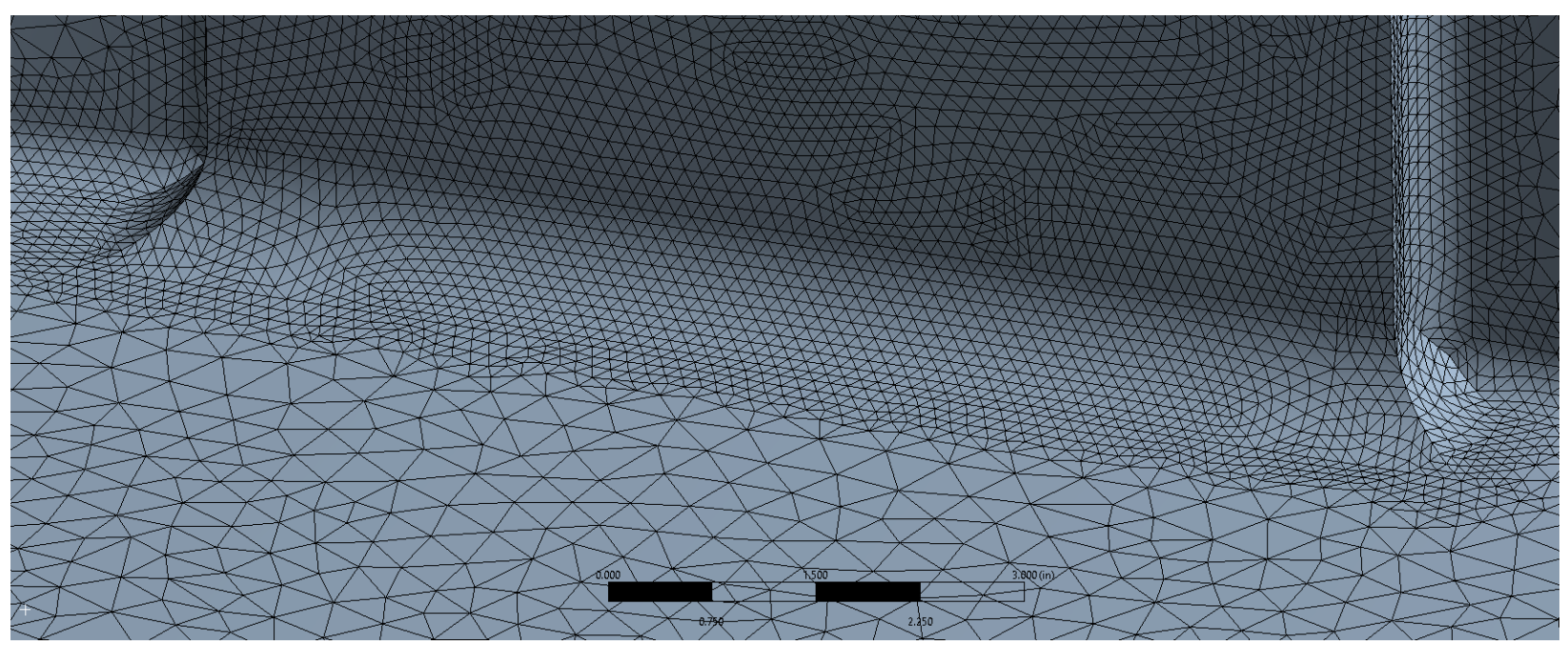

Figure B.3. Finite element model mesh. 


\section{B.2 MODEL SIMPLIFICATIONS}

The model was simplified from a full 3D geometry to a 3D planar-symmetric model with symmetry specified through the XY plane. The tank is sectioned along this plane in Figure B.1. The simplification assumes that the differences in the pipe and tube sizes on the lid will have a negligible impact on the resulting stresses. The flanges on the pipe ends and the flow diverter plates that rest on the bottom of the vessel were removed from the model. Additionally, individual parts were assumed to be fully bonded at the part interfaces where welds and bolted connections are present.

\section{B.3 FEA BOUNDARY CONDITIONS AND LOADS}

The tank lid is vertically supported by four 3.5 -inch diameter pads, and 0.90 -inch pins secure the tank laterally in slots. The slots allow for the vessel to have unconstrained lateral motion in the direction of the slot when the tank expands and contracts during heating and cooling cycles. These supports are shown in the Creo model in Figure B.4.

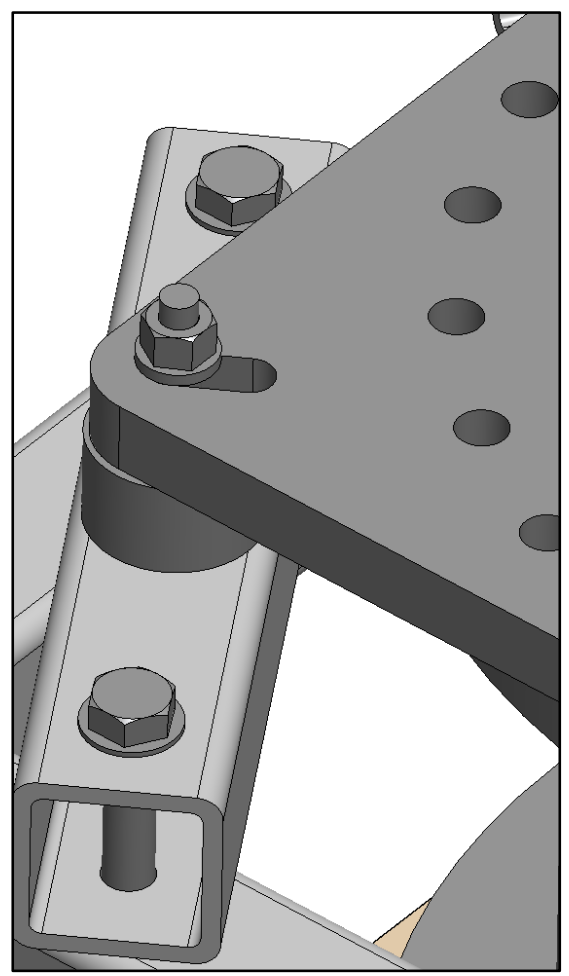

Figure B.4. Pump tank supported by pad and pin.

The pads are simulated in ANSYS, with circular cosmetics and frictionless supports applied to these regions. These boundary conditions are shown in blue in Figure B.5. The lateral constraint is represented by assigning a frictional contact to the vertical surface of a slot, as shown in green in Figure B.6.

A pump and motor assembly will be mounted to the blank flange depicted at the top of the tank assembly. This pump assembly is simulated in the ANSYS model by applying a pressure load across the top surface of the flange in the vertical direction. The pump vendor estimated the weight of the pump to be $1,000 \mathrm{lb}$, so a force of 1,000 lbf was applied in the simulation. This load is depicted below in Figure B.7.

For the results shown in Section B.5, the tank was modeled with a $21.5 \mathrm{psig}$ internal pressure. The pressure is applied to all inside surfaces of the pump tank. The pressure is applied as normal to the 
selected surfaces highlighted in red in Figure B.8. Later in Section B.6, the tank pressure was varied parametrically from 0 to 30 psi.

Standard Earth gravity of $386.09 \mathrm{in} / \mathrm{s} 2$ is applied to the model. A thermal condition of $700^{\circ} \mathrm{C}$ is assigned to all bodies. No thermal gradients in the structures were modeled. The loads and thermal condition are applied in a stepwise fashion, with the thermal load being applied before the structural loads are applied.

In the reinforced section-to-tank shell interfaces, $3 / 4$-inch corner radii were added to simulate fillet weld geometry as shown in Figure B.9. The purpose of the fillets is to provide a more accurate understanding of the stresses in this region. The lower portion of this reinforced section, where it is shown that higher stresses are present, is observed closely. More information on these stresses is provided in a later section.

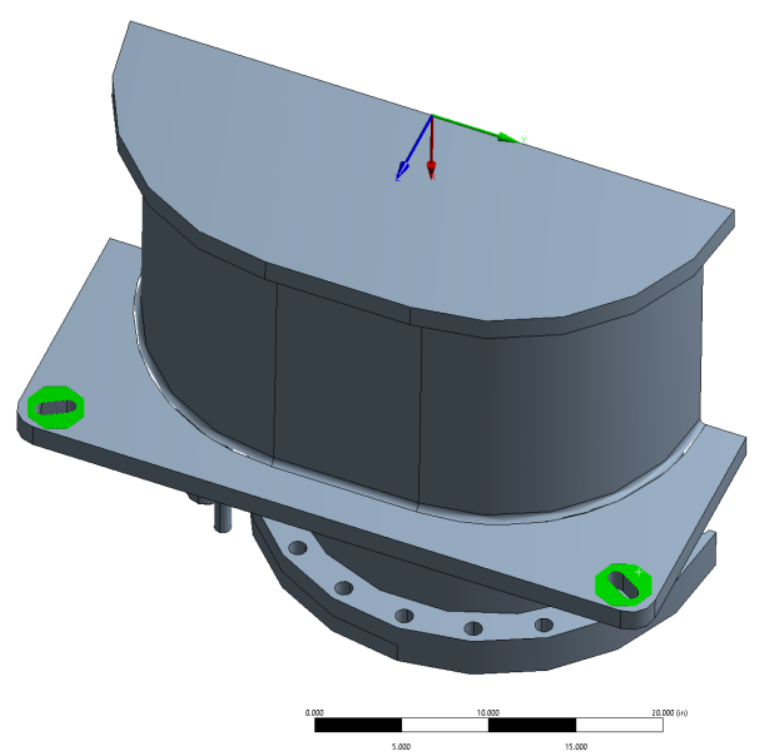

Figure B.5. Tank vertical supports boundary conditions.

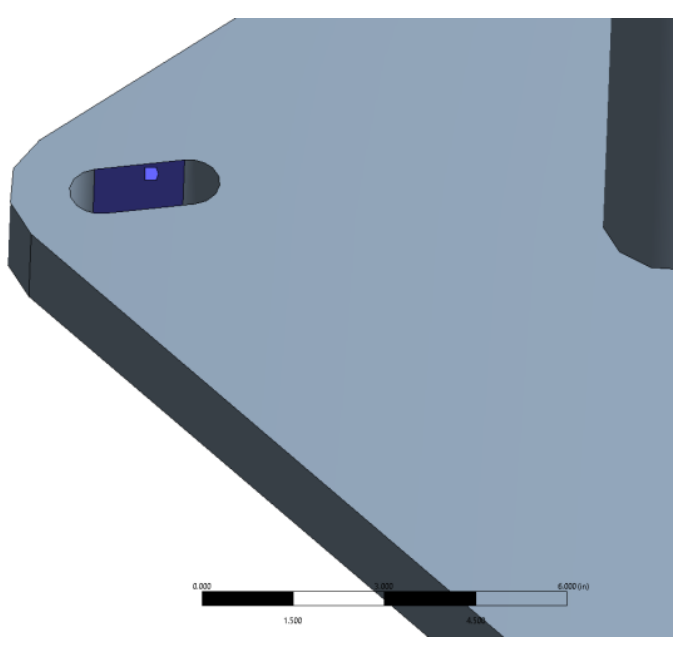

Figure B.6. Tank lateral boundary condition. 


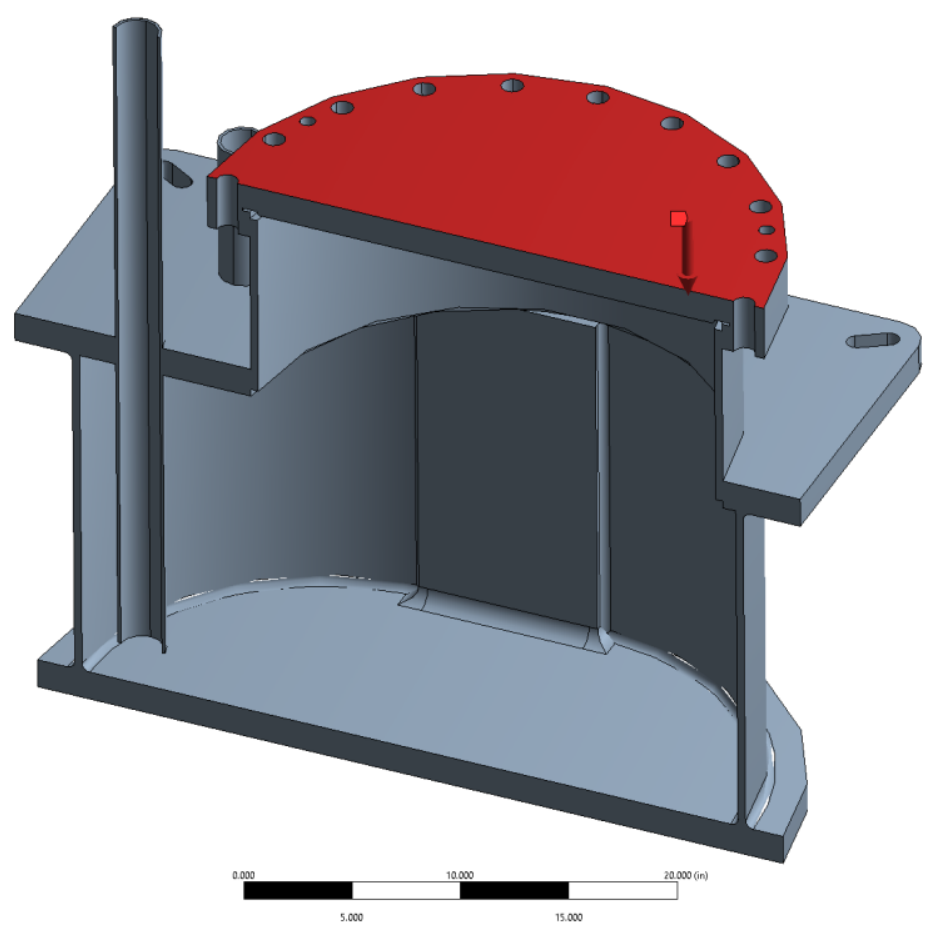

Figure B.7. Pump assembly load of $1,000 \mathrm{lbf}$.

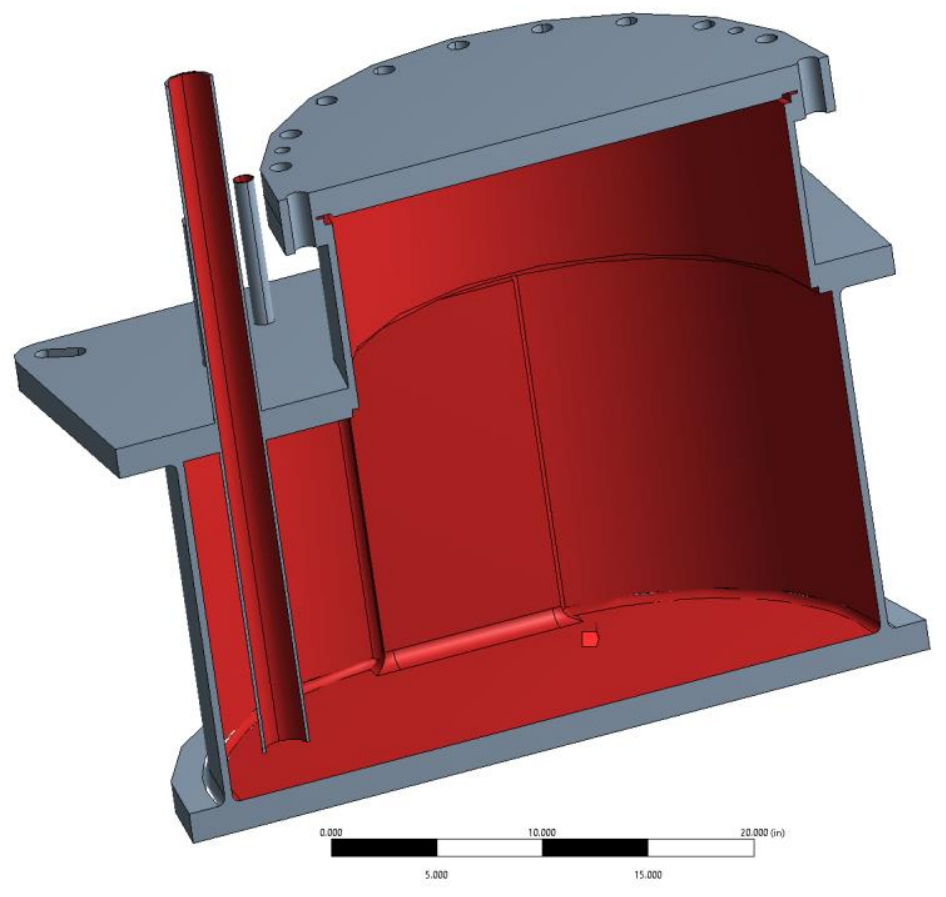

Figure B.8. Pressure of 21.5 psi applied to surfaces highlighted in red. 


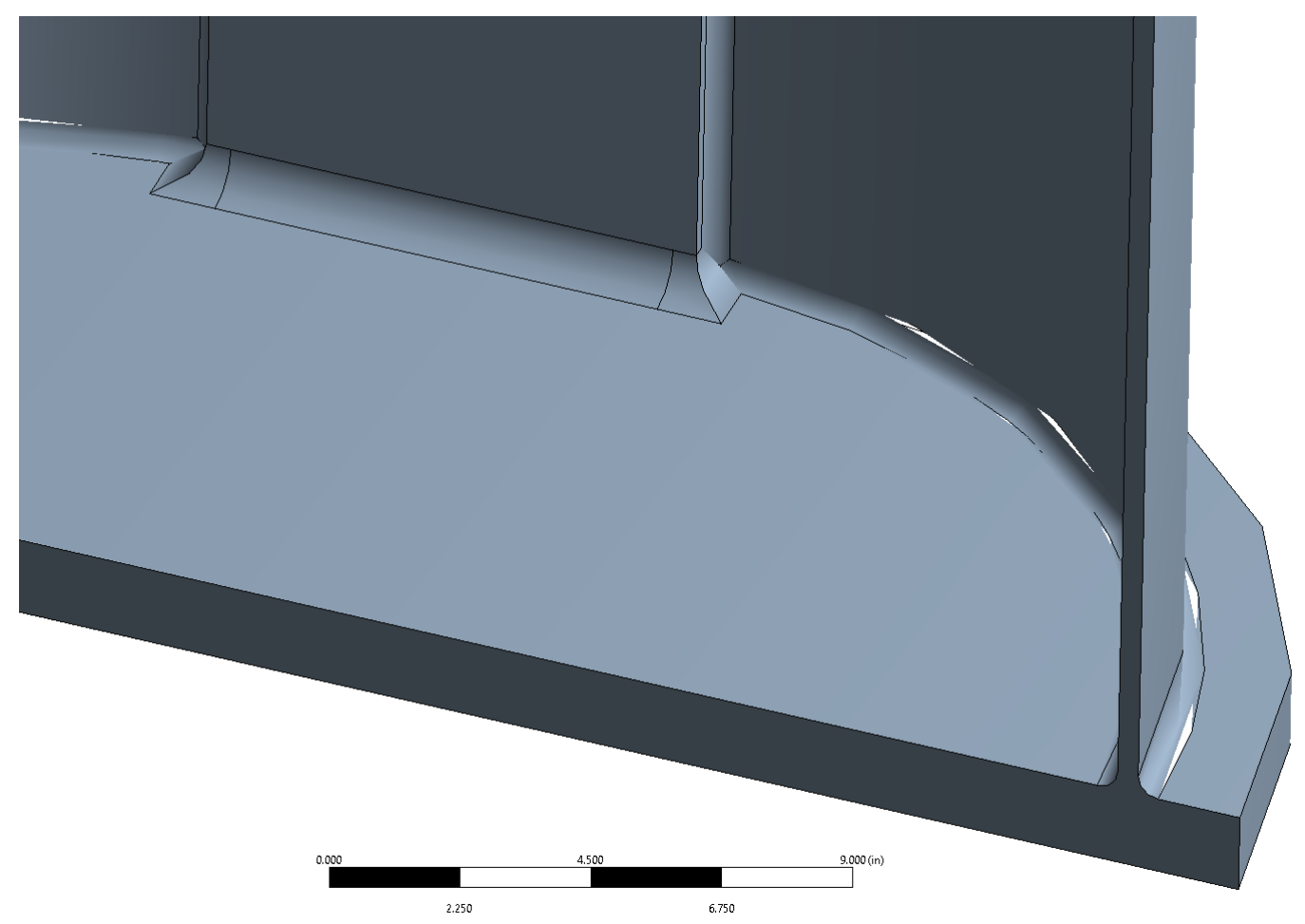

Figure B.9. Section reinforced with fillet welds.

\section{B.4 MATERIAL PROPERTIES}

The tank is fabricated from alloy C-276, a nickel-molybdenum-chromium superalloy. Applicable temperature-dependent material properties used for the simulation were taken from the Haynes International and Special Metals material specifications. The properties are provided in Table B.1 and Table B.2. The modulus of elasticity values at $600^{\circ} \mathrm{C}$ and $700^{\circ} \mathrm{C}$ were not provided in the specifications and were therefore calculated using extrapolation.

Table B.1. Temperature-dependent mean coefficient of thermal expansion

\begin{tabular}{cc}
\hline Temperature $\left({ }^{\circ} \mathbf{C}\right)$ & $\begin{array}{c}\text { Mean coefficient of thermal } \\
\text { expansion }\left(\boldsymbol{\mu m} / \mathbf{m}^{\circ} \mathbf{C}\right)\end{array}$ \\
\hline 100 & 12.2 \\
200 & 12.4 \\
300 & 12.9 \\
400 & 13.2 \\
500 & 13.5 \\
600 & 13.6 \\
700 & 14.1 \\
800 & 14.8 \\
\hline
\end{tabular}


Table B.2. Temperature-dependent modulus of elasticity

\begin{tabular}{cc}
\hline Temperature $\left({ }^{\circ} \mathbf{C}\right)$ & Modulus of elasticity $(\mathbf{G P a})$ \\
\hline RT & 205 \\
200 & 195 \\
300 & 189 \\
400 & 183 \\
500 & 178 \\
$* 600$ & 172 \\
$* 700$ & 166 \\
\hline
\end{tabular}

*Extrapolated values

\section{B.5 FEA RESULTS FOR 21.5 PSI TANK PRESSURE}

The resulting von Mises stresses of the inside and outside of the tank are shown in Figure B.10 and Figure B.11. The peak stress in the model exists exclusively on the corner edge of the inside weld of the reinforced section, as shown in Figure B.12 for tank pressures above a couple psi. The stress along the bulk of the weld was also probed in the area noted in Figure B.13.

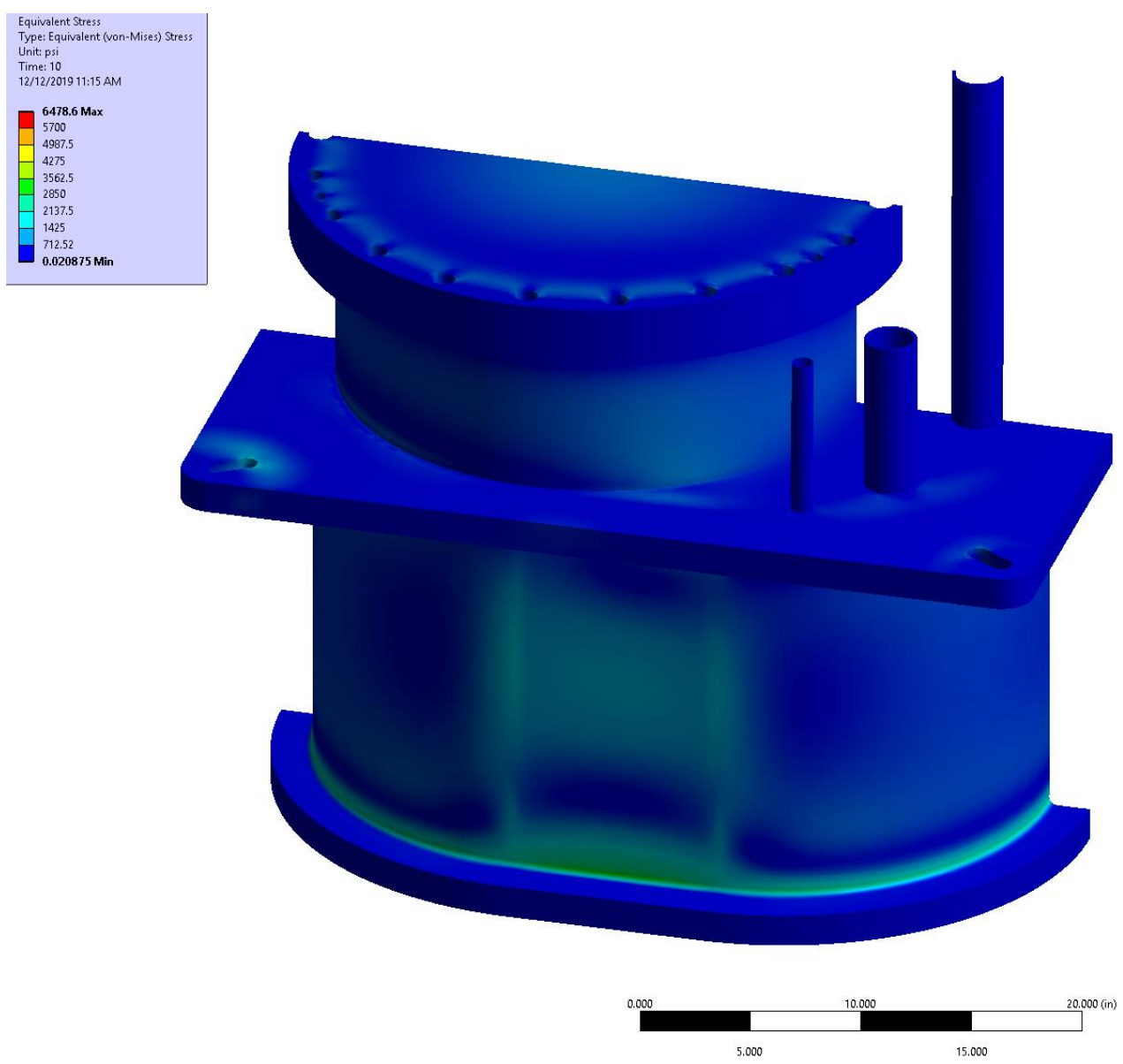

Figure B.10. Tank external von Mises stress results for tank pressure of 21.5 psig. 

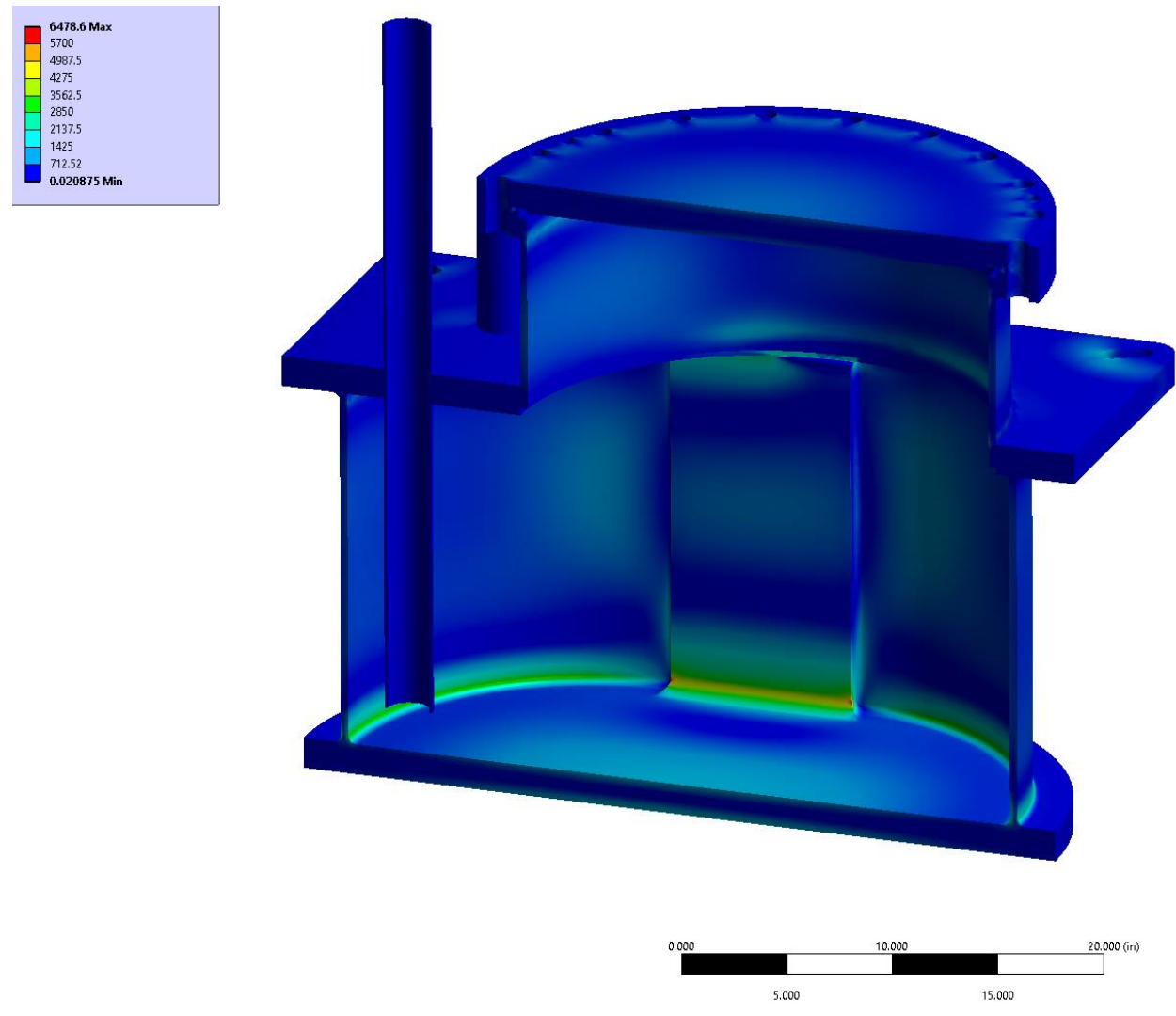

Figure B.11. Tank internal von Mises stress results for tank pressure of $21.5 \mathrm{psig}$.

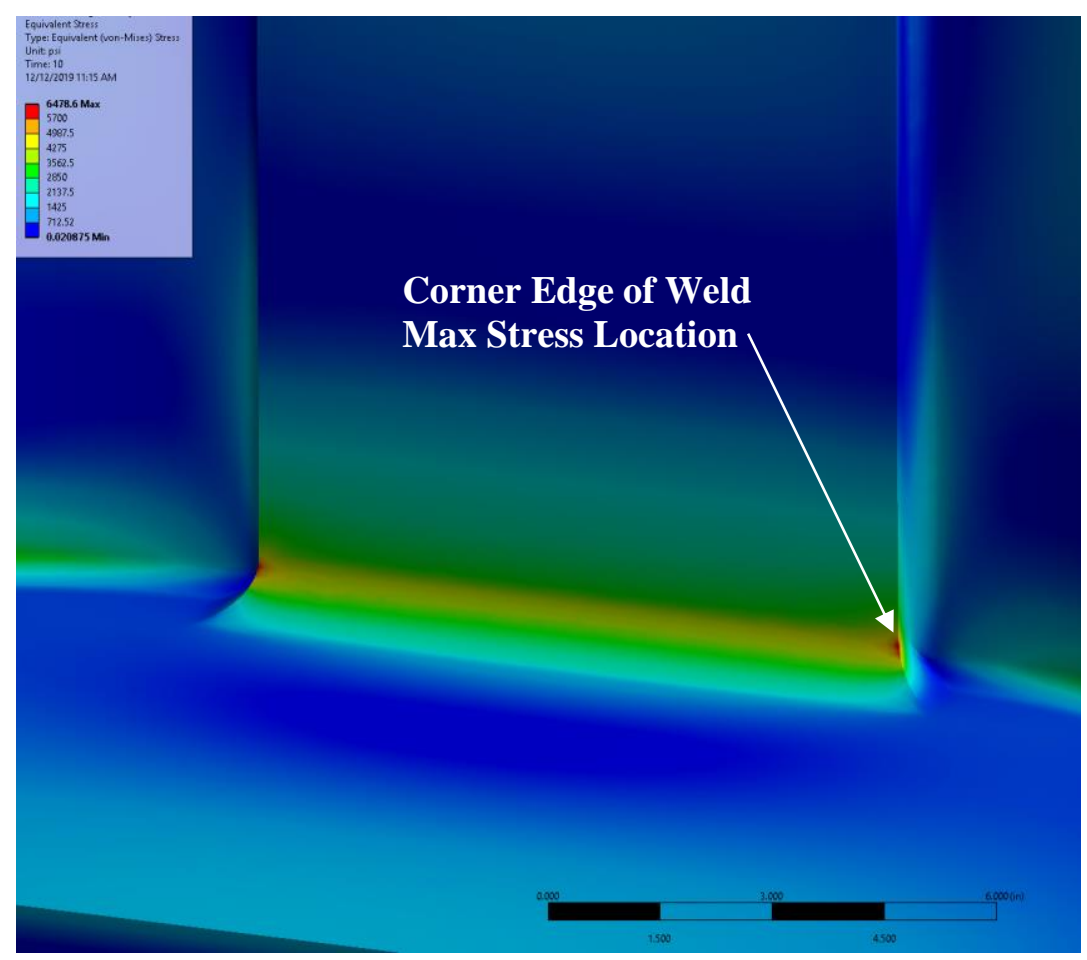

Figure B.12. Detail of von Mises stress results for tank pressure of 21.5 psig: reinforced section. 


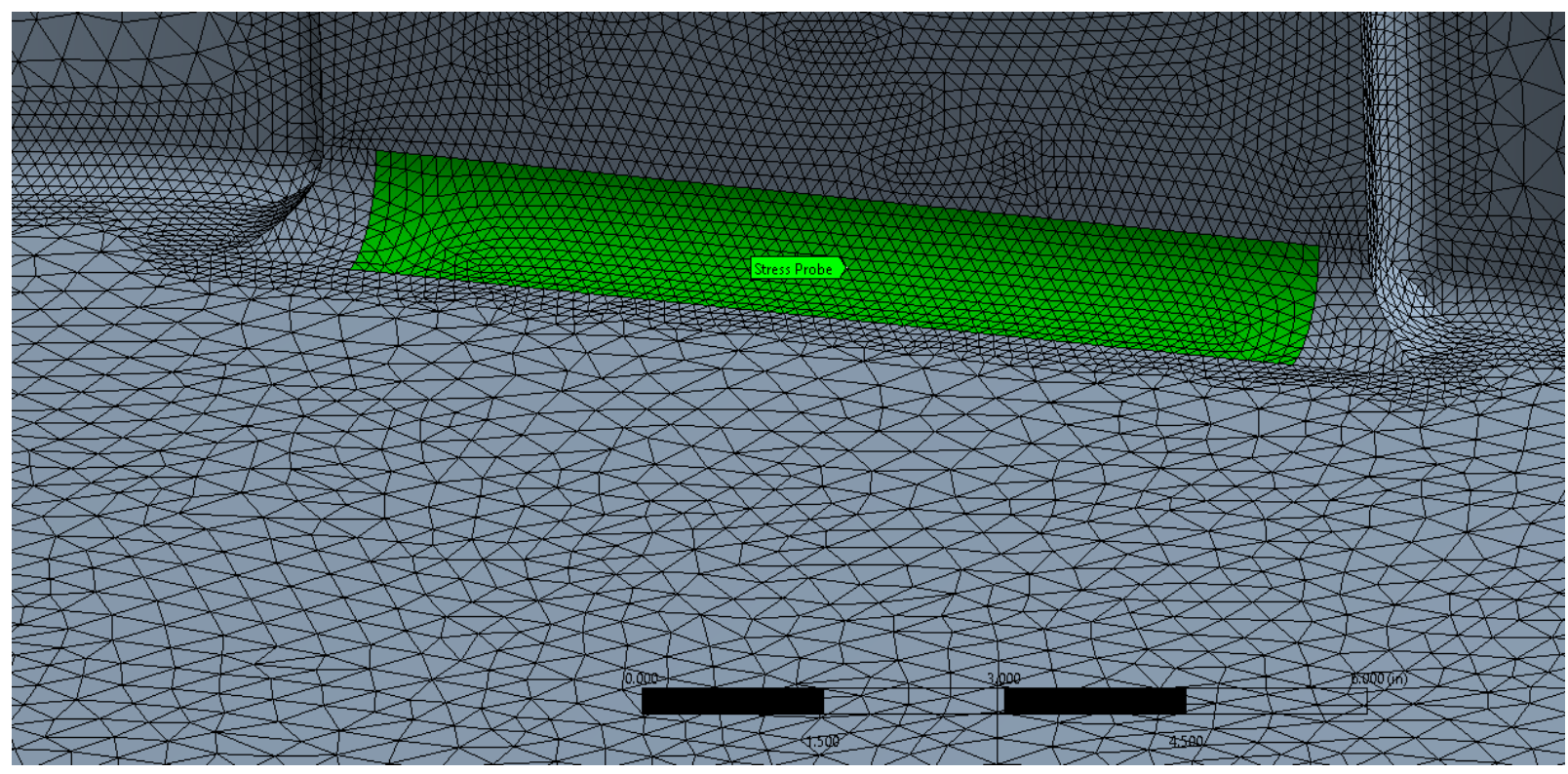

Figure B.13. Inside bottom edge von Mises stress results.

\section{B.6 FEA RESULTS FOR PARAMETRIC VARIATION OF TANK PRESSURE}

The model was solved for variations in the tank pressure from 0 to 30 psig. Figure B.14 charts the maximum stress (typically located at the corner edge of the weld) and the peak stress in the region noted in Figure B.13 vs. applied internal tank pressure. At a tank pressure of 21.77 psig, the FEA indicates a maximum stress of $6.56 \mathrm{ksi}$ which is located at the corner edge of the weld (location illustrated in Figure B.12). 


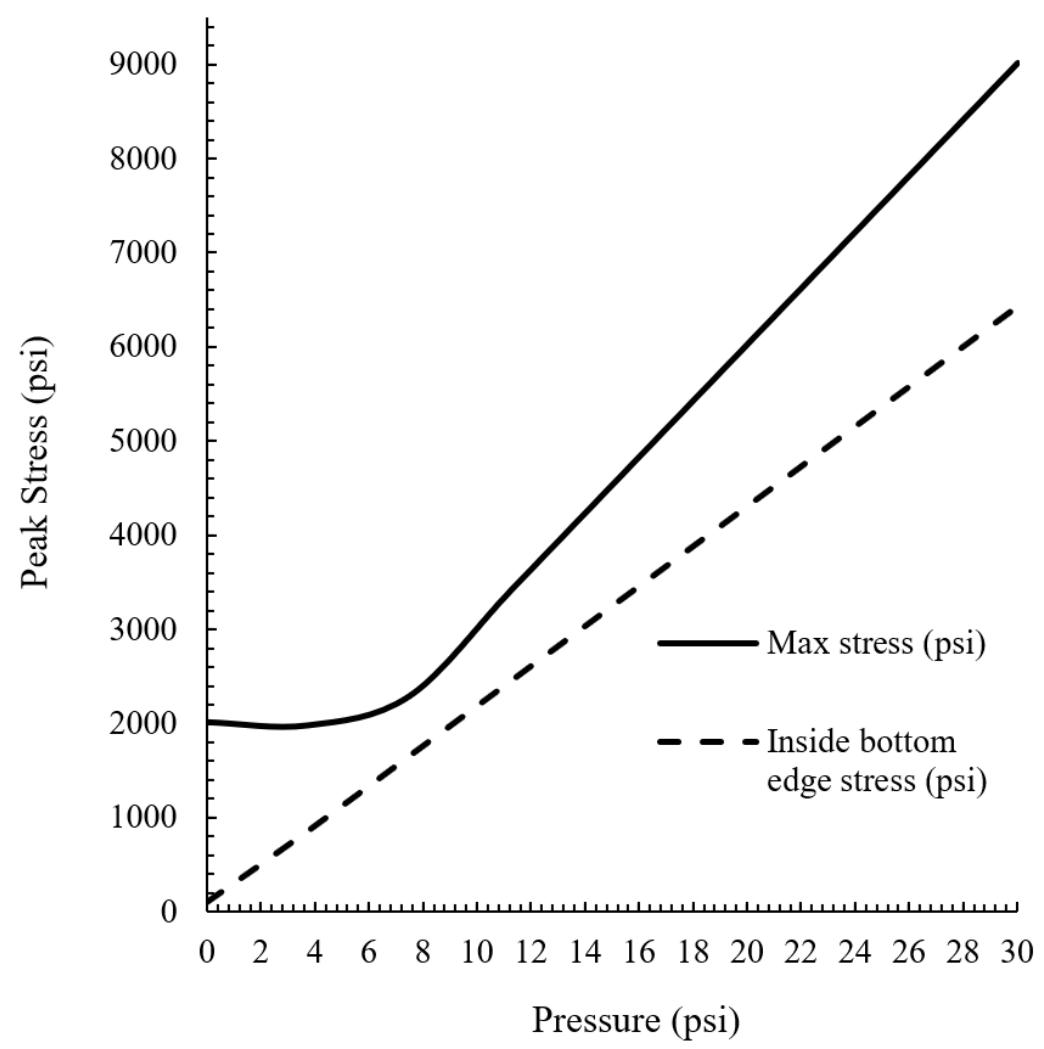

Figure B.14. Tank pressure vs. maximum stress in the pump tank assembly.

\section{B.7 TANK PRESSURE RELIEF SETPOINT}

As noted in Section 2.3, alloy C-276 is code rated up to $676^{\circ} \mathrm{C}$ in the ASME 2010 BPVC. For greater temperatures, allowed stresses were determined using the ASME analysis methodology and data from a major material manufacturer. At elevated temperatures of interest, the allowed stress is limited by its long-term creep behavior. For $1300^{\circ} \mathrm{F}\left(705^{\circ} \mathrm{C}\right)$, the analysis of the manufacturers creep data yielded a recommended allowed stress of $6.56 \mathrm{ksi}$.

Based on the FEA analysis and using an allowed stress of $6.56 \mathrm{ksi}$, the proposed pressure relief setpoint is $21.5 \mathrm{psig}$ for a vessel temperature limit of $1300^{\circ} \mathrm{F}\left(705^{\circ} \mathrm{C}\right)$.

Other supporting considerations:

- The vessel will be limited to $\leq 3$ years of cumulative service at elevated temperature.

- Being on the cold side of the loop, the vessel will generally be operated at $<700^{\circ} \mathrm{C}$.

- At least eight thermocouples will monitor the vessel temperature. An automated control system will control the tank temperature and will include pre-defined heater trips to prevent overtemperature.

- As illustrated in Figure B.10 and Figure B.11 and Figure B.14., the stresses in the majority of the vessel are significantly lower than the stress at the corner edge of the weld shown in Figure B.12.

- Material test coupons will be incorporated into the loop for periodic testing.

- The vessel is surrounded by a 4" high temperature insulation jacket with inner and outer fiberglass fabric sheets. Additional personnel barriers can be incorporated per environmental, health, and safety personnel guidance. 


\section{APPENDIX C. HEATER PLATE ELEMENT TESTING}

\section{C.1 ALUMINUM NITRIDE HEATER STABILITY}

To test the durability of the aluminum nitride heater plate, a test plate was cyclically heated in a furnace, and the resistance of the heater was inspected between cycles. The heater plate was placed in a furnace, where 6 heat-hold-cool cycles were completed. Table C. 1 summarizes the temperature and test durations. After each high-temperature test, the heater was allowed to cool to room temperature and the resistance was measured multiple times using a 4-point probe. The cumulative degree hours (average temperature $x$ length of time at temperature) was determined and plotted vs. resistance in the heating element, as shown in Figure C.1. Results showed little variation in heater resistance, with a minimum value of $1.67 \mathrm{ohms}$ and a maximum of $1.83 \mathrm{ohms}$. This testing provided confidence that the heaters will be stable for long durations at high temperatures.

Table C.1. Test heater plate furnace test summary

\begin{tabular}{ccc}
\hline Test & $\begin{array}{c}\text { Hold temperature } \\
\left({ }^{\circ} \mathbf{C}\right)\end{array}$ & $\begin{array}{c}\text { Hold duration } \\
\text { (hours) }\end{array}$ \\
\hline 1 & 830 & 1 \\
2 & 830 & 50 \\
3 & 880 & 50 \\
4 & 925 & 50 \\
5 & 925 & 108 \\
6 & 925 & 168 \\
\hline
\end{tabular}

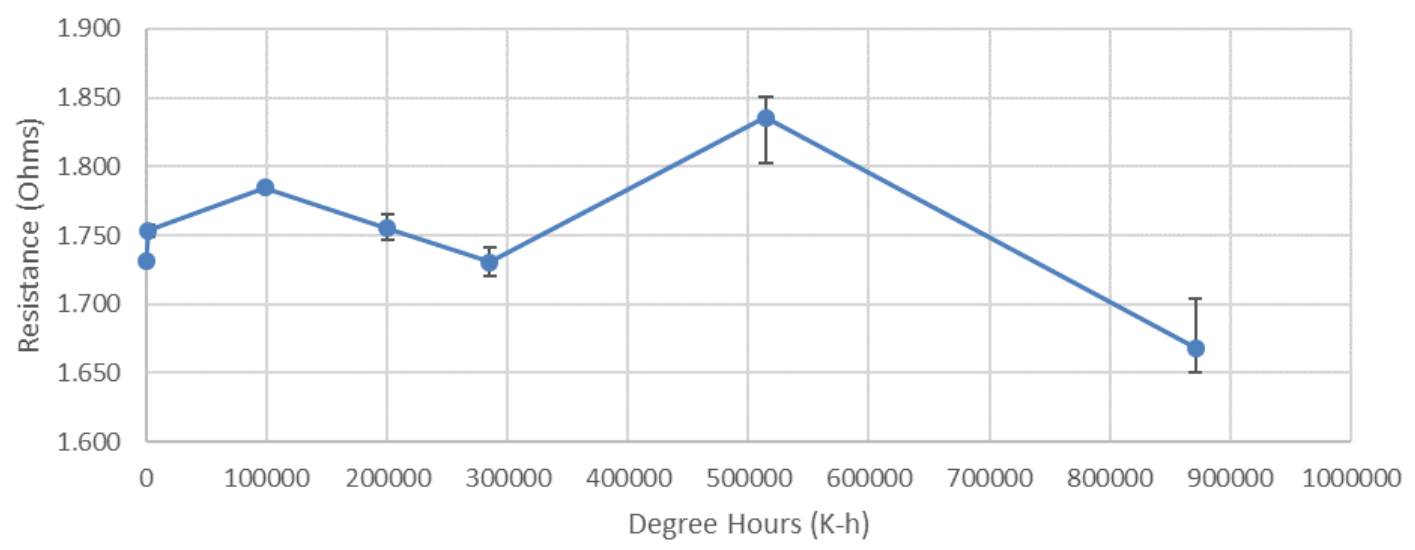

Figure C.1. 4-probe resistance vs. cumulative degree hours in AIN heater plate.

\section{C.2 BRAZE TESTING}

A pair of custom wire terminals was fabricated from Ni-200 tubing to perform braze testing on the AlN heater plate contact pads. Nioro ${ }^{\circledR}$ foil braze $(\mathrm{Au} / \mathrm{Ni}, 82 / 18)$ was placed between the $\mathrm{Ni}$ terminals and the Pt contact pads, and then the assembled items were placed in a vacuum furnace at $980^{\circ} \mathrm{C}$. After removing the heater plate from the furnace, the Ni terminals were found to have separated from the heater, removing the contacts from the AlN. This was initially thought to be due to the difference in thermal expansion coefficients in the AIN and Ni contacts. Testing continues using a lower cool down rate to minimize stress formation between the $\mathrm{Ni}$ and $\mathrm{AlN}$, and an alternative method for making electrical contact with a spring-loaded terminal is also being explored. 


\section{APPENDIX D. PIPE STRESS ANALYSIS}

A finite element analysis was conducted on the FASTR piping layout using ANSYS version 19.3 engineering simulation design software. Stresses were analyzed using the expected structural and thermal loads for a wide range of operating conditions. ANSYS was used to model the geometry, create a mesh, and apply the appropriate thermal/structural loads and boundary conditions.

The purpose of the analysis was to estimate the potential stresses of the piping network, to assist in sizing the spring hangars for the main heater and heat exchanger, and to provide insight for potential revision and optimization of the piping layout. A revised FEA is envisioned for the future that accounts for design changes and models the loop features in more rigorous detail.

\section{D.1 MODEL GEOMETRY AND SIMPLIFICATIONS}

A simplified layout of the FASTR loop was modeled in ANSYS using DesignModeler, Figure D.1. The detailed geometry of the main heater and heat exchanger were not modeled. Instead simplified representations of those components were modeled. The top of the pump tank was modeled as a simple plate. In addition, the geometry of the flanges and the pipe extensions for the test ports were not modeled.

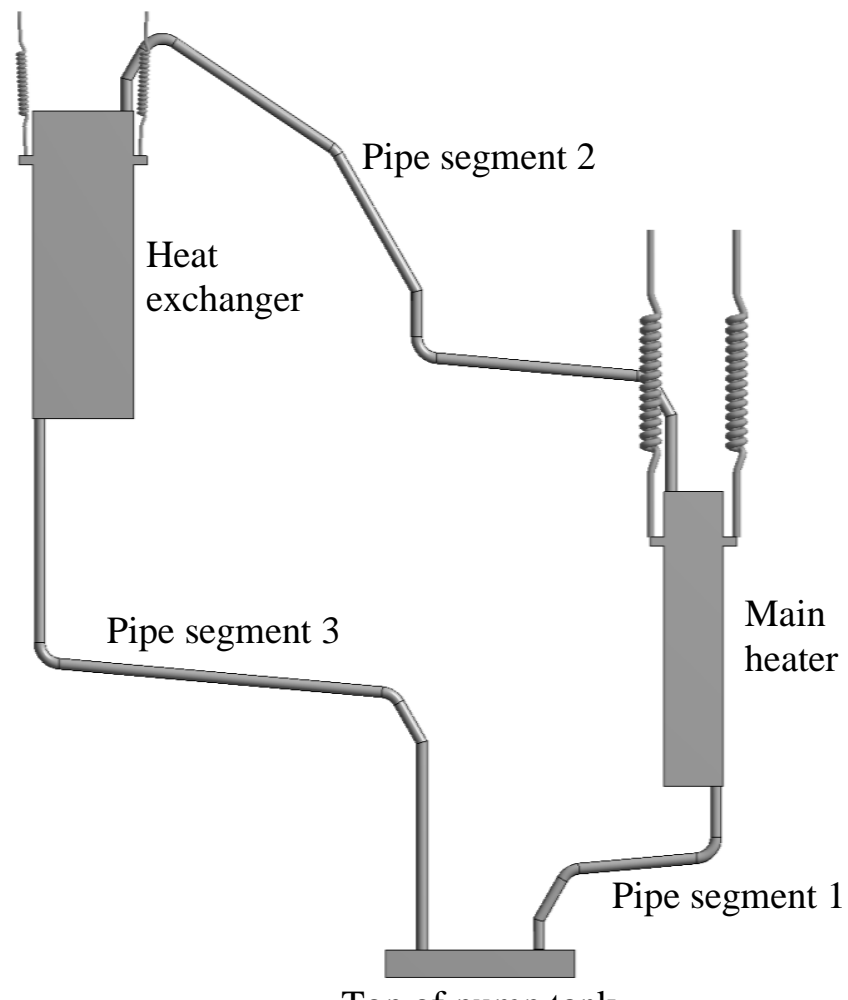

Top of pump tank

Figure D.1. Piping stress FEA results - simplified geometry modeled. 


\section{D.2 BOUNDARY CONDITIONS AND MATERIAL PROPERTIES}

The FASTR loop main components and piping network are designed to align on the same vertical plane. Therefore, a symmetry boundary condition was applied and only half the system was modeled in ANSYS. This reduced the computational burden of the analysis.

As the heat exchanger and main heater were modeled using a simplified representation, the mass of the heat exchanger, main heater, piping and insulation were included in the model as applied downward forces. At the base of the heat exchanger a $342.3 \mathrm{lbf}$ force was applied and a $294.1 \mathrm{lbf}$ force was applied to the base of the main heater. Note, as the model uses half-symmetry, these forces represent half of the actual system weight.

The mass of salt within the heat exchanger and main heater were also applied as downward forces. For cases where the loop is filled with salt. A force of $31.7 \mathrm{lbf}$ load was applied to the heat exchanger and a $7.2 \mathrm{lbf}$ force was applied to the base of the main heater.

The spring hangars were modeled using ANSYS's spring connection feature. The spring stiffness were 17 $\mathrm{lbf} /$ in for the main heater and $21 \mathrm{lbf} / \mathrm{in}$ for the heat exchanger. The spring preload was varied parametrically and discussed in a following section.

For cases where the loop is filled with salt, a hydrostatic pressure is applied to the inside of the pipes assuming a fluid density of $0.056 \mathrm{lbm} / \mathrm{in}^{3}$ and a reference free surface height of $205 \mathrm{ft}$. This resulted in a maximum hydrostatic pressure of $11.5 \mathrm{psi}$ at the bottom of the piping network.

Frictionless support boundary conditions were applied to the top, right, and symmetry plane face of the bottom plate. These surfaces constrain the model with respect to movement. The pump frame and tank, Sections 2.7 and 2.8, are designed to accommodate lateral thermal expansion and constrains movement in the vertical direction.

For material properties, the values used for the coefficient of thermal expansion and Young's modulus are provided in Table D.1 [18]. The system reference initial temperature for thermal expansion was set to $77^{\circ} \mathrm{F}$. A constant Poisson's ratio of 0.307 was applied. As with the pump tank analysis discussed in Appendix B, an allowed stress of $6.56 \mathrm{ksi}$ was assumed for $1300^{\circ} \mathrm{F}$.

Table D.1. Coefficient of thermal expansion and Young's Modulus

\begin{tabular}{ccc}
\hline $\begin{array}{c}\text { Temperature } \\
{ }^{\circ} \mathbf{C}\left({ }^{\circ} \mathbf{F}\right)\end{array}$ & $\begin{array}{c}\text { Coef. of Thermal } \\
\text { Expansion }\left(\mathbf{1} /{ }^{\circ} \mathbf{C}\right)\end{array}$ & $\begin{array}{c}\text { Young's Modulus } \\
(\mathbf{P a})\end{array}$ \\
\hline $\mathbf{2 5}(\mathbf{7 7})$ & 0 & $2.05 \mathrm{E}+11$ \\
\hline $\mathbf{1 0 0}(\mathbf{2 1 2})$ & $1.22 \mathrm{E}-05$ & $2.03 \mathrm{E}+11$ \\
\hline $\mathbf{2 0 0}(\mathbf{3 9 2})$ & $1.24 \mathrm{E}-05$ & $1.98 \mathrm{E}+11$ \\
\hline $\mathbf{3 0 0}(\mathbf{5 7 2})$ & $1.29 \mathrm{E}-05$ & $1.92 \mathrm{E}+11$ \\
\hline $\mathbf{4 0 0}(\mathbf{7 5 2})$ & $1.32 \mathrm{E}-05$ & $1.86 \mathrm{E}+11$ \\
\hline $\mathbf{5 0 0}(\mathbf{9 3 2})$ & $1.35 \mathrm{E}-05$ & $1.8 \mathrm{E}+11$ \\
\hline $\mathbf{6 0 0}(\mathbf{1 1 1 2})$ & $1.36 \mathrm{E}-05$ & $1.78 \mathrm{E}+11$ \\
\hline $\mathbf{7 0 0}(\mathbf{1 2 9 2})$ & $1.41 \mathrm{E}-05$ & $1.67 \mathrm{E}+11$ \\
\hline $\mathbf{8 0 0}(\mathbf{1 4 7 2})$ & $1.48 \mathrm{E}-05$ & $1.59 \mathrm{E}+11$ \\
\hline
\end{tabular}




\section{D.3 MODEL RESULTS}

During operation, the loop will be heated from room temperature to approximately $932^{\circ} \mathrm{F}\left(500^{\circ} \mathrm{C}\right)$ before filling the pump tank with salt. The gas space of the pump tank will then be pressurized to push salt up into the loop. After the loop is filled, the pump can be started, and isothermal or non-isothermal loop operations can commence. The piping network experiences a range of conditions and loads over these operations. The following sections explore this range of conditions and summarizes the results.

\section{Spring Preload}

During loop installation, a preload can be applied to the spring hangars. A baseline $178.1 \mathrm{lbf}$ load for the main heater and a $218.2 \mathrm{lbf}$ load for the heat exchanger were assumed for each of the two hangars per component. The tension preload for all the hangars were then parametrically increased or decreased. For this analysis, the system was assumed to be filled with salt that is static and isothermal at $1300^{\circ} \mathrm{F}$. As shown in Figure D.2, the applied preload of the springs has an important impact on the predicted maximum pipe stress. The baseline preload values yielded the lowest maximum pipe stress. These baseline values are used in the FEA studies in the following sections. Future studies may investigate independently varying the hangar preload for the main heater and heat exchanger.

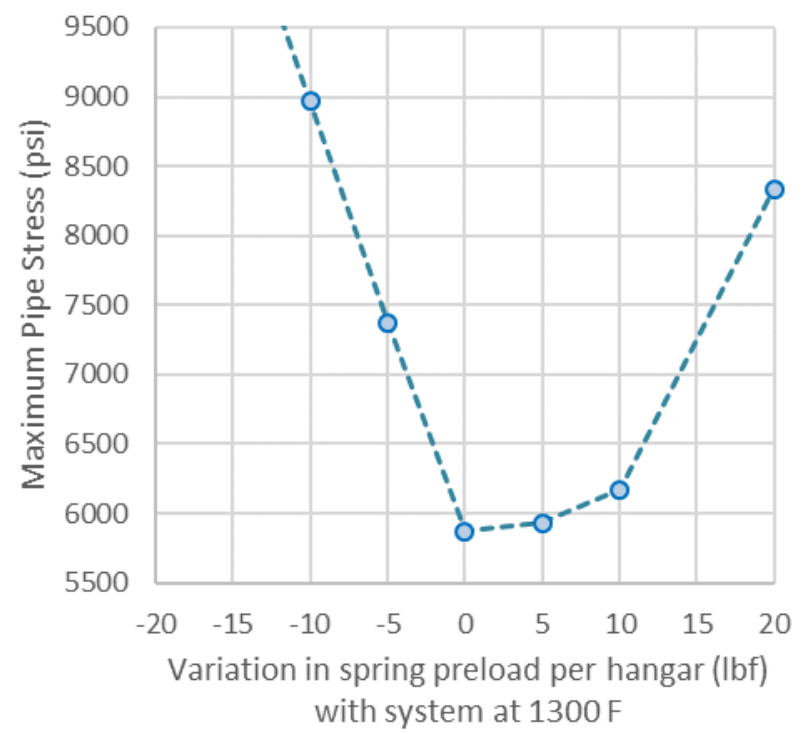

Figure D.2. Piping stress FEA results - variation of spring hangar preload.

\section{Pump Speed}

With the loop under isothermal conditions at $1300^{\circ} \mathrm{F}$, the pump flow rate was parametrically varied between 30-70 gpm. To model the increased pressure in the pipes due to the pumped flow, an internal pressure was applied to each of the three pipe segments shown in Figure D.1. This pressure is in addition to the hydrostatic pressure in the piping. The pressure to pump the salt at the desired flowrates were determined using simple pressure loss equations around the loop and included an additional 3 psi overpressure. Table D.2 provides the additional applied pressure due to the pump for the three piping segments.

The results are illustrated in Figure D.3. The maximum pipe stress does not vary substantially and occurs in pipe segment 2 for all cases. The approximately 3 psi increase in pressure in pipe segment 2 due to different pump flow rates has a minor impact on predicted maximum pipe stress. 
Table D.2. Dynamic pressure in each pipe segment due to pump operation

\begin{tabular}{cccc}
\hline $\begin{array}{c}\text { Pump Flowrate } \\
(\mathbf{g p m})\end{array}$ & $\begin{array}{c}\text { Pipe Segment 1 } \\
\text { Pressure (psi) }\end{array}$ & $\begin{array}{c}\text { Pipe Segment 2 } \\
\text { Pressure (psi) }\end{array}$ & $\begin{array}{c}\text { Pipe Segment 3 } \\
\text { Pressure (psi) }\end{array}$ \\
\hline 30 & 8.1 & 3.8 & 3.3 \\
\hline 40 & 11.7 & 4.3 & 3.5 \\
\hline 60 & 21.5 & 5.9 & 4.1 \\
\hline 70 & 27.7 & 6.9 & 4.5 \\
\hline
\end{tabular}

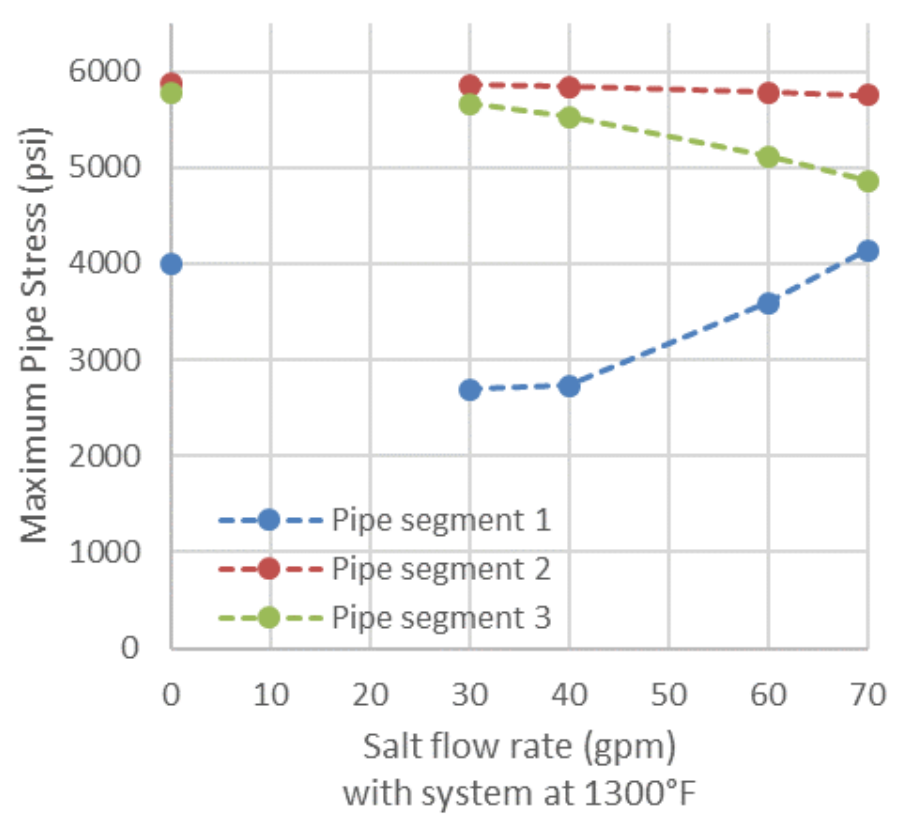

Figure D.3. Piping stress FEA results - variation of salt flow rate.

\section{Loop Isothermal Conditions}

A range of isothermal conditions were analyzed for cases where the loop was filled or drained of salt, and whether the pump was operating. Figures D.4 and D.5 summarize the maximum piping stress results. The maximum pipe stress is higher when the loop is drained of salt than when the loop is filled. This is the result of the interaction between the added salt mass and the assumed spring hangars preload. Consistent with the previous section, pump operation slightly reduces the predicted maximum stress. All cases analyzed are below the allowed stress, as the allowed stress increases for decreasing system temperature. 


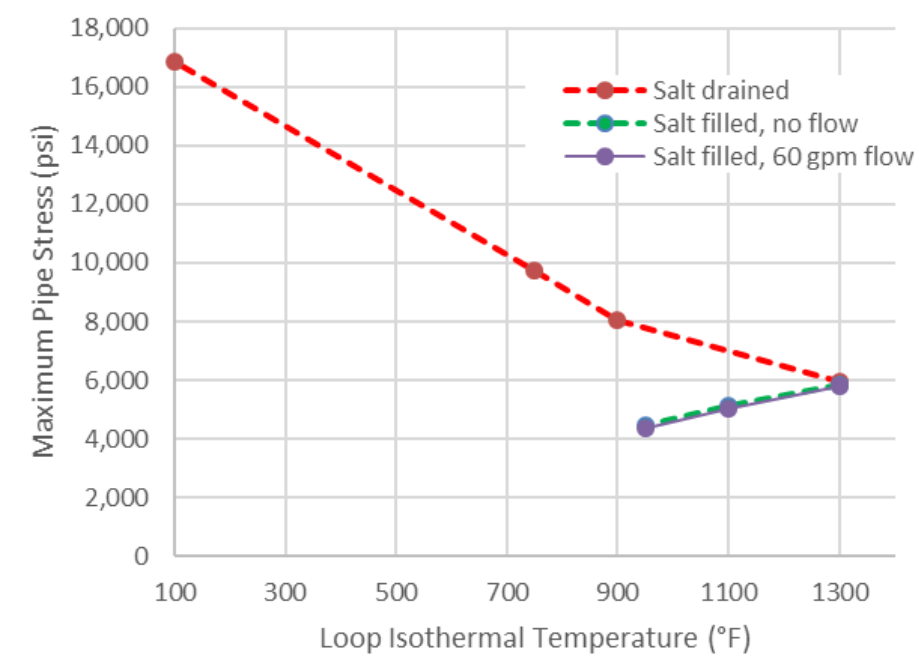

Figure D.4. Piping stress FEA results - variation of isothermal loop conditions.

\section{Loop Temperature Differential}

During pumped operation, the loop can be heated with the main heater and cooled by the heat exchanger to generate a temperature gradient across the loop. To analyze the maximum pipe stress for various temperature gradients across the loop, the temperature of pipe segment 2 was specified as the hot temperature and pipes segments 1 and 3 were specified to be the cold temperature. Given these imposed temperatures, ANSYS determined the vertical temperature gradient across the heat exchanger and main heater. For the cases analyzed, the pump was assumed to be operating at $30 \mathrm{gpm}$. As the pump tank is designed for a maximum of $1300^{\circ} \mathrm{F}$, the maximum temperature of the cold side of the loop was restricted to $1300^{\circ} \mathrm{F}$. The results from parametrically varying the maximum temperature and loop temperature gradient are summarized in Figure D.5. For cases where the maximum loop temperature is $1319^{\circ} \mathrm{F}$ or below, the predicted maximum pipe stress is below the assumed allowed stress. Additional optimization of the piping network may be necessary to lower the maximum pipe stress for the cases where the hot side of the loop is at $1337^{\circ} \mathrm{F}$.

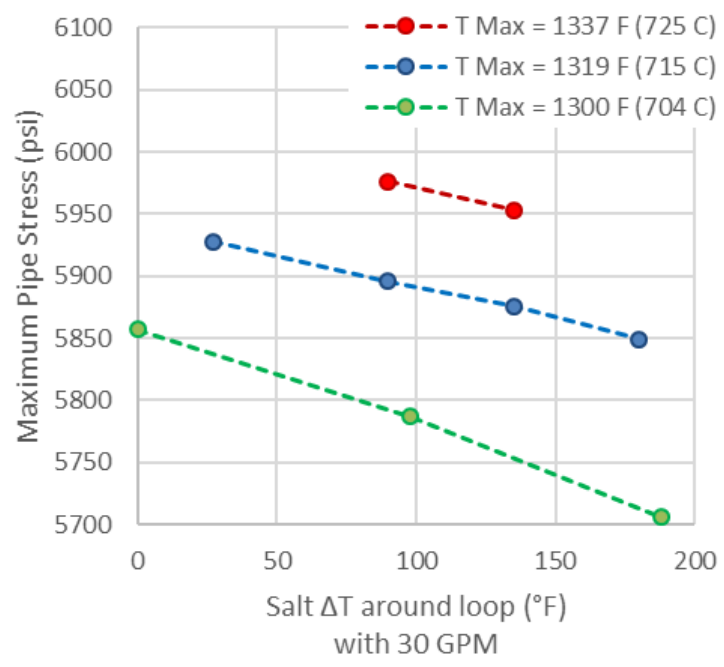

Figure D.5. Piping stress FEA results - variation of maximum loop temperature and temperature gradient. 